\title{
United Kingdom: 2011 Article IV Consultation-Staff Report; Staff Supplement; Staff Statement; Public Information Notice on the Executive Board Discussion; and Statement by the Executive Director for the United Kingdom
}

Under Article IV of the IMF's Articles of Agreement, the IMF holds bilateral discussions with members, usually every year. In the context of the 2011 Article IV consultation with the United Kingdom, the following documents have been released and are included in this package:

- $\quad$ The staff report for the 2011 Article IV consultation, prepared by a staff team of the IMF, following discussions that ended on June 6,2011, with the officials of the United Kingdom on economic developments and policies. Based on information available at the time of these discussions, the staff report was completed on July 12, 2011. The views expressed in the staff report are those of the staff team and do not necessarily reflect the views of the Executive Board of the IMF.

- $\quad$ A staff supplement of July 25, 2011 and a staff statement of July 26, 2011 updating information on recent economic developments.

- $\quad$ A Public Information Notice (PIN) summarizing the views of the Executive Board as expressed during its July 27, 2011 discussion of the staff report that concluded the Article IV consultation.

- A statement by the Executive Director for the United Kingdom.

The document listed below has been or will be separately released.

\section{Selected Issues Paper}

The policy of publication of staff reports and other documents allows for the deletion of market-sensitive information.

\author{
Copies of this report are available to the public from \\ International Monetary Fund • Publication Services \\ $70019^{\text {th }}$ Street, N.W. • Washington, D.C. 20431 \\ Telephone: (202) 623-7430 • Telefax: (202) 623-7201 \\ E-mail: publications@imf.org Internet: http://www.imf.org
}

\section{International Monetary Fund Washington, D.C.}




\title{
INTERNATIONAL MONETARY FUND
}

\section{UNITED KINGDOM}

\section{Staff Report for the 2011 Article IV Consultation}

Prepared by Staff Representatives for the 2011 Consultation with the United Kingdom

\author{
Approved by Ajai Chopra and Tamim Bayoumi
}

July 12,2011

Context. Implementation of a wide-ranging policy program is underway, aiding the post-crisis repair of the economy. However, the recovery stalled over the last several months, inflation remains elevated, and unemployment is still unacceptably high. The financial system has stabilized and bank balance sheet repair continues, but this process is not complete and is vulnerable to setbacks.

Macroeconomic policy mix. The weakness in growth and rise in inflation raises the question whether it is time to adjust macroeconomic policies. The answer is no, as the deviations are largely temporary. Strong fiscal consolidation is underway and remains essential to achieve a more sustainable budgetary position, thus reducing fiscal risks. The inflation overshoot is driven largely by transitory factors, and hence maintaining the current scale of monetary stimulus is appropriate given fiscal adjustment and subdued wage growth. This macroeconomic policy mix will also assist in rebalancing the economy toward sustainable growth led by investment and external demand.

Risk scenarios. Nonetheless, there are significant risks to inflation, growth, and unemployment arising from uncertainties surrounding sovereign turmoil in parts of the euro area, headwinds from fiscal policy, volatile commodity prices, and the housing market. Policy flexibility will be essential to respond to shocks, with the appropriate response depending on the nature of the shock. For example, if there is mounting evidence that weak demand is likely to cause the economy to stall and enter a period of prolonged low growth and subdued inflation, a significant loosening of macroeconomic policies will be required.

Financial sector policy. Strong domestic measures and international coordination are needed to further bolster financial stability. Indeed, the stability and efficiency of the UK financial system is a "global public good" due to potential spillovers and thus requires the highest quality of supervision and regulation. In this context, continued build up of capital and liquidity buffers ahead of Basel III requirements is essential.

Mission details. The Article IV team comprised Mr. Chopra (head), Messrs. Fletcher, Kannan, and Takizawa, and Ms. Ruiz-Arranz (all EUR). Ms. Pazarbasioglu (MCM) joined the mission to discuss conclusions of the Financial Sector Stability Assessment. Mr. Marston and Ms. Mateos y Lago (both SPR) joined to discuss conclusions of the Spillover Report. The mission's concluding statement was published on June 6, 2011 and can be found at http://www.imf.org/external/np/ms/2011/060611.htm. 


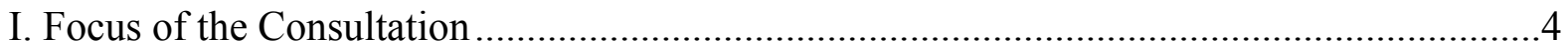

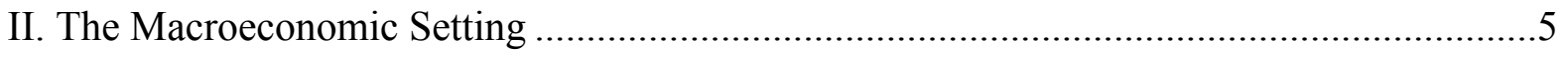

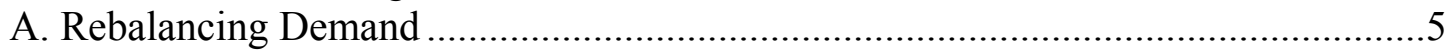

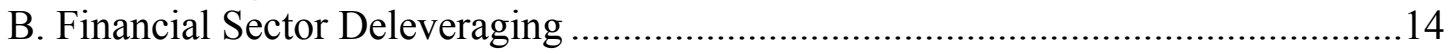

III. The Central Scenario and Risks .................................................................................20

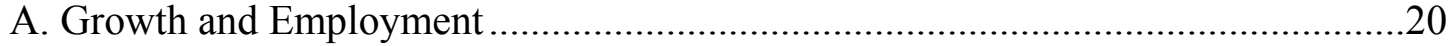

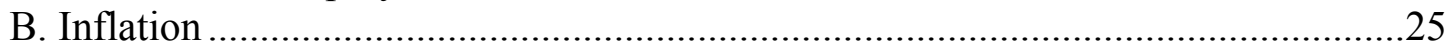

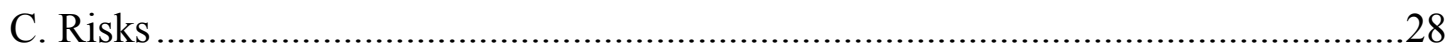

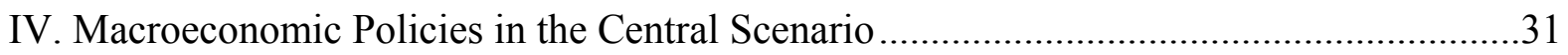

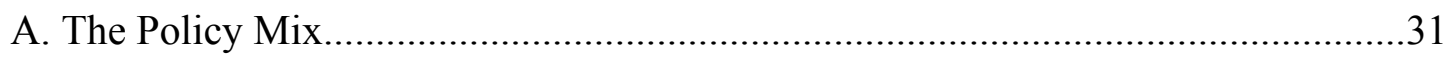

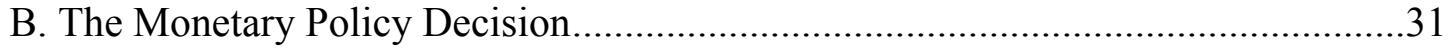

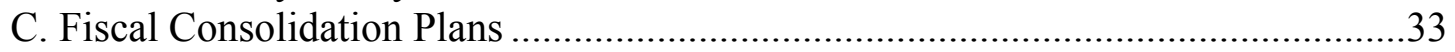

V. Macroeconomic Policies in Risk Scenarios ................................................................3

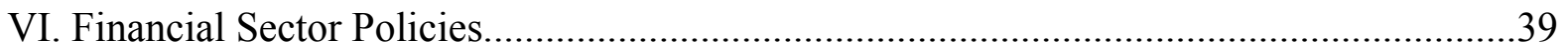

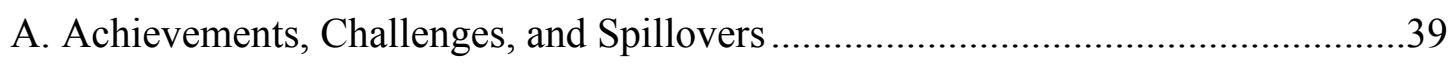

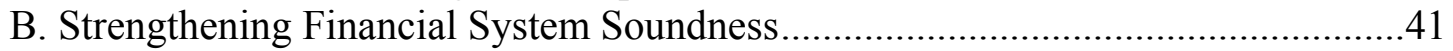

C. Strengthening the Domestic Oversight Framework ..............................................42

D. Strengthening the Capacity to Deal with Systemically Important Financial

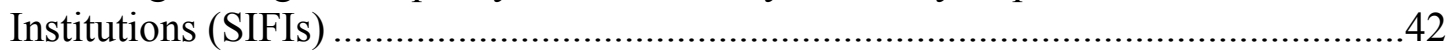

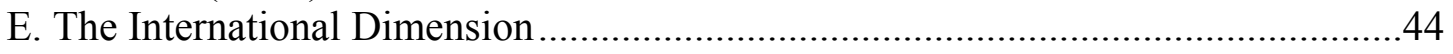

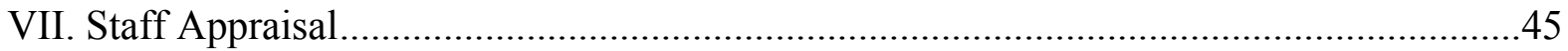

Figures

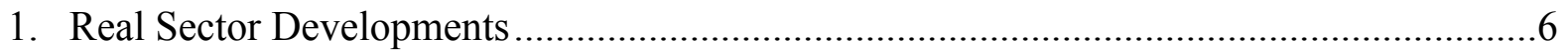

2. Behavior of Key Macro Variables Around Recession Times......................................... 7

3. Financial Position of Households .............................................................................

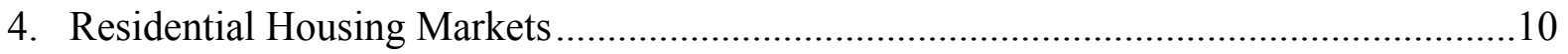

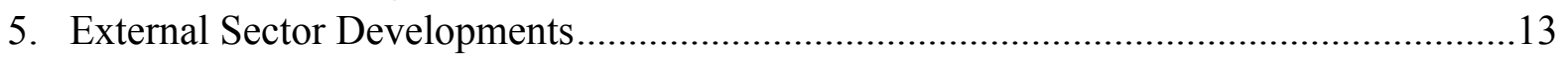

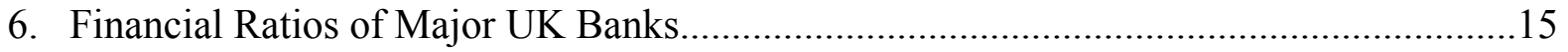

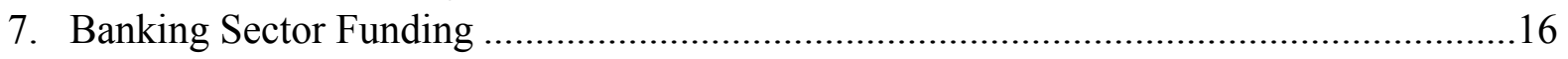

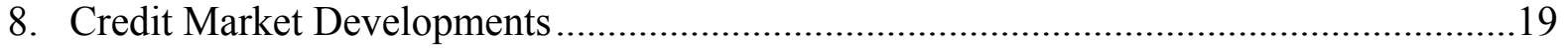

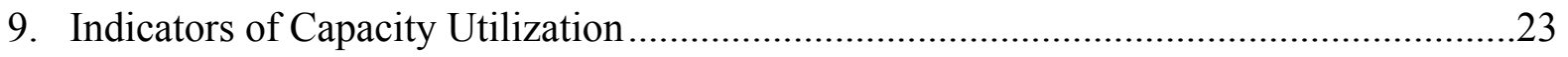

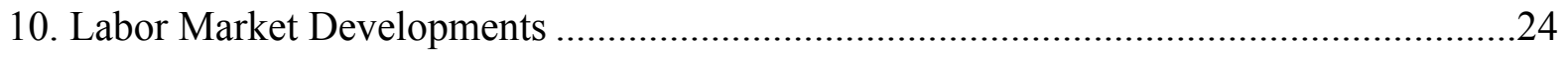

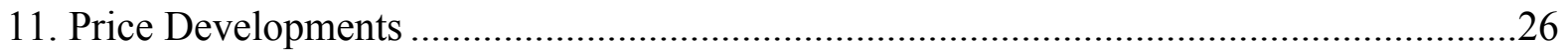

12. External Claims of Consolidated UK-Owned MFIs .................................................29

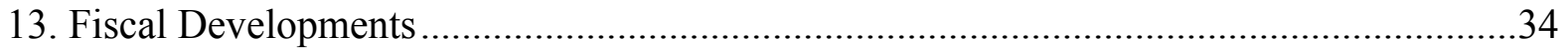


Tables

1. Selected Economic and Social Indicators, 2007-12 …..............................................48

2. Statement of Public Sector Operations, 2008/09-15/16 ..................................................49

3. Statement of General Government Operations, 2004-10 ...........................................50

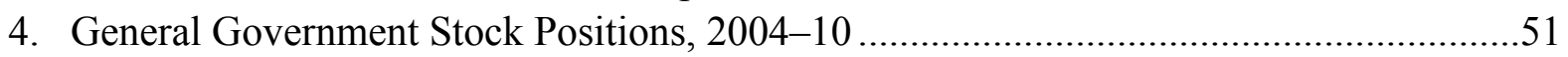

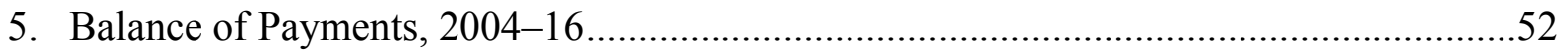

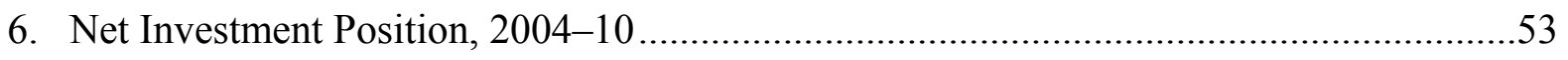

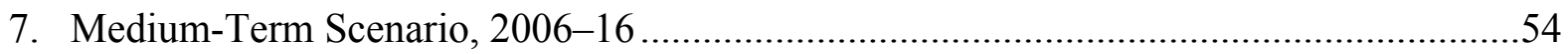

\section{Boxes}

1. What is Driving the Household Saving Rate in the UK?............................................11

2. What Does Okun's Law Tell Us About the Output Gap? ............................................21

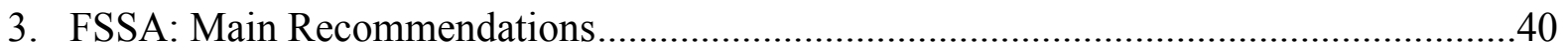

\section{Annex}

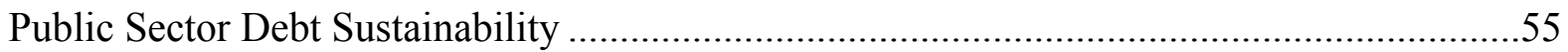




\section{Focus OF THE CONSUltation}

1. Recovery from the financial crisis is underway, but is bumpy and incomplete. Output is still 4 percent below its peak in March 2008, a gap that is the third largest in the G7 after Italy and Japan, and growth was flat in the six months from October 2010. At the same time, headline inflation is elevated at $4 \frac{1}{4}$ percent, although core inflation excluding the effects of VAT hikes is more tame at about 1 1/4 percent. Bank balance sheet repair continues and bank lending conditions are less tight, but credit growth remains soft. The centerpiece of the government's economic strategy-strong fiscal consolidation to preserve confidence in debt sustainability-is in progress. ${ }^{1}$

\section{The challenge going forward is to ensure sustainable recovery and balance sheet} repair while remaining flexible to respond to shocks. Specifically, the goals are to move the economy to a more balanced and sustainable equilibrium, return inflation to target, reduce unemployment and close the output gap, ensure fiscal sustainability, and move to a safer financial system. Against this background, the focus of the consultation was on the following issues and questions:

- What is the progress and outlook on rebalancing demand and financial sector deleveraging? (Section II)

- In view of the progress and outlook on these fronts, what is the central scenario for the economy? Is the recent slowdown in growth and rise in inflation largely temporary? What are the key risks and uncertainties around the central scenario? (Section III)

- Is it time to adjust monetary or fiscal policy in light of the weakness in growth and rise in inflation? (Section IV)

- How should monetary and fiscal policy react if risks materialize? (Section V)

- What remains to be done to bolster the financial system's soundness, strengthen the oversight framework, and fortify the capacity to deal with systemically important financial institutions? What are the potential spillovers from the UK's large and interconnected financial system? (Section VI)

\section{The focus on these issues occurs against a backdrop of two concurrent IMF} reports on the UK. The first is a Financial Sector Stability Assessment (FSSA) update under

\footnotetext{
${ }^{1}$ Policies over the last year have been broadly in line with recommendations of past Article IV consultations. In particular, the government has implemented strong fiscal consolidation together with an accommodative monetary stance, a policy mix supported by Directors during the 2010 Article IV consultation. The framework for financial regulation and supervision has also been strengthened, as recommended by Directors, though further progress is necessary.
} 
the IMF's Financial Sector Assessment Program (FSAP), which analyzes financial sector health and associated policies. The second is a Spillover Report, which analyzes spillovers emanating from UK policies to the rest of the world. This staff report discusses and integrates the key points of these documents.

\section{The Macroeconomic Setting}

\section{A. Rebalancing Demand}

4. Economic recovery was strong for most of $\mathbf{2 0 1 0}$, but slowed in recent quarters. Recovery from the deep recession of 2008-09 was led by a classic turn in the inventory cycle and rebounding private investment (Figures 1 and 2). Together, these forces fueled average GDP growth of $2 \frac{3}{4}$ percent (saar) in the first three quarters of 2010. However, growth turned flat in late 2010/early 2011. ${ }^{2}$ This slowdown partly reflects intensifying fiscal consolidation - most notably with a $2 \frac{1}{2}$ percentage-point VAT hike on January 1, 2011 — and weak consumer confidence in the wake of spiking import prices and a soft housing market. However, the flat GDP numbers have diverged from other economic indicators - such as employment and PMI surveys - which have been stronger.

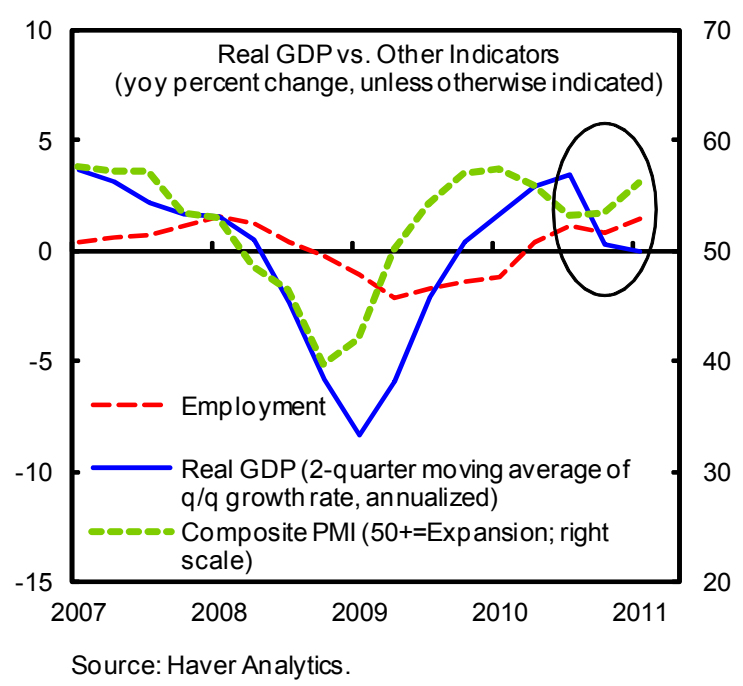

\section{Fiscal headwinds will continue as the government moves toward a more} sustainable fiscal position. The financial crisis pushed the overall fiscal deficit to 11 percent of GDP in FY09/10, a post-war record and one of the highest deficits in the world. With public finances on a clearly unsustainable path, the June 2010 budget laid out a 5-year adjustment plan that would cut the deficit to $1 \frac{1 / 2}{2}$ percent of GDP by FY15/16. Progress was made in FY10/11, with the deficit dropping to 93/4 percent of GDP; further deficit reduction (to 8 percent of GDP) is expected in FY11/12.

\section{The necessary increase in public saving implies that growth must rely on private} sector-led demand. Specifically, increased demand must come from some combination of lower private saving (higher private consumption), higher private investment, and higher net exports. Recent developments and prospects for each of these items are examined in turn.

\footnotetext{
${ }^{2}$ Unusually cold weather temporarily lowered GDP in Q4 2010, with an offsetting rebound in Q1 2011. As a result, average GDP growth over Q4 2010-Q1 2011, which was zero, is free from weather effects and provides a better view of the underlying trend than the noisier quarterly numbers.
} 


\section{Figure 1. Real Sector Developments}

The UK's downtum was deeper and longer than in most countries.

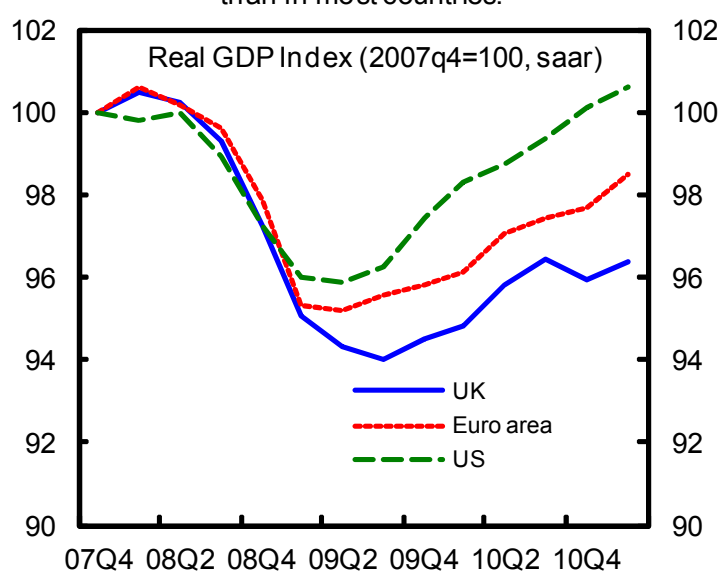

Short-termin dicators point to continued expansion...

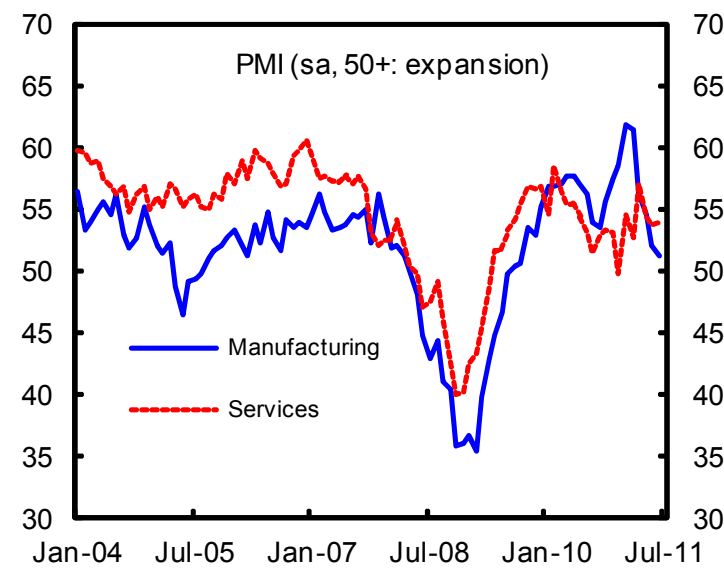

Consumer confidence has d ropped while investment intentions rise, reflecting the shift from consumption to investment-led growth.

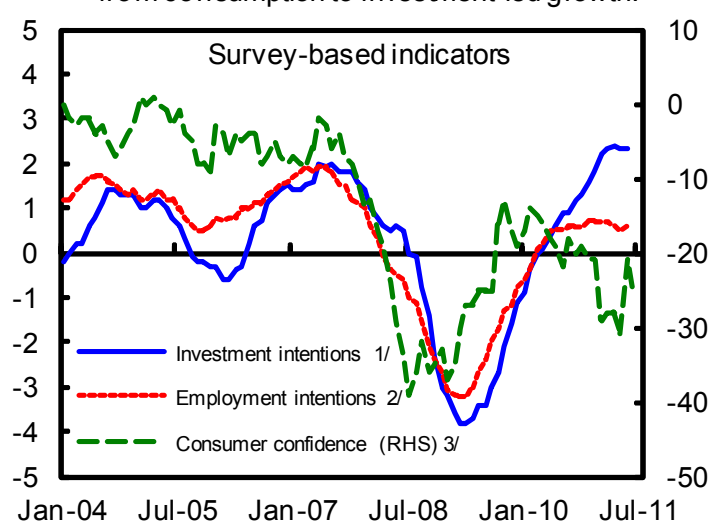

Jul-05 Jan-07 Jul-08 Jan-10 Jul-11
Recovery has been powered by inventory restocking and, more recently, net exports.

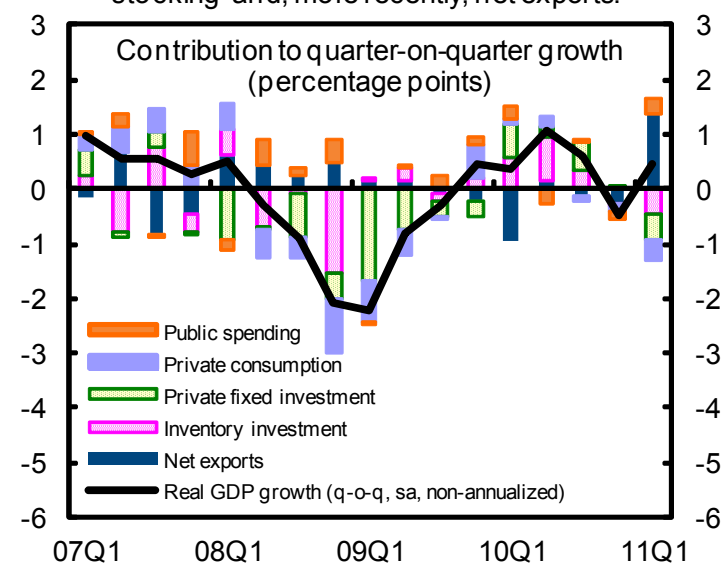

...with manufacturing orders remaining a key engine of recovery.

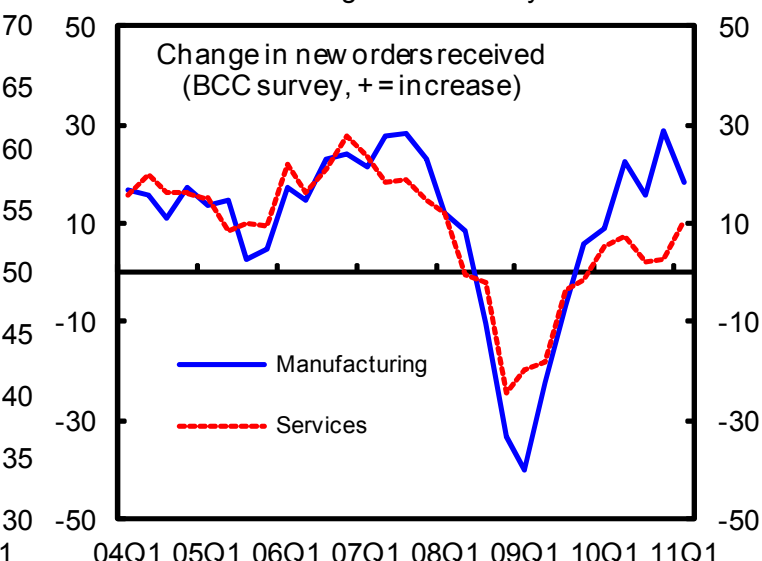

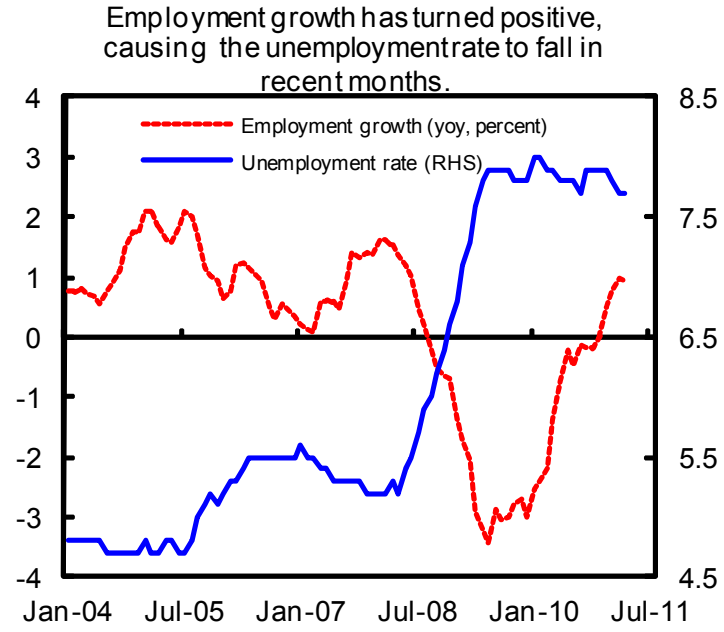

Sources: Bank of England; British Chambers of Commerce; and Office for National Statistics.

1/Bank of England Agents' Survey, manufacturing.

2/ Bank of England Agents' Survey, services.

3/ GfK Consumer Confidence Barometer. 
Figure 2. Behavior of Key Macro Variables Around Recession Times 1/ (Last pre-recession quarter $\mathrm{t}-1=100$, unless otherwise noted)

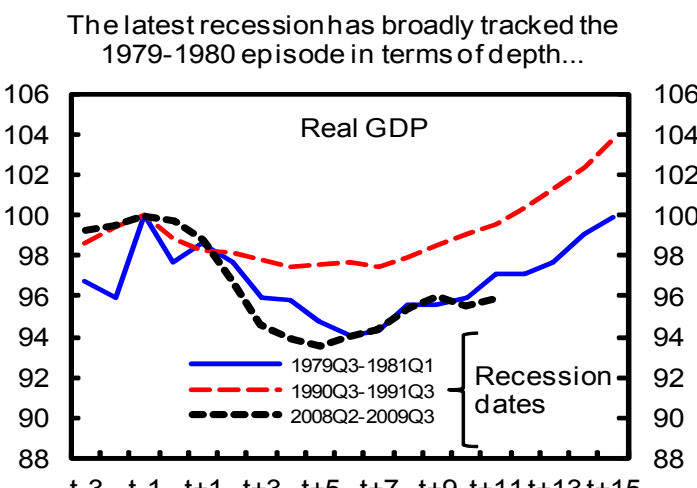

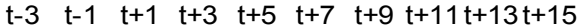

as the saving rate surged from very low precrisislevels.

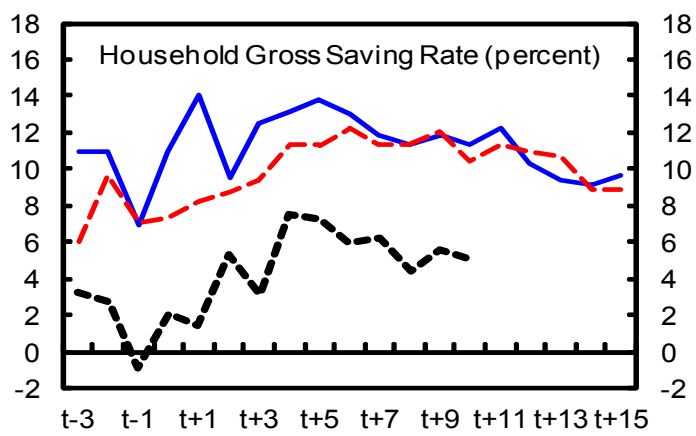

Following historical patterns, the recovery has also been led by the turn in the inventory cycle...

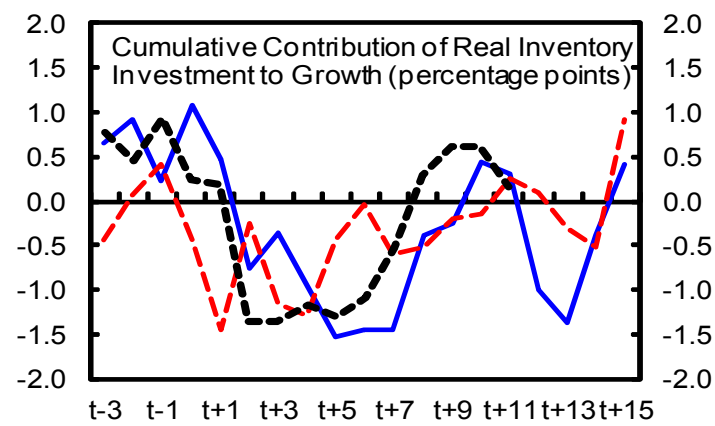

Exports have begun to recover, reflecting global growth ...

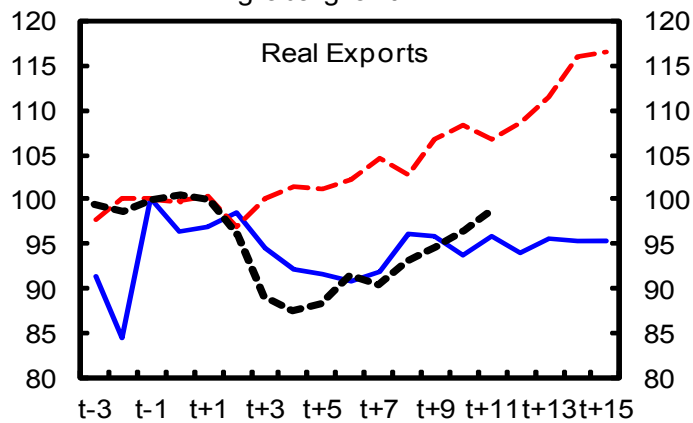

Sources: Haver Analytics; and IMF staff calculations.

$1 /$ The starting point of recessions is marked from the previous peak in GDP. ...featuring a similarly large decline in household consumption...

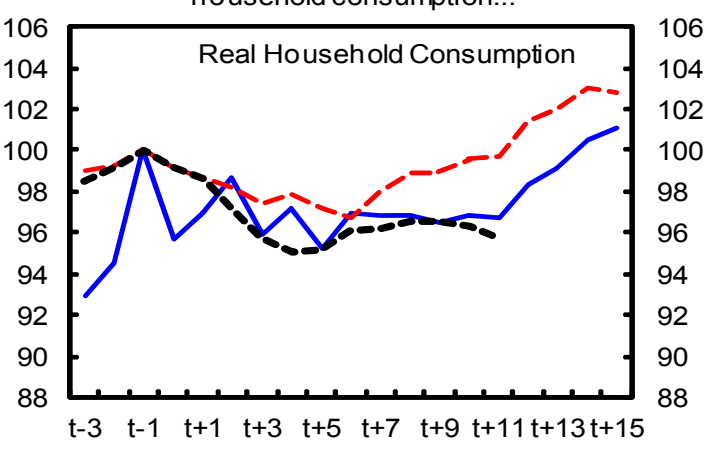

Fixed investment suffered an unusually steep drop, but was rebounding un til recent quarters.

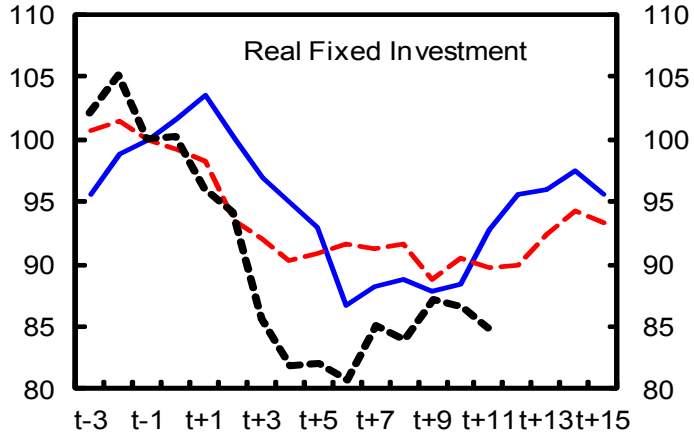

... and supported by public spending.

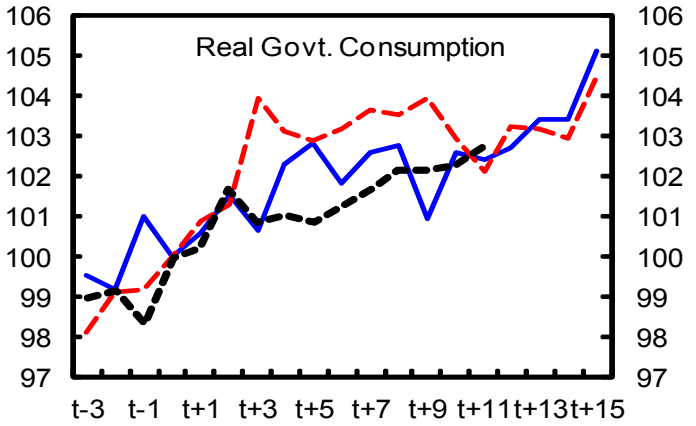

...but import growth has been strong un til recently, resulting in little improvement in net exports.

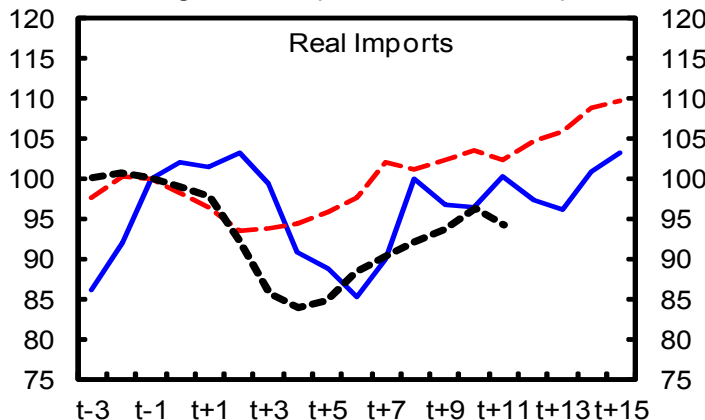




\section{Private consumption}

\section{Private consumption has remained weak as households have faced a marked}

tightening in real disposable income. Nominal wage growth has remained sluggish over the past year given low productivity growth and continued slack in the labor market. Higher commodity prices and indirect taxes have further reduced households' real incomes. These factors, along with a weak housing market, pushed consumer confidence in early 2011 down to levels last seen during the depths of the crisis, though it has rebounded somewhat in recent months (Figure 1).

8. House prices are likely to weigh on consumption going forward. During the boom, rising house prices helped boost consumption and cut the household saving rate to only 2 percent (Figure 3). Although these trends sharply reversed during the crisis, housing valuation ratios are still about 30 percent above their historical averages. Some softness in house prices thus seems likely going forward. But unlike the US or Spain, new home construction in the UK remained relatively muted during the boom due to the UK's tight planning restrictions (Figure 4). As a result, supply constraints are likely to prevent house prices from fully falling back to their historical averages. In addition, if real interest rates remain below their historical average - as expected by markets even in the medium term (Section IV.B) - then housing valuation metrics are also unlikely to revert fully to their historical averages. On balance, staff's central scenario assumes a reduction in the house price-to-income ratio of 12 percent over the medium term (though house prices still rise slightly in nominal terms). Indeed, house prices have already started retreating again in recent quarters. An econometric analysis of the UK's saving rate suggests that upward pressure on the saving rate from subdued house prices should be offset by the fiscal consolidation, which should depress private saving, resulting in a broadly flat household saving rate over the medium term (Box 1 and companion Selected Issues paper).
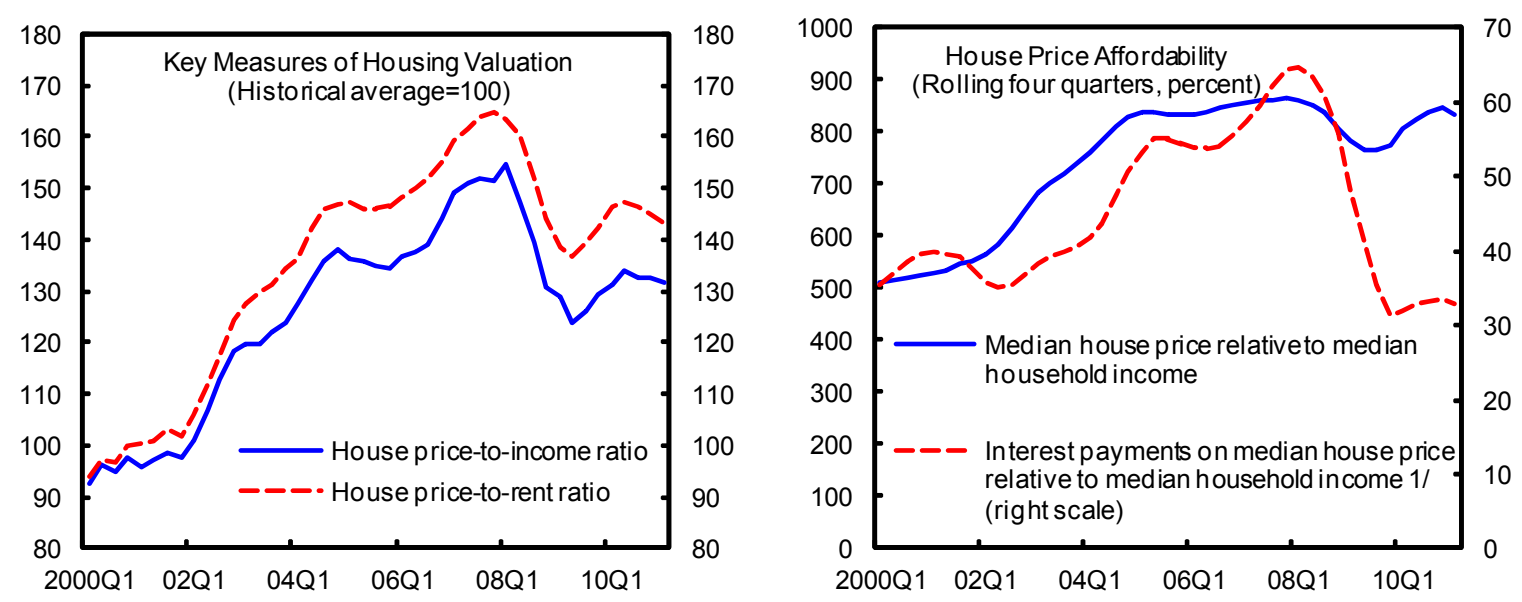

Sources: Haver Analytics; Land Registry; UK Dept. for Work and Pensions; and IMF staff estimates. 1/Based on standard variable rate mortgage. 
Figure 3. Financial Position of Households
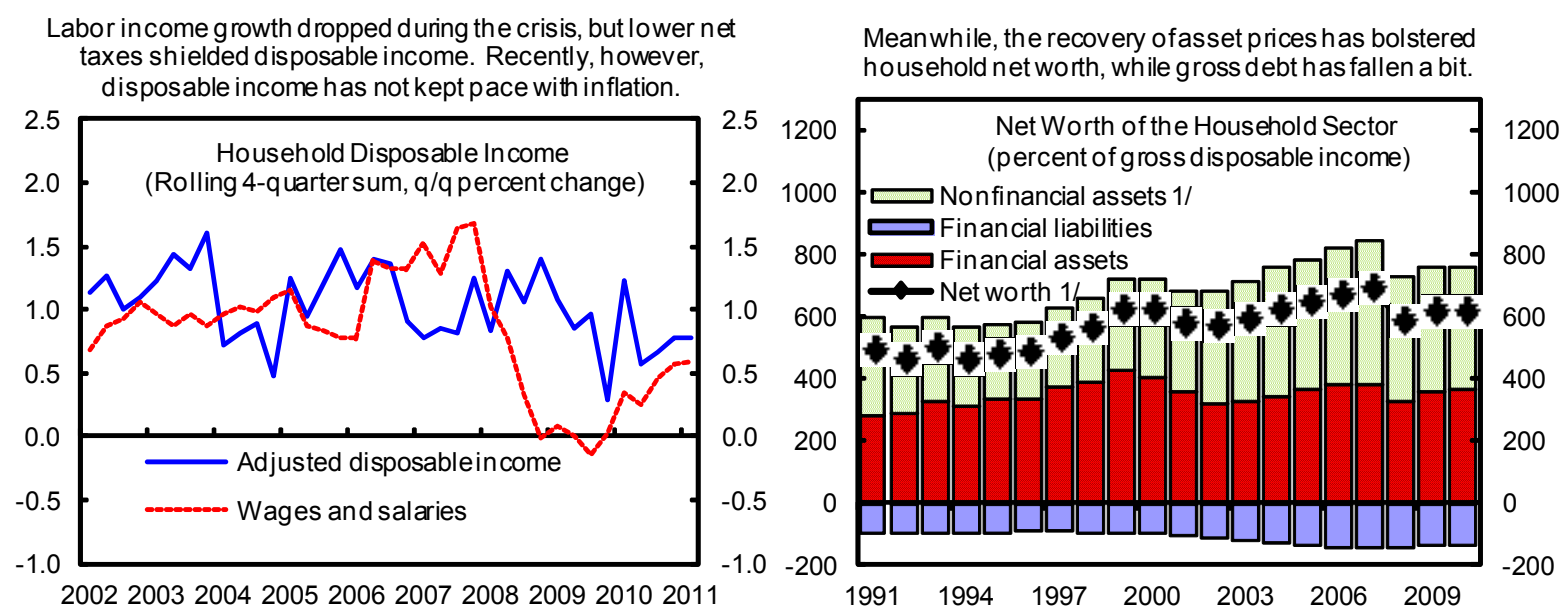

Higher asset prices have prompted the household
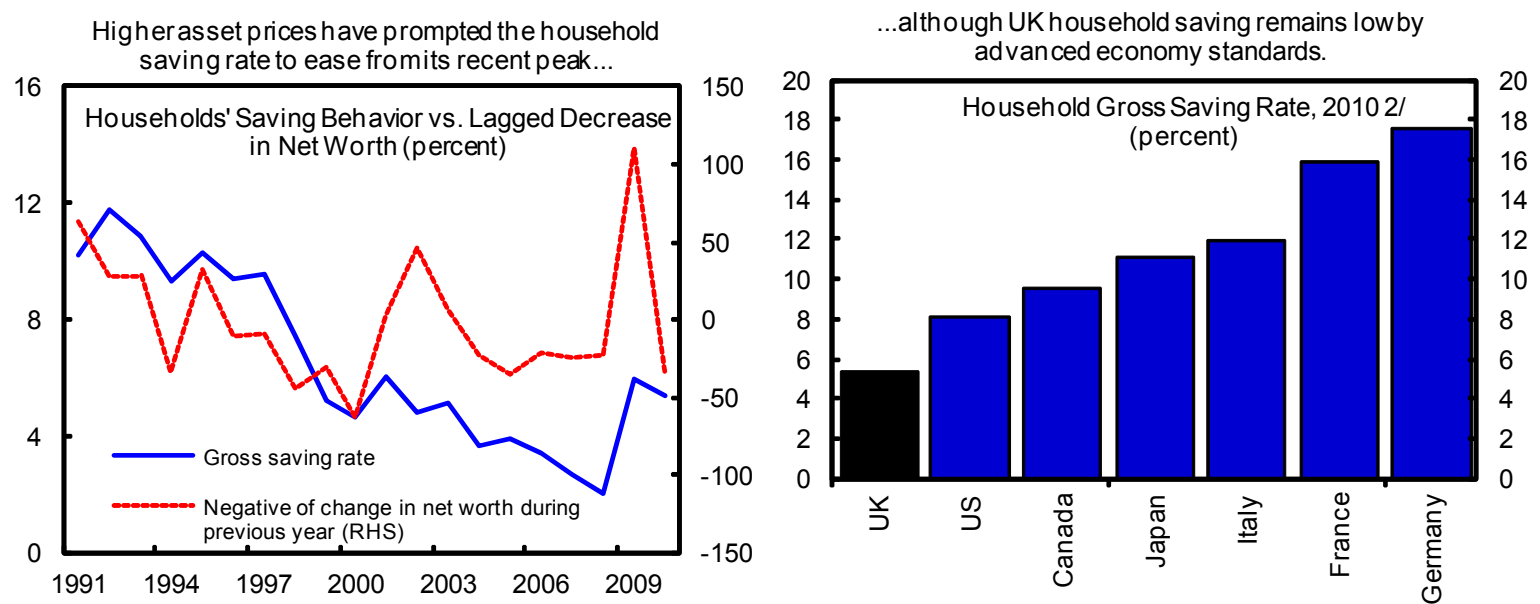

The stock of household debt is higher than in any other $\mathrm{G} 7$ country...

...implying significant cash flow relief for in debted households as interest rates have come down.
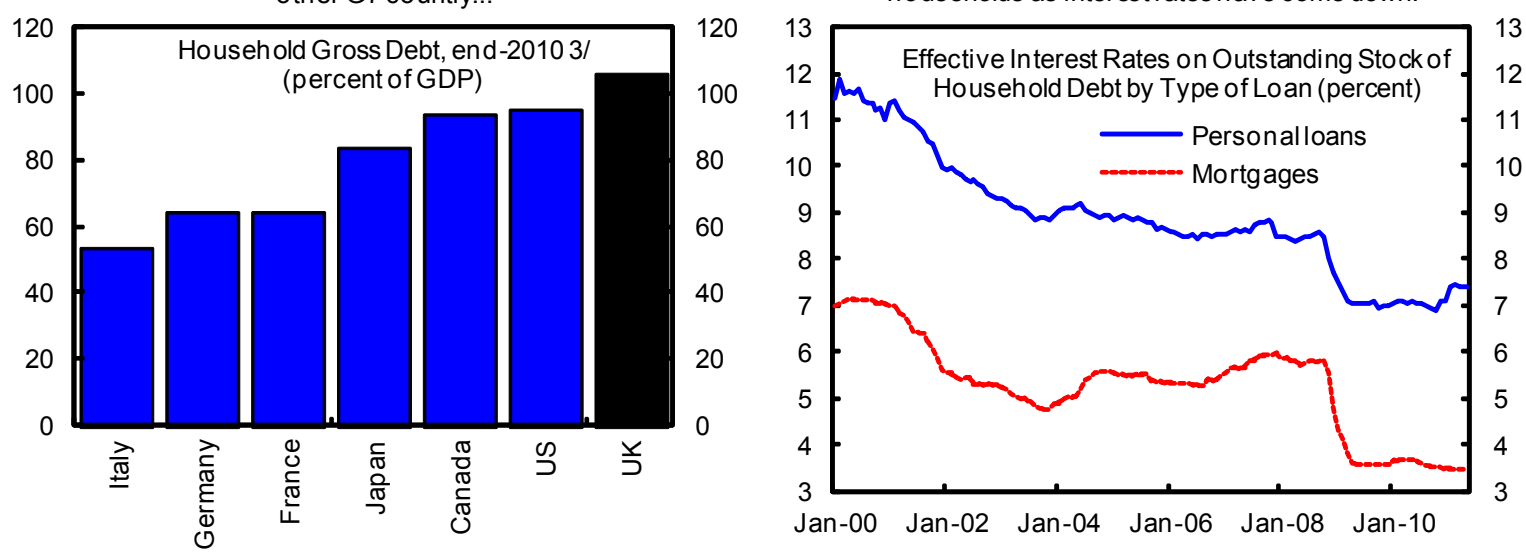

So urces: Haver Analytics; OECD; and IMF staff calculations. $1 / 2010$ staff estimate.

2/ Italy and Japan are estimates for 2009.

3/ France, Germany, Italy, and Japan are estimates for 2009. 
Figure 4. Residential Housing Markets
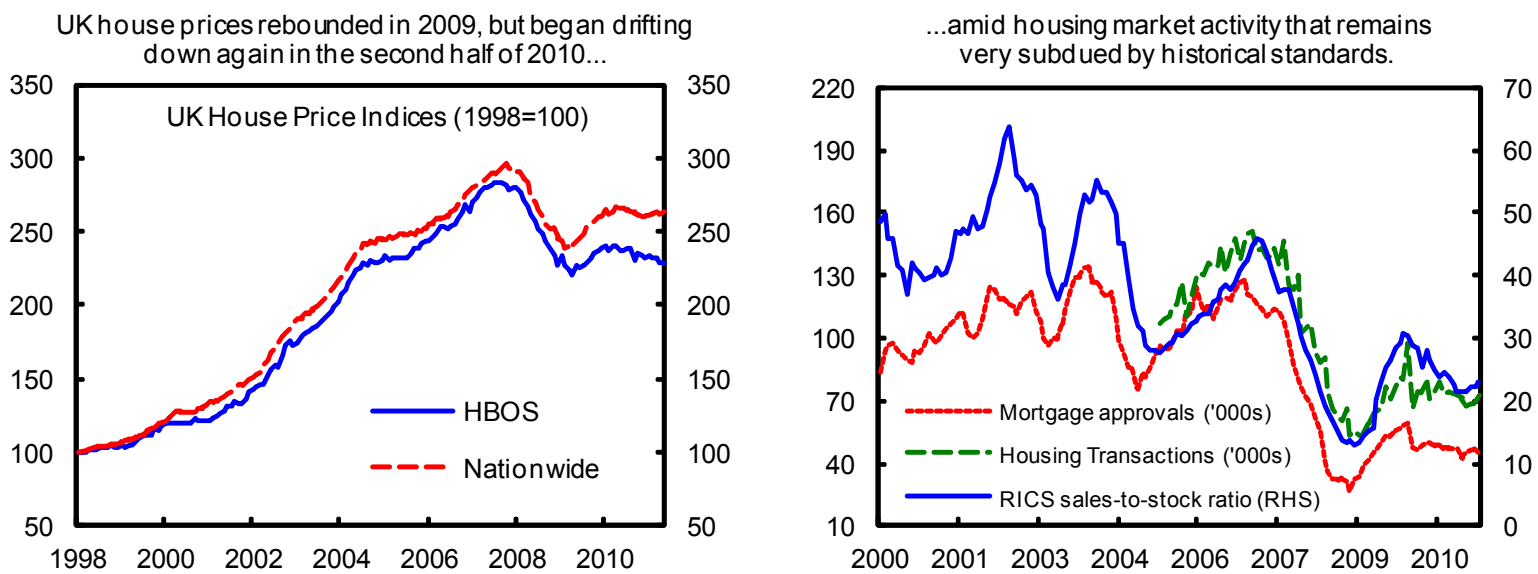

Nonetheless, house prices are still well above historical averages in relation to household income...
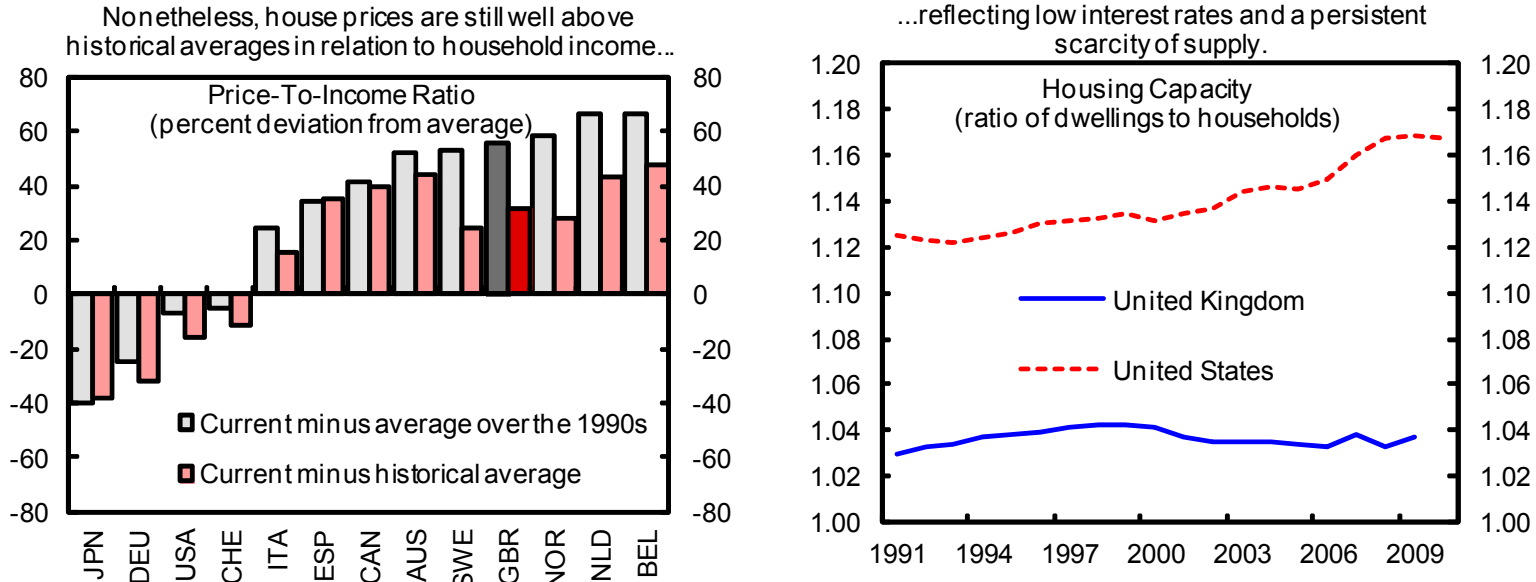

Construction of new un its, which was relatively limited even during theboom times, has continued to decline.

Relative to the US, UK repossession and mortgage default

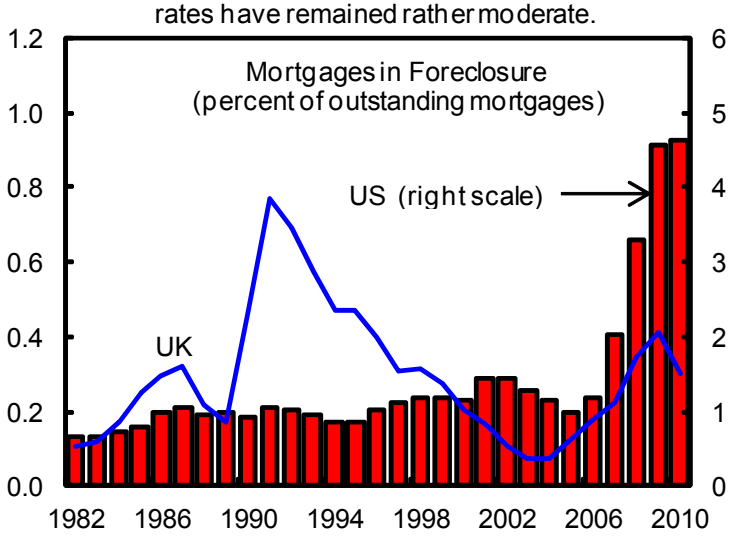

Sources: Bank of England; Haver Analytics; OECD; UK Communities and Local Govemment; UK Council of Mortgage Lenders; UK Department for Work and Pen sions; UK Office for National Statistics; US Cen sus Bureau; US Mortgage Bankers Association; and IMF staff estimates and calculations. 


\section{Box 1. What Is Driving the Household Saving Rate in the UK?}

The UK's household saving rate has long been relatively low. The gross household saving rate averaged only 4.4 percent in the UK in the ten years through 2009, the lowest rate among G7 economies.

\section{Empirical analysis suggests that several factors} contribute to this low household saving rate. A panel regression for $\mathrm{G} 7$ economies (with country fixed effects and time trends) finds the following variables to be statistically significant in explaining the household saving rate (see companion Selected Issues paper for more details): the dependency ratio (as people save less when young and in retirement); the unemployment rate (as people smooth consumption over the cycle by saving less when unemployed); inflation (a proxy for uncertainty and to control for rising nominal interest income in times of high inflation); the real long-term interest rate (the rate of substitution between consumption today and consumption tomorrow); the general government fiscal balance (a potential substitute of household saving); and, in the case of Anglo-Saxon economies, tangible wealth (mainly housing wealth), reflecting more liberalized mortgage lending in Anglo-Saxon economies (e.g., higher maximum loan-to-value ratios), which makes it less necessary to save for home purchases and easier to withdraw equity. According to these results, about 30 percent of the difference between the UK saving rate and the

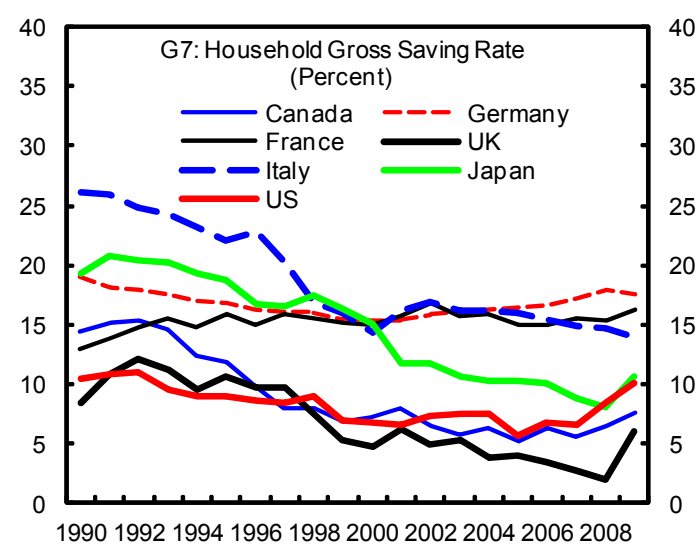

Sources: OECD; and IMF staff calculations.

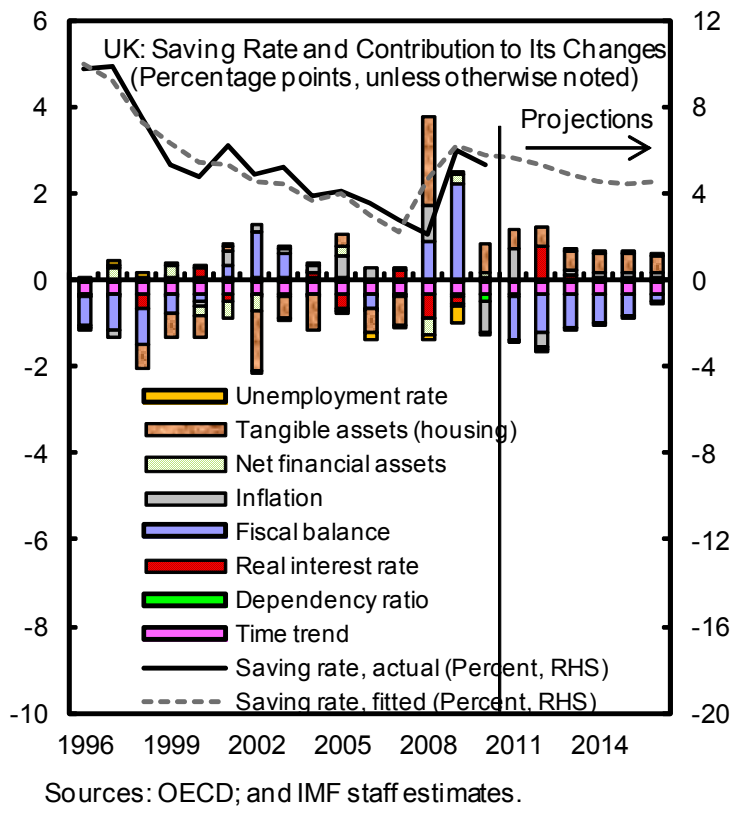
average for G7 countries in the past decade can be explained by these variables. An estimated model shows that increases in the value of the housing stock and declines in the real long-term interest rate drove much of the secular decline in the saving rate through 2007, although a house price correction and spike in the fiscal deficit in 2008-09 are estimated to have undone the entire decline in the past decade.

The model suggests that the ongoing fiscal consolidation and house price movements will be key determinants of the saving rate going forward. Specifically, the model suggests that the fiscal consolidation will reduce the saving rate by about $3 \frac{1}{2}$ percentage points by 2016 . This need not occur through hyper-rational Ricardian effects - i.e., households saving less today in anticipation of lower taxes tomorrow - but could simply reflect sticky household consumption in the face of higher taxes/lower transfers that reduce household income. The central scenario also assumes that the house price-to-income ratio falls by 12 percent as valuations fall closer to their historical average. This, together with a modest increase in real interest rates and roughly no change in the other explanatory variables, keeps the saving rate broadly flat (it falls just slightly) over the medium term. However, the saving rate could veer significantly from this central scenario if house prices deviate significantly from central scenario assumptions. 


\section{Private investment}

9. The outlook for private investment is brighter. After falling to unsustainably low levels during the crisis, investment rebounded in 2010. Staff expects this trend to continue over the medium term, with the investment-to-GDP ratio returning to its pre-crisis level by 2016. Factors supporting such an investment recovery include low interest rates, corporates' high cash surpluses, and relatively faster growth in the export sector (see below), which is more capital-intensive. However, the risk is that corporates may be hesitant to ramp up investment while consumption growth remains moderate and large macroeconomic uncertainty persists (Section III.C).

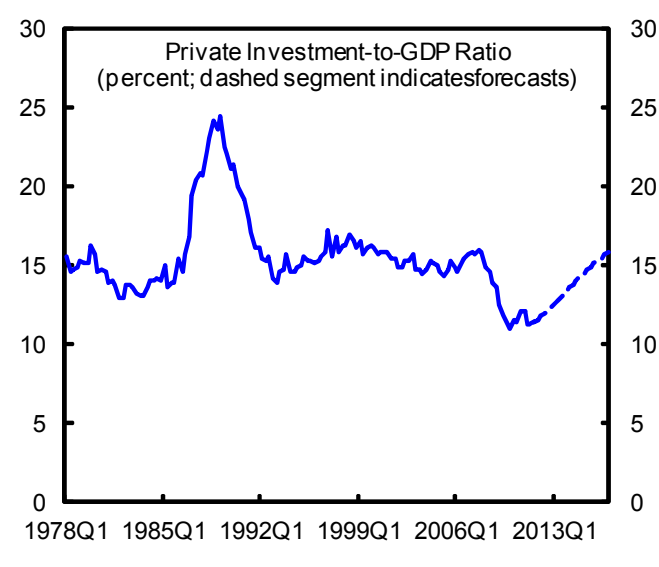

\section{Net exports}

Sources: ONS; and IMF staff estimates.

10. Significant depreciation at the onset of the crisis has not yet translated into rapid net export growth. The CPI-based real effective exchange rate (REER) depreciated by some 25 percent between mid-2007 and early 2009 (Figure 5). Based on standard IMF methodologies, sterling now appears to be broadly in line with fundamentals. However, the depreciation has not resulted in a sustained narrowing of the current account deficit. Although goods export volumes have expanded solidly during the recovery, growth of service exports has been weaker, as global deleveraging has hindered growth of financial services. Meanwhile, a low degree of import substitution has kept import volumes elevated. As a result, the current account deficit stands at 3 percent of GDP, the same as its pre-crisis level. The UK's low labor productivity growth during the crisis due to labor hoarding (Section III.A), which has caused the unit labor cost (ULC)-based REER to appreciate considerably more than the CPI-based REER, may provide a partial explanation for weak net export performance. Indeed, the ULC-based measure is nearly back to levels observed in the mid-2000s. This interpretation gives some hope for current account adjustment going forward, as UK relative labor productivity may improve as labor hoarding unwinds. If it does not, sterling may be more overvalued than suggested by standard IMF methodologies.

Estimates of Exchange Rate Valuation 1/ (percent)

\begin{tabular}{lrr}
\hline & May 2011 & Oct 2010 \\
\cline { 2 - 3 } Macro Balance & -4 & -4 \\
Equilibrium RER & -2 & -4 \\
External Sus tainability & 1 & 0 \\
Overall & about 0 & about 0 \\
\hline 1/ +/- indicates exchange rate over/undervaluation; see IMF \\
Occasional Paper No. 261 for details on the methodology underlying \\
the estimates in this table. \\
Source: IMF staff estimate.
\end{tabular}

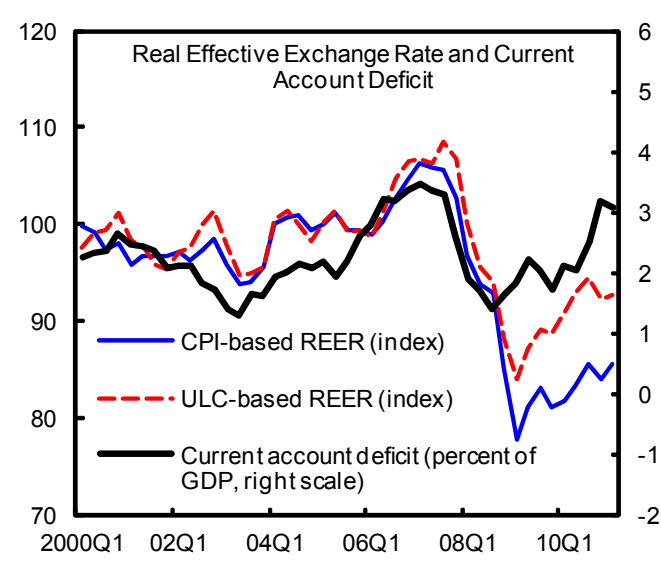

Sources: ONS; and IMF Intemational Financial Statistics. 


\section{Figure 5. External Sector Developments}
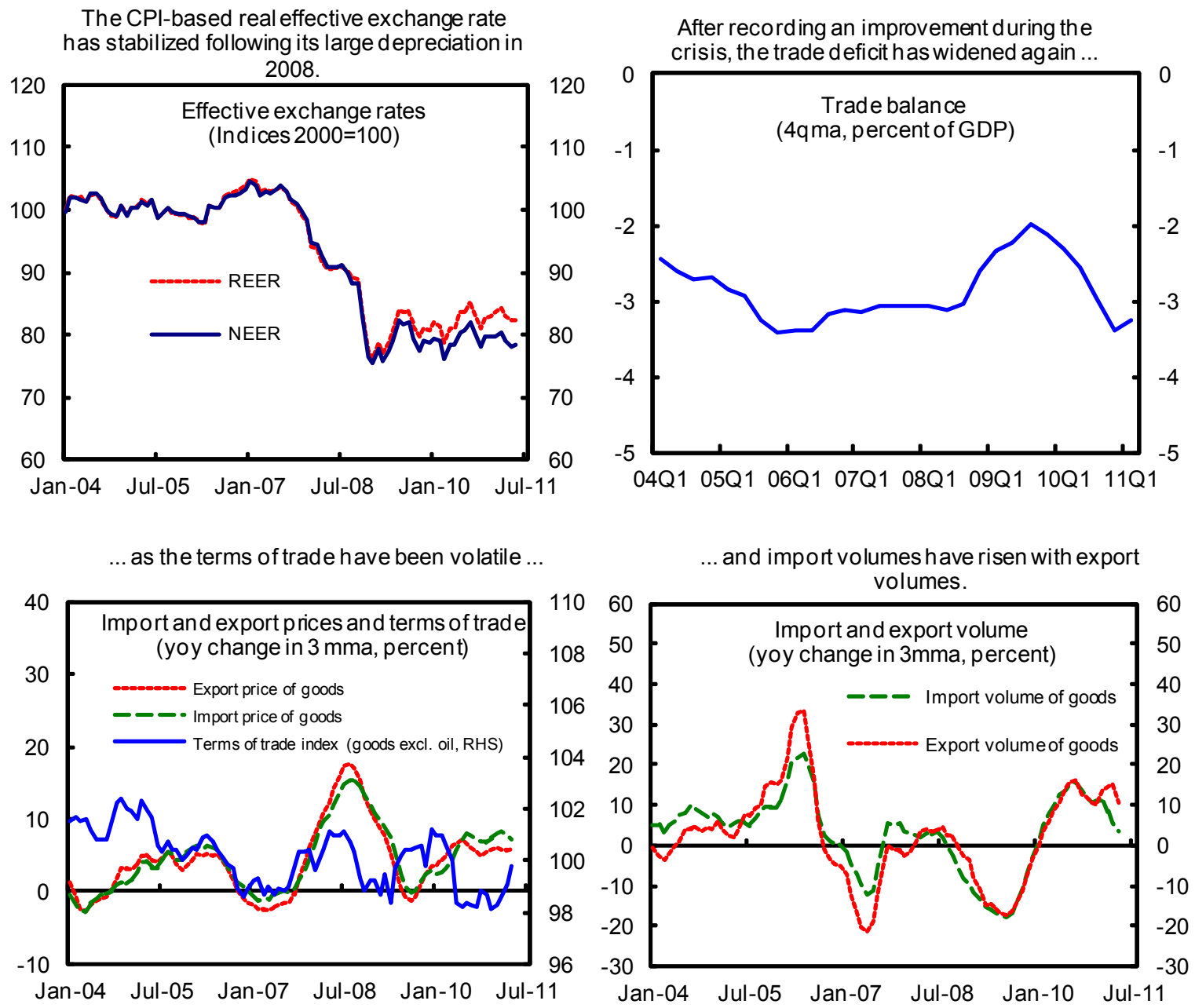

An improving income balance has prevented sharperdeterioration in the current account...
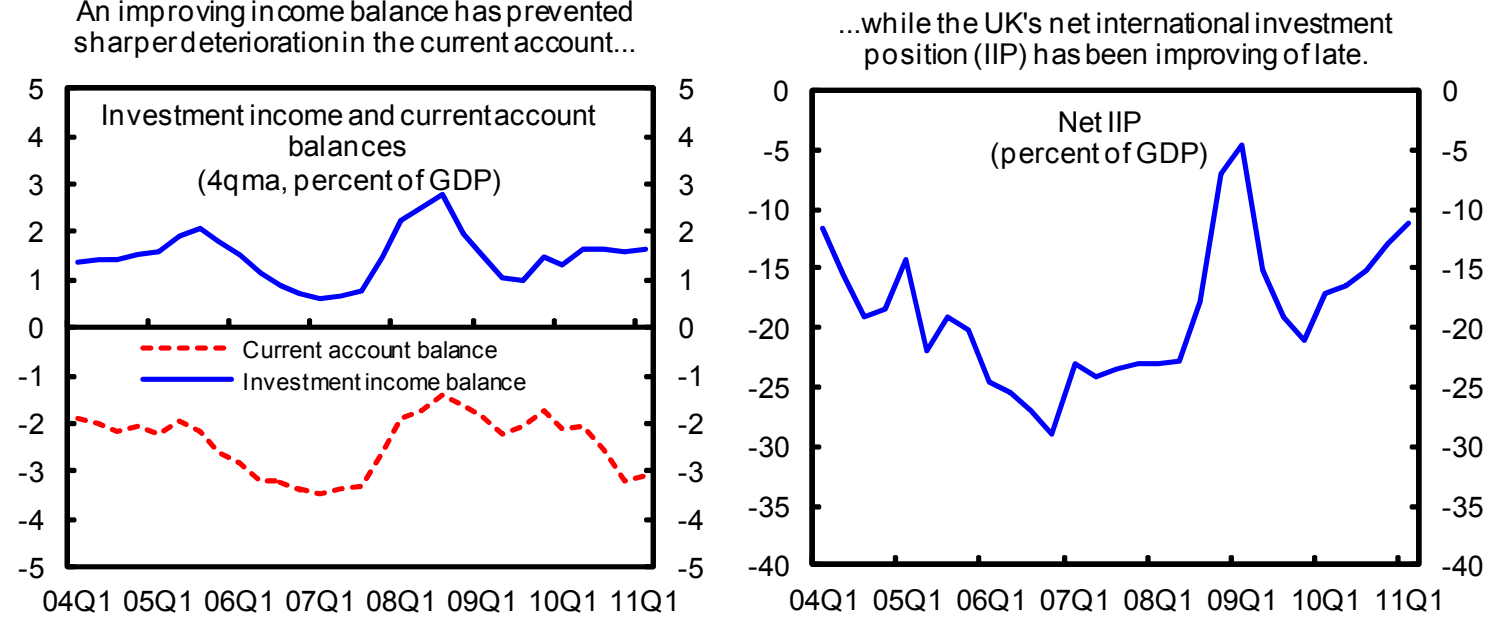

Sources: Haver Analytics; MF, International Financial Statistics; and IMF staff calculations. 
11. In any case, fiscal adjustment plans give a strong reason to expect a narrowing of the current account deficit going forward. Fiscal consolidations are associated with current account adjustments, both because they compress domestic demand directly (indeed, domestic demand growth is projected to be lower in the UK than its trading partners in the coming years) and because fiscal consolidation allows looser monetary policy, which helps keep the exchange rate competitive.

Studies suggest that each 1 percent of GDP of fiscal consolidation typically reduces the current account deficit by 0.2-0.6 percent of GDP. ${ }^{3}$ With fiscal adjustment of nearly 7 percent of GDP programmed between 2010 and 2015, this implies that the current account

Growth Rates of Domestic Demand (percent)

\begin{tabular}{lcccc}
\hline & $2000-07$ & $2008-09$ & 2010 & $\begin{array}{c}2011-16 \\
\text { (Proj.) }\end{array}$ \\
\cline { 2 - 5 } & 3.0 & -3.1 & 2.4 & 1.7 \\
UK & 2.9 & -1.4 & 2.0 & 2.3 \\
\hline
\end{tabular}

Sources: WEO; and IMF staff estimates. deficit might fall by about $2 \frac{1}{2}$ percent of GDP over this period, bringing the current account close to balance. The latest GDP outturn (Q1 2011) is encouraging in this regard, with net exports contributing 1.3 percentage points to q-o-q GDP growth.

\section{Prospects for orderly rebalancing toward private sector-led growth will depend} in part on the pace of financial sector healing. Recent developments and the outlook in this area are examined next.

\section{B. Financial Sector Deleveraging}

13. Banks have buttressed their balance sheets over the last year (Figures 6-7). With core tier 1 ratios above 10 percent, all major banks are ahead of schedule in their transition to Basel III rules. Banks are addressing the funding vulnerabilities that lay behind the crisis by reducing their reliance on wholesale funding, increasing the share of stable customer deposits, and lengthening the duration of their liabilities. In doing so, UK banks have accounted for over a quarter of the deleveraging of global cross-border lending since the start of the crisis. There has also been also been a modest shift in the composition of assets in favor of liquid instruments and away from riskier securities and derivatives. System-wide profitability improved in 2010, largely driven by lower loan provisioning, as new impairments peaked in 2008-09.

\section{Despite challenging market conditions, major UK banks managed to raise} significant levels of term funding, both in capital markets and through private placements (Figure 7). Refinancing needs for 2010 were fully met, and some 2011 maturities were pre-financed. Wholesale funding costs have increased moderately since mid-

\footnotetext{
${ }^{3}$ See Bernheim, D., 1988, "Budget Deficits and the Balance of Trade," Tax policy and the Economy, Vol. 2, pp. 1-31 and Bluedorn, J., and D. Leigh, 2011, "Revisiting the Twin Deficits Hypothesis: The Effect of Fiscal Consolidation on the Current Account" (www.imf.org/external/np/seminars/eng/2010/eui/pdf/BL.pdf).
} 
2010, though there is some variation across banks. This has led some banks to increase rates paid on deposits, although these remain at historically low levels. Securitization has recovered considerably from its mid-crisis lows, but it remains a less attractive source of funding than before the crisis due to changes in the regulatory treatment of securitized assets and increased spreads paid to investors. Covered bond issuance has increased significantly, although it is still a relatively small part of total debt issuance.

Figure 6. Financial Ratios of Major UK Banks 1/
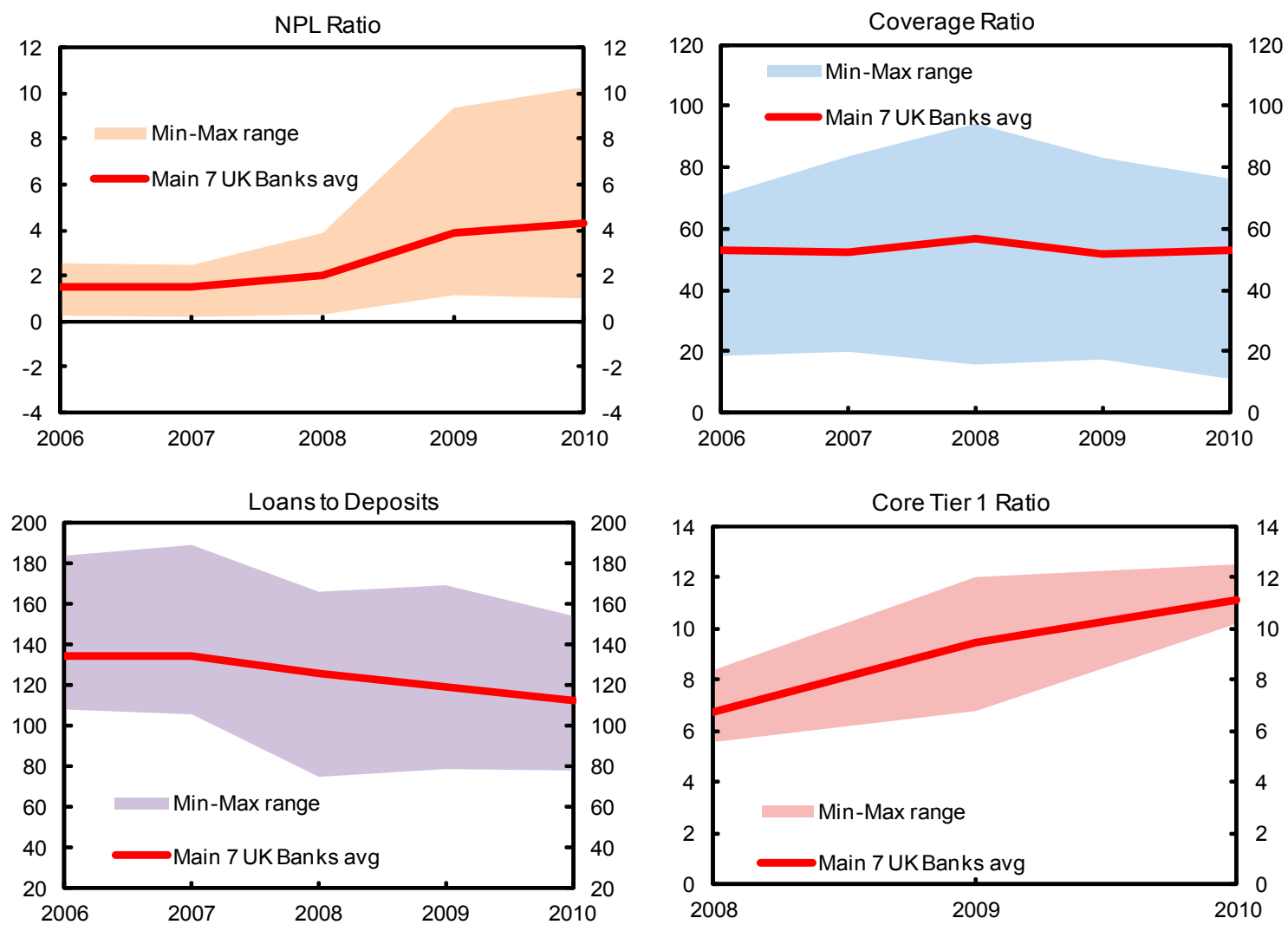

Sources: Annual reports of individual banks; and IMF staff estimates.

1/Sample includes Barclays, HSBC Holdings Plc, Lloyds Banking Group, Nationwide Building Society, Royal Bank of Scotland, Stand ard Chartered, and Santander UK.

UK Banking System: Selected Financial Soundness Indicators (End-of-period, percent)

\begin{tabular}{lrrrrrrr}
\hline & 2004 & 2005 & 2006 & 2007 & 2008 & 2009 & 2010 \\
\cline { 2 - 7 } & 12.7 & 12.8 & 12.9 & 12.6 & 12.9 & 14.8 & 15.9 \\
Regulatory capital to risk-weighted assets & 7.0 & 6.1 & 6.1 & 5.5 & 4.4 & 5.4 & 5.4 \\
Regulatory capital to assets & 1.9 & 1.0 & 0.9 & 0.9 & 1.6 & 3.5 & 4.0 \\
Nonperforming loans to total loans & 61.5 & 54.0 & 54.6 & $\ldots$ & 38.1 & 41.1 & 35.4 \\
Provisions to nonperforming loans 1/ & 0.7 & 0.8 & 0.5 & 0.4 & -0.4 & 0.1 & 0.2 \\
Return on assets 2/ & 10.9 & 11.8 & 8.9 & 6.2 & -10.3 & 2.6 & 3.9 \\
Return on equity 2/ & & & & & & &
\end{tabular}

Source: UK authorities.

$1 /$ Break in data series in 2006.

2/ Net income after extraordinary items and taxes (period average). 
Figure 7. Banking Sector Funding
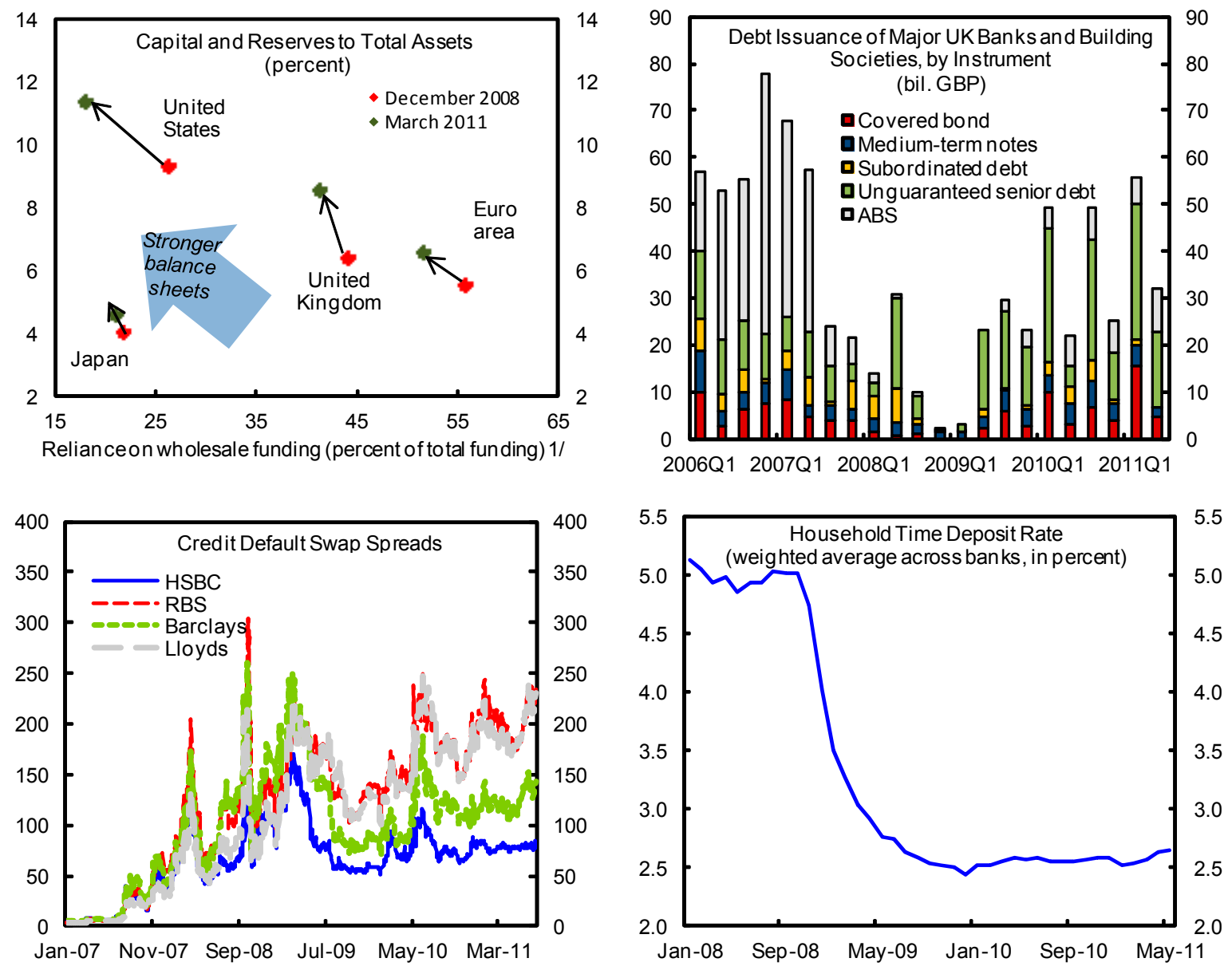

Sources: Bank of England; Bloomberg; EU Consolidated Ban king Data; and IMF staff estimates.

$1 /$ Total fund ing is local- and foreign-currency wholesale funding plus deposits.

\section{Exit from crisis-related measures is proceeding as planned to reduce the} government's large contingent liabilities and restore market discipline (see Appendix II of the accompanying FSSA for a detailed update on the status of financial sector support measures). The two large banks with government stakes have made significant progress in restructuring their balance sheets and their funding and liquidity profiles.

\section{Although conditions in the banking sector have improved, challenges remain:}

- $\quad$ Deposits have been growing faster than loans since 2009, but the funding gap remains large (Figure 6) and reliance on wholesale funding will remain elevated. Banks will need to refinance a large amount of public support and private-sector debt over the next two years. They therefore remain vulnerable to higher funding costs and disruptions in wholesale funding markets. 

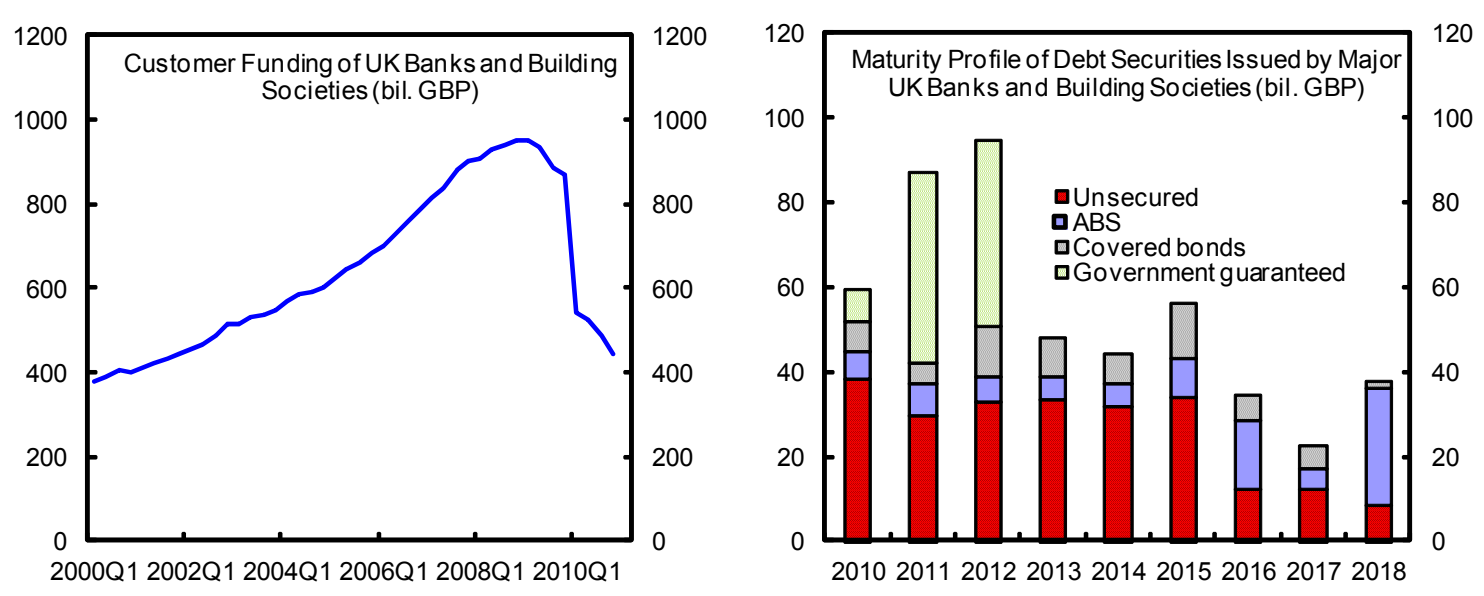

Sources: Bank of England; and Financial Services Authority, Prudential Risk Outlook.

- $\quad$ Asset quality remains fragile. Nonperforming loans continued to increase in 2010, albeit at a more moderate pace than in 2008 and 2009. The low interest rate environment has significantly reduced debt-servicing costs and helped contain default rates, which remain low relative to previous crises and to the U.S. ${ }^{4}$ However, bank exposures to some EU periphery countries generated significant impairments for select banks. Furthermore, lender forbearance may be disguising the true extent of risks, particularly in the commercial real estate sector (CRE) where a large number of loans are in breach of financial covenants but not yet declared in default (more than 12 percent as of end-2010). The high level of indebtedness of UK households and some CRE companies aggravates these vulnerabilities. Various combinations of rapid interest rates increases, a slower recovery, and further declines in property prices could inflict significant losses on banks (see companion Selected Issues paper).

- Stress tests conducted as part of the FSSA indicate that banks have reasonably solid capital buffers but funding risks remain a key vulnerability. Solvency concerns are limited to a low-probability confluence of adverse macroeconomic shocks. Risks from exposures to vulnerable European sovereigns seem manageable but potential major spillovers to the private sector in those countries and to core European banks would be more problematic. Major UK banks have adequate liquidity buffers under most scenarios, but remain vulnerable to sustained disruptions in funding markets.

\footnotetext{
${ }^{4}$ Higher default rates on US mortgages may partly reflect US bankruptcy laws, which make mortgage defaults less costly to households than in the UK. These bankruptcy differences may also cause house price declines to dampen consumption more in the UK, as households have more incentive to cut spending to avoid default.
} 

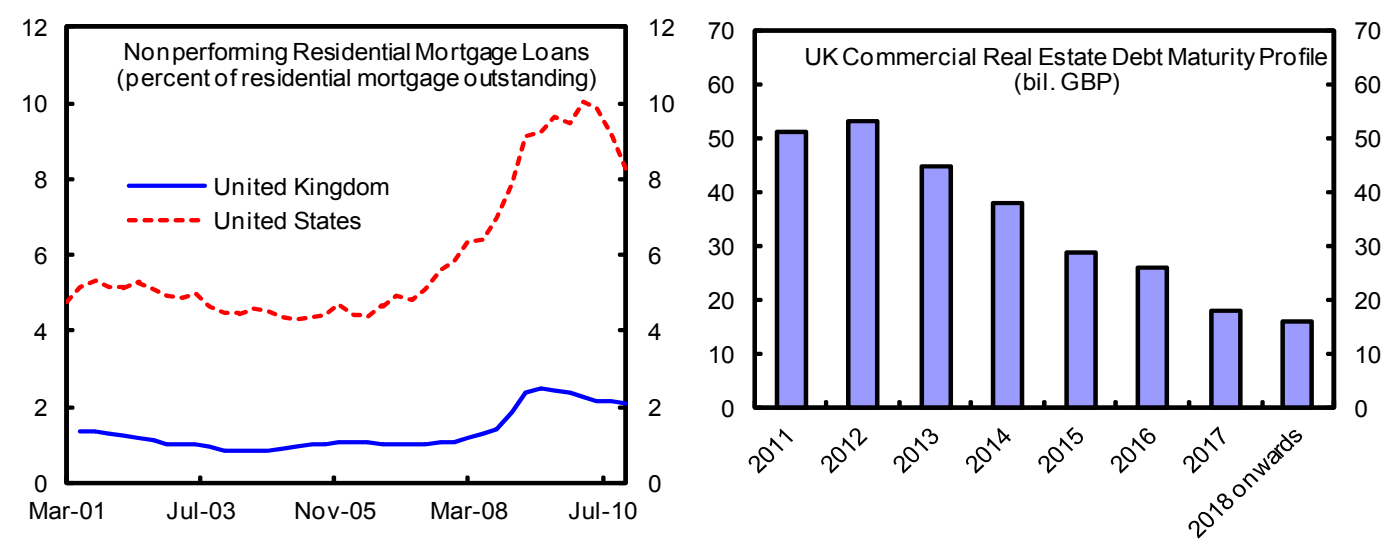

Sources: Bank of England; Council of Mortgage Lenders; Mortgage Bankers Association; and IMF staff calculations.

17. Against this background, credit growth remains subdued. While credit conditions have improved recently, they remain significantly tighter than before the crisis (Figure 8).

- $\quad$ Net lending to the corporate sector has continued to fall. Credit availability has improved for large companies, but remains restrictive for smaller businesses and for CRE companies. The 2011Q1 credit conditions survey indicated that weaker credit demand, possibly associated with the slow recovery, is also contributing to the weakness in bank lending to small businesses. In contrast, lower credit demand from large corporates reflects increased reliance on capital markets as a source of finance for corporate investment. There is also significant differentiation in the cost of funding across corporates: spreads on lending to small businesses have kept increasing, while those for large borrowers are falling.

- $\quad$ Lending to the household sector is slightly positive but still subdued. Lending standards, albeit tighter than before the crisis, have started to loosen slightly (Figure 8). Despite an increase in default rates on secured lending in the first quarter

Credit Conditions Survey: Spreads over Reference Rates on Lending to Corporates by Firm Size (Net percentage balances) 1/ 2/

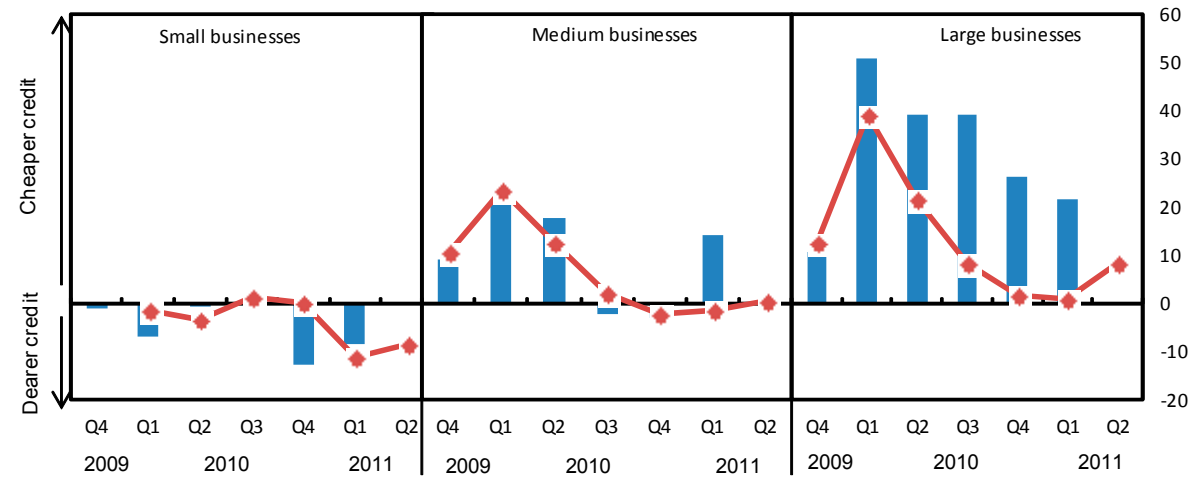

Source: Bank of England.

$1 /$ Net percentage balances are calculated by weighing together the responses of those lenders who an swered the question. The blue bars show the responses over the previous th ree months. Thered diamonds show the expectations over the next three months. Expectations balances have been moved forward one quarter so th at they can be comared with the actual outturns in the following quarter.

$2 / \mathrm{A}$ positive balanceindicates that spreads over reference rates have become narrow, such thatall else being equal, it is

cheaper for corporates to borrow. 
of 2011, lenders report increased risk appetite towards borrowers with high loan-tovalue ratios, as competition has squeezed margins. The availability of unsecured credit, which remained very restrictive after the crisis, has improved of late, but spreads on credit card lending continue to increase, reflecting significantly higher default rates than for secured lending.

Figure 8. United Kingdom: Credit Market Developments
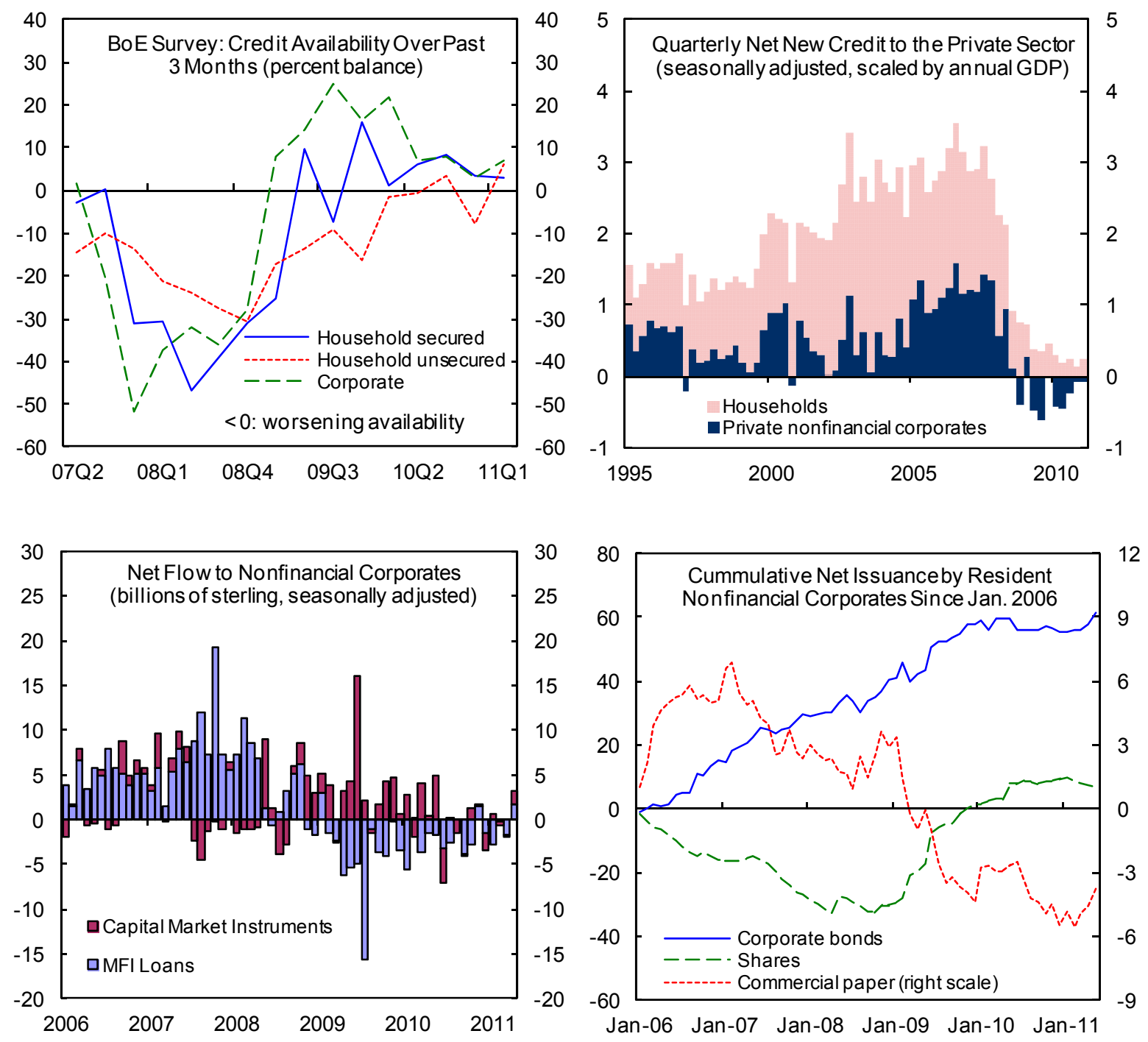

Sources: Bank of England; and IMF staff calculations. 


\section{The Central Scenario AND Risks}

\section{A. Growth and Employment}

\section{Staff's central scenario is that rebalancing occurs and financial sector health} continues to improve as described in the above sections. In this scenario, staff project growth - led by investment and net exports - to gradually rise from $1 \frac{1}{2}$ percent in 2011 to around $2 \frac{1}{2}$ percent over the medium term. ${ }^{5}$ This is consistent with the output gap nearly closing by 2016, assuming

- a negative output gap at end-2010 of around 23/4 percent of GDP (Box 2; Figure 9) and

- $\quad$ medium-term potential growth of 2 percent. This potential growth rate is consistent with labor force growth of $1 / 2$ percent and labor productivity growth of $1 \frac{1}{2}$ percent. The latter is slightly below the historical average of $13 / 4$ percent, as lingering effects of the crisis — such as skill erosion from long-term unemployment - are expected to dent medium-term potential growth. ${ }^{6}$

19. The unemployment rate is expected to decline only slowly. Unemployment spiked to 8 percent at the start of the crisis (Figure 10). It then stabilized around this level for over a year, though it has eased slightly in recent months to 7.7 percent. Though painful, the spike in unemployment was relatively muted compared to the size of recession. This partly reflected labor hoarding — which has caused UK productivity growth to significantly underperform other major economies since the start of the crisis - as well as lower immigration and labor force participation. The unwinding of these forces is likely to similarly slow improvements in unemployment during the recovery.

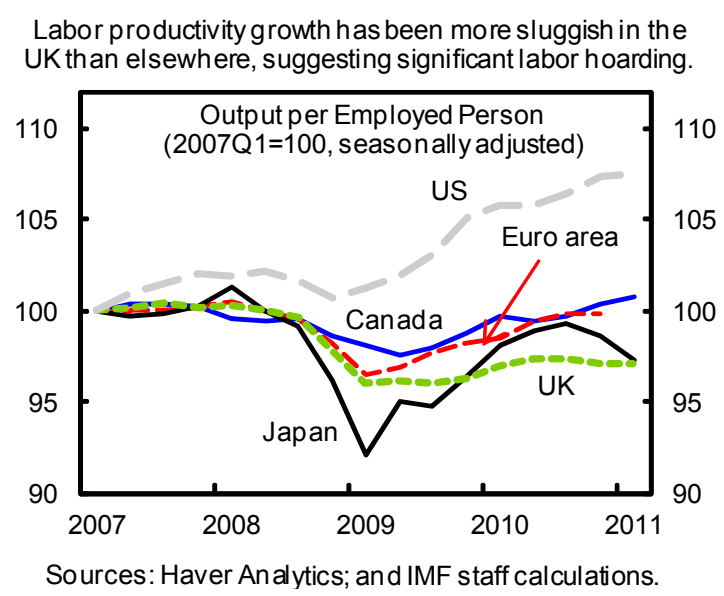

\footnotetext{
${ }^{5}$ The projections in this report are those in the June 2011 World Economic Outlook Update. New data since this update point to the likelihood that the preliminary estimate for Q2 real GDP growth will fall short of staff's forecast for the quarter, but it is unclear how much of a possible shortfall is due to erratic factors. The next forecast round will be published with the September 2011 World Economic Outlook.

${ }^{6}$ This estimate for historical average labor productivity does not adjust for changes in hours worked. The forward-looking projections based on these estimates thus implicitly assume that trends in hours worked remain unchanged.
} 


\section{Box 2. What Does Okun's Law Tell Us About the Output Gap?}

Unemployment increased sharply during the crisis. The unemployment rate increased by almost 3 percentage points to around 8 percent, a level not seen since the mid-1990s.

The high unemployment rate yields some insight into the size of the output gap through Okun's law. Okun's law, which is empirically supported by an extensive literature, postulates that there is a stable relationship between the unemployment rate and the output gap. ${ }^{1}$ This relationship can be estimated empirically for the UK and then used to estimate the current output gap, based on the distance between the current unemployment rate and the steady-state level of unemployment $\left(U^{*}\right){ }^{2}$

Three different methods are used to estimate $U^{*}$ : The first method takes the average unemployment rate over the last business cycle (6.8 percent), measured from the peak in output in the second quarter of 1990 to the last peak in the first quarter of 2008. The second measure utilizes a slow-moving filter to extract the underlying trend unemployment rate. ${ }^{3}$ This yields a $U^{*}$ of 6.4 percent in the fourth quarter of 2010. The advantage of this approach is that it allows the steady-state unemployment rate to change over time. The third estimate of $U^{*}$ uses the Office for Budget Responsibility's (OBR) measure of steady-state unemployment (5.25 percent).

The different measures of the steady-state unemployment rate suggest that the output gap in 2010 was between -2.3 percent and $\mathbf{- 5 . 6}$ percent. As the Okun's law equation implies, the range of output gap estimates is directly related to the range of estimated $U^{*}$ s. As the unemployment rate has remained persistently high, the output gap estimates have also remained fairly constant, despite the recovery in output during most of 2010 .

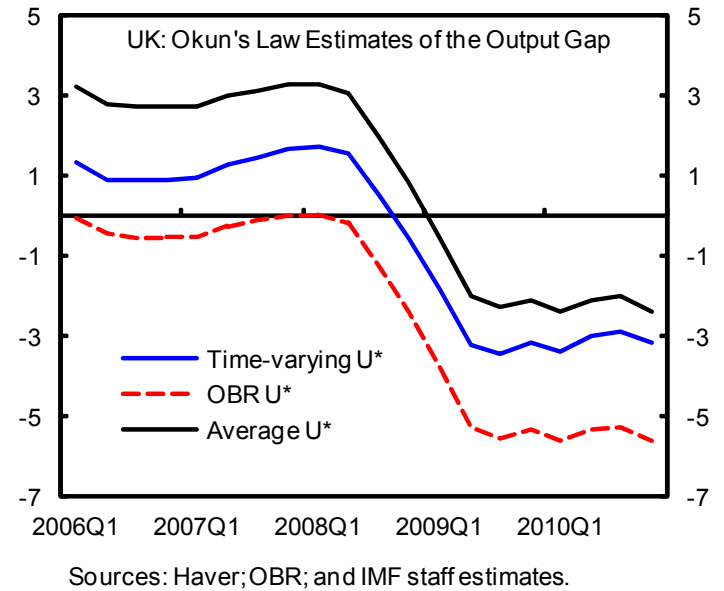

Sources: Haver;OBR; and IMF staff estimates.

${ }^{1}$ See, for example, Knotek, E., 2007, “How Useful Is Okun's Law?” Federal Reserve Bank of Kansas City Economic Review (Fourth Quarter), pp. 73-103.

${ }^{2}$ The relationship is estimated using a dynamic version of Okun's law, which relates changes in the unemployment rate to lagged changes in output and the unemployment rate itself. See Chapter 3 of the Spring 2010 World Economic Outlook for more details. The resulting estimate is that a 1 percentage point increase in output reduces the unemployment rate by 0.49 percentage points, based on a sample ranging from 1988Q2 to 2008Q1.

${ }^{3}$ An HP filter is utilized for this purpose. Four candidate smoothing parameters were considered: 1600, 10000, 50000, and 100000. To determine which smoothing parameter is the most appropriate, the resulting unemployment gap was inserted into the following wage equation:

$$
\Delta w_{t}=\alpha+\sum_{s=1}^{4} \beta_{s} \Delta w_{t-s}+\delta\left(U_{t}-U_{t}^{*}\right)+\varepsilon_{t}
$$

The smoothing parameter that yielded the largest $R^{2}$, which in this case was 100000 , was used. 


\section{Box 2. What Does Okun's Law Tell Us About the Output Gap? (continued)}

The output gap estimate based on Okun's law falls within the range of other estimates of the output gap. The measure of the output gap using the time-varying filtered estimate of $U^{*}$ is close to the lower end of the estimates of the output gap presented in the Selected Issues paper of the 2010 Article IV consultation, which have been updated. The estimated size of the output gap for 2010, averaged across all models, is -2.7 percent.

\section{Other considerations suggest this estimate} could be too high or too low:

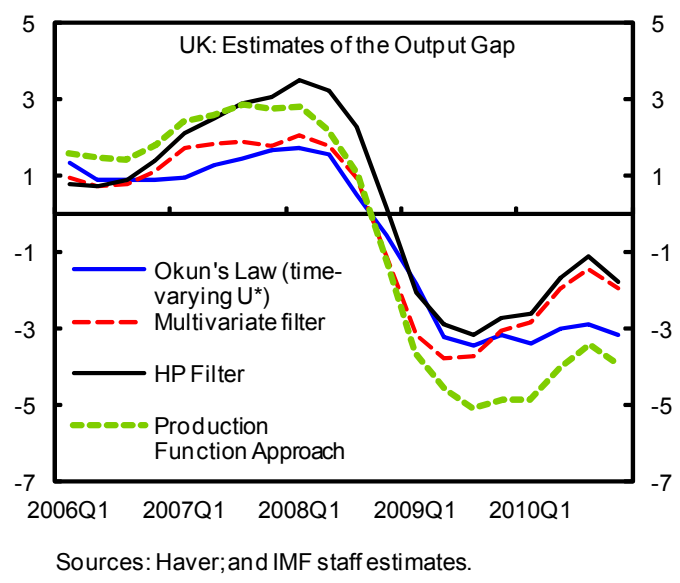

- On the one hand, labor hoarding could imply a wider output gap. Although the unemployment rate increased during the crisis, this increase was smaller than what would have been expected given the size of the output decline. As a result, the fall in productivity during this recession was larger than that experienced during previous recessions. This drop in productivity could be evidence of unusually high labor hoarding by firms, implying that there is "hidden underemployment" within firms that is not being captured by the unemployment rate. This underestimate of true unemployment could result in an underestimated output gap using Okun's law.

- $\quad$ On the other hand, direct surveys that ask firms how much spare capacity they have and how easily they can hire additional workers suggest a relatively small output gap (Figure 9).

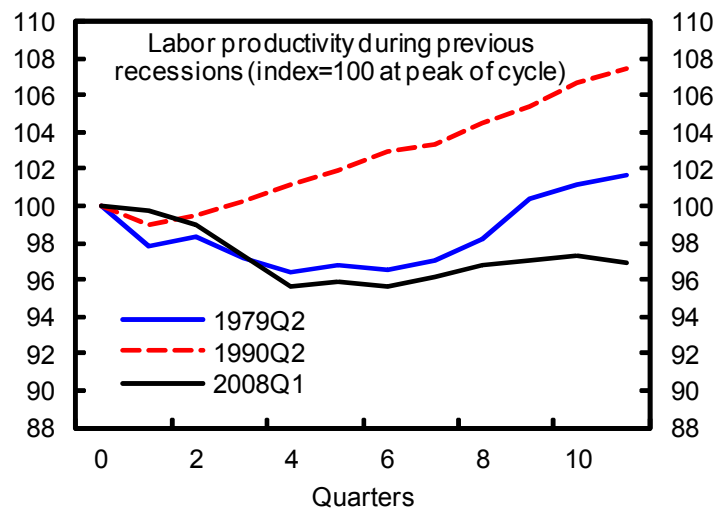

Sources: ONS; and IMF staff calculations.

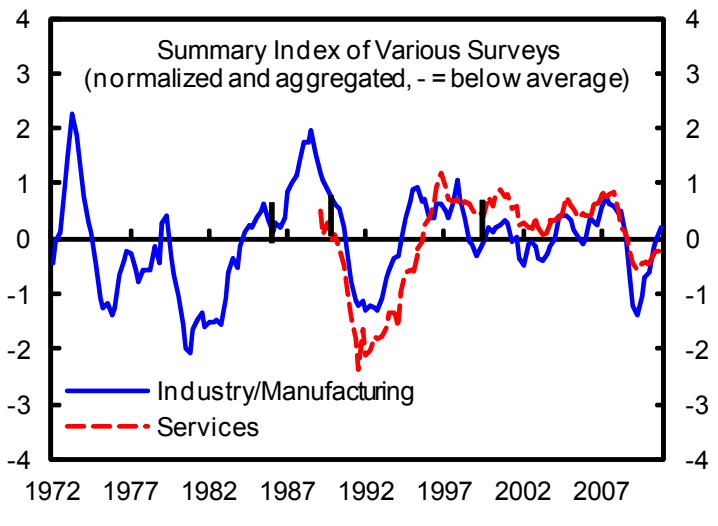

Sources: $\mathrm{CBI}$; Haver; and IMF staff calulations.

On balance, staff estimates a negative output gap of $23 / 4$ percent at end-2010, though uncertainty around this estimate is large. 
Figure 9. Indicators of Capacity Utilization
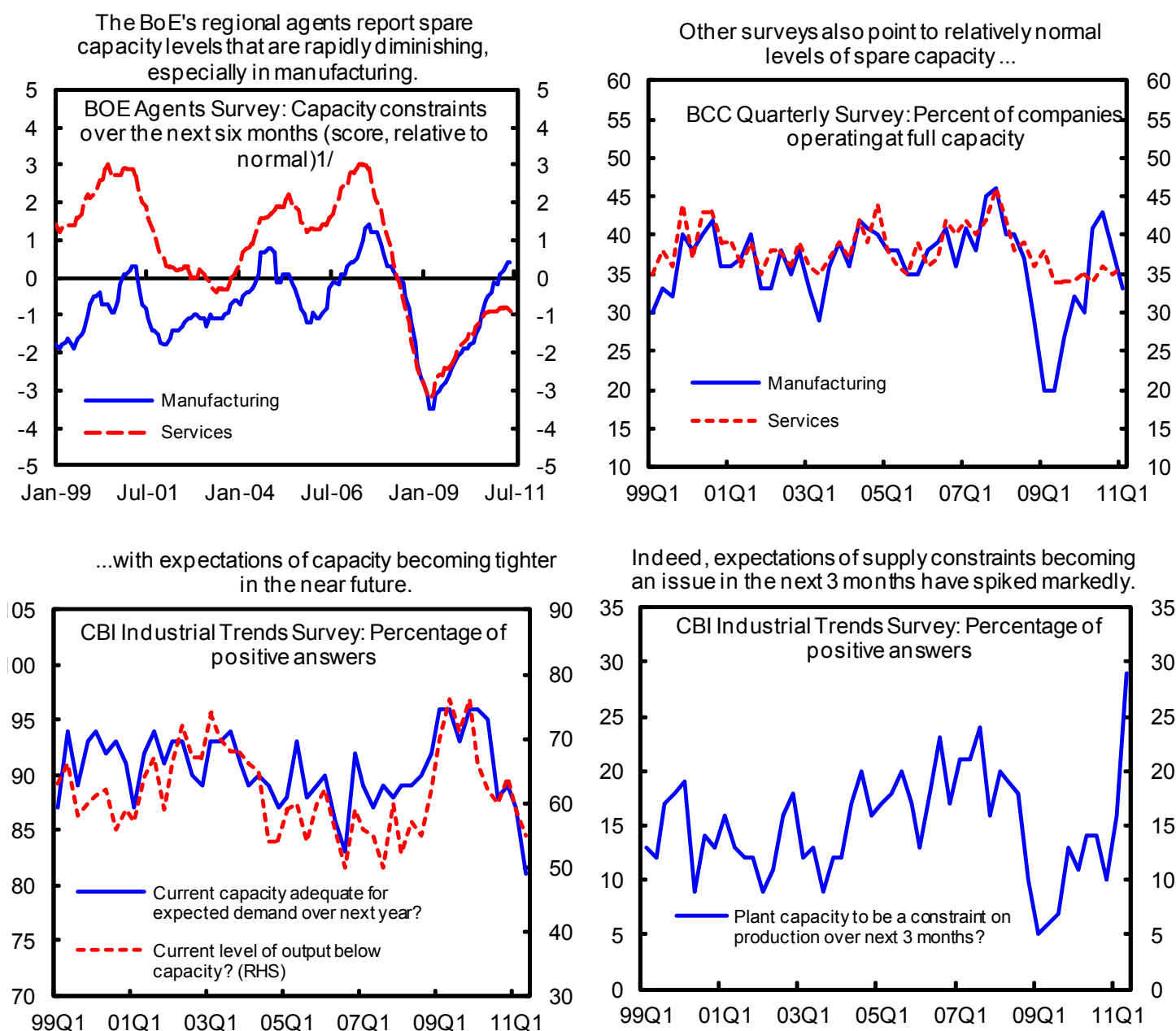

Indeed, expectations of supply constraints becoming an issue in the next 3 months have spiked markedly.

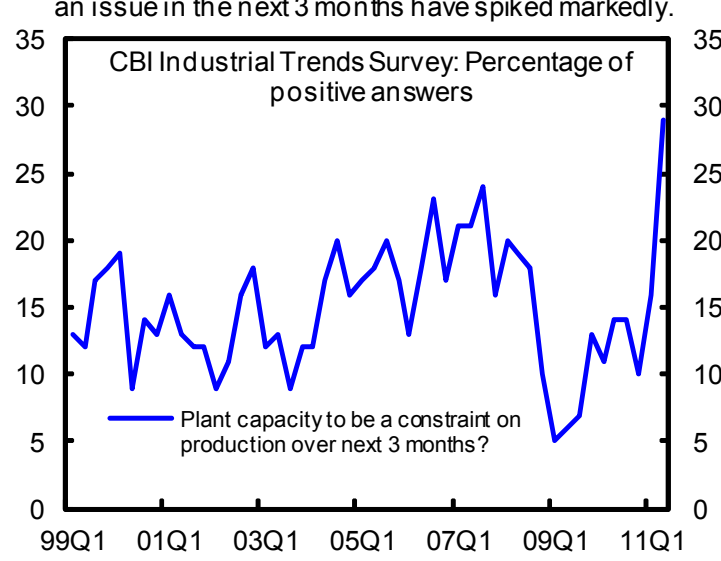

The service sector is facing less difficulty recruiting newstaff compared to the volatile manufacturing sector.

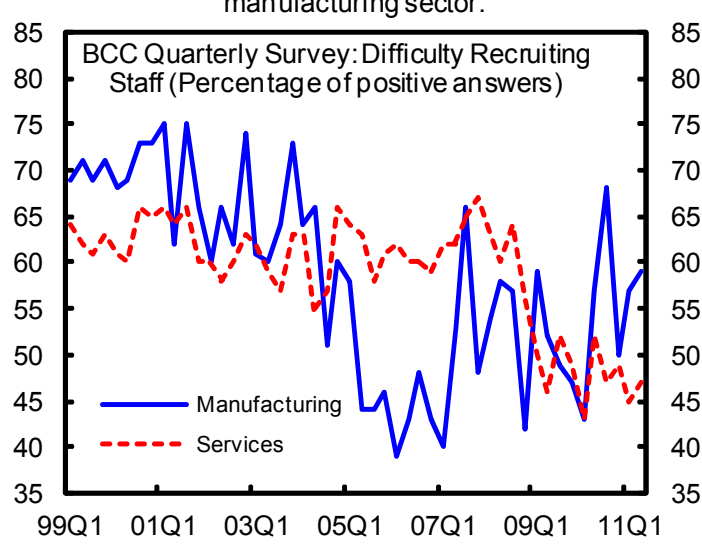

In sum, survey in dicators suggest that capacity utilization has retumed to average levels in manufacturing, but remain slightly belowfor services.

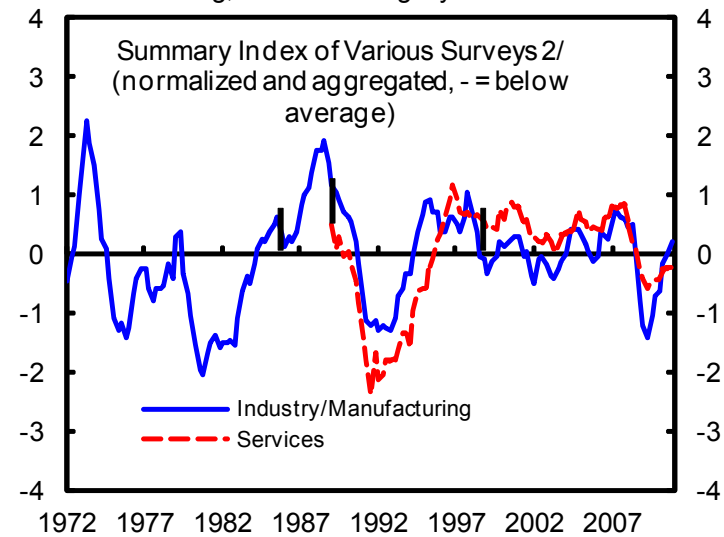

Sources: Haver Analytics; and IMF staff calculations.

1/ Before January 2005: based on companies' current situation, rather than being forward-looking.

2/ Based on a range of survey in dicators (provided by the Bank of England, British Chambers of Commerce,

Confederation of British Industry, and Eurostat, respectively) for capacity constraints and recruitment difficulties;

normalized to average zero over the cycle, with un it standard deviation. Vertical bars in chart mark structural breaks in series due to inclusion of new indicators. 
Figure 10. Labor Market Developments
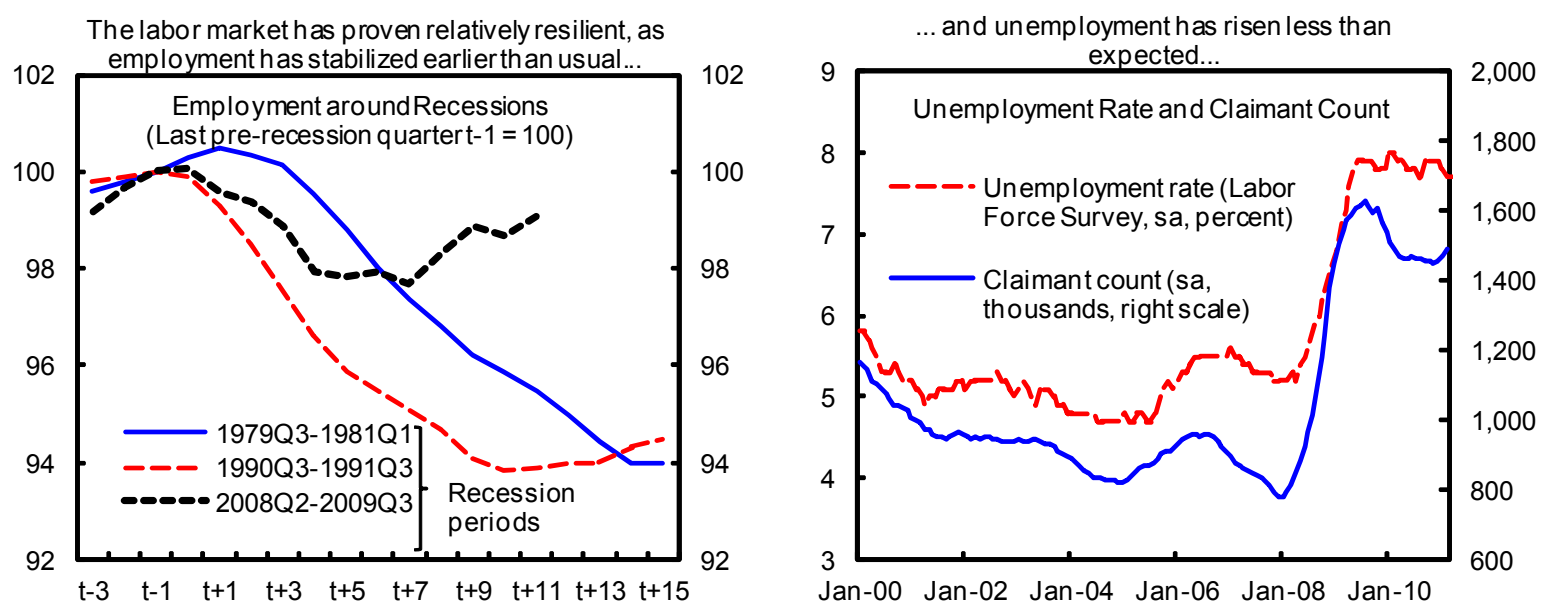

...supported by a cyclical fall in labor participation and some easing in net immigration, although both

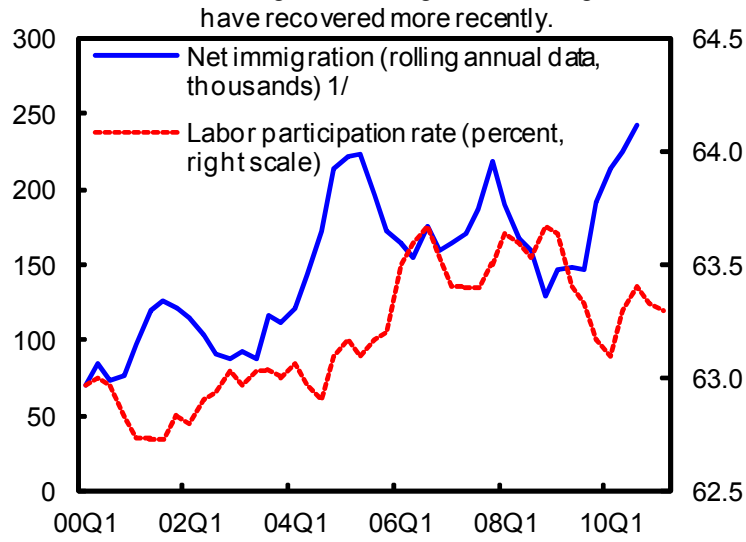

Similarly, hours worked fell during the recession but have

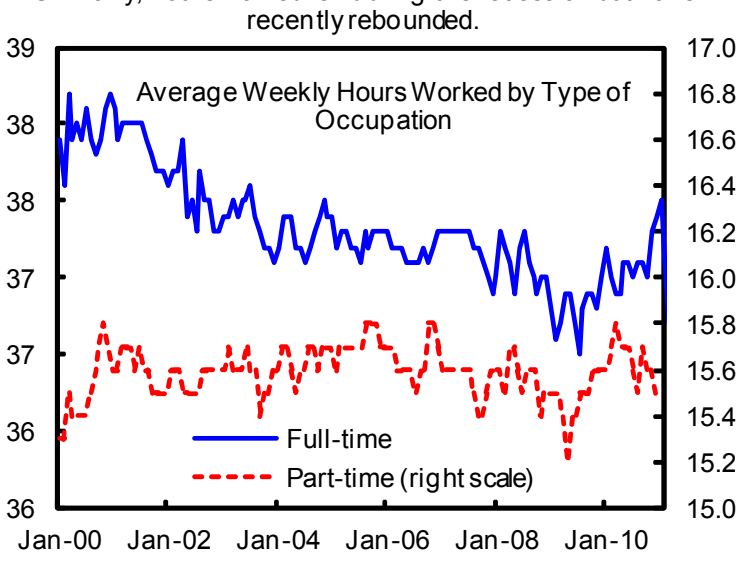

Such labor hoarding during the downturn was helped by wage moderation, in cluding nominal pay freezes in many firms.

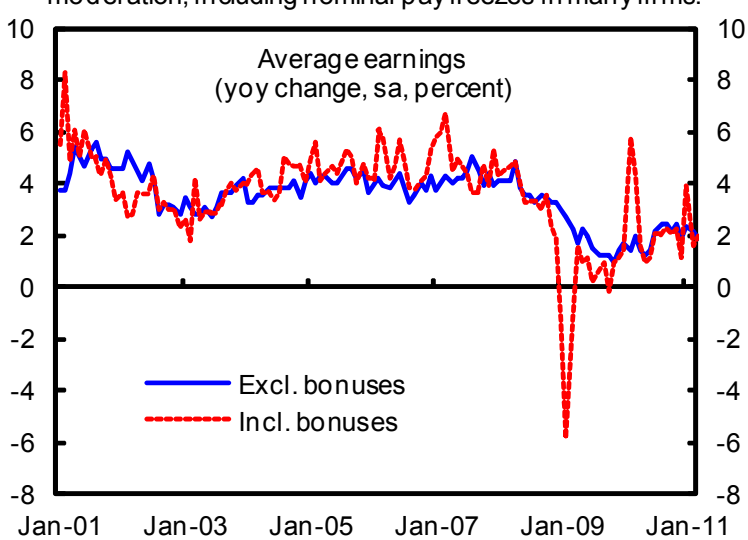

Despite the labor market's resilience, both vacancy data and surveys point to continued slack, at least

in services.

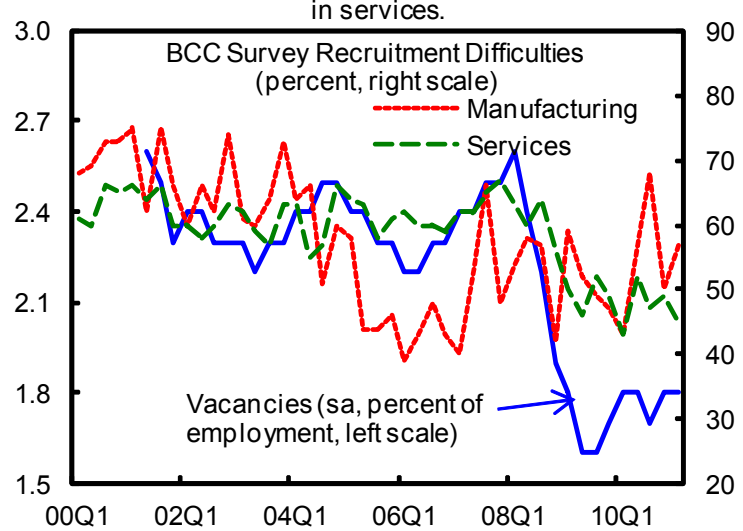

Sources: Haver Analytics; Office for National Statistics; and IMF staff estimates.

1 / Estimates based on provisional data from the International Passenger Survey. 


\section{B. Inflation}

\section{Inflation has been well above the 2 percent target since early 2010 (Figure 11), but this mainly reflects transitory factors: ${ }^{7}$}

- $\quad$ As in other countries, spiking commodity prices have been an important contributor to UK headline inflation. While headline inflation is $4 \frac{1}{4}$ percent, core inflation is lower at $23 / 4$ percent. Recent commodity price increases will continue to put upward pressure on inflation in the near term, including through utility price hikes in the second half of 2011. However, with futures pointing to broadly stable commodity prices going forward, price pressures from this source should gradually dissipate.

- Unlike in many other countries, indirect tax hikes have been a key driver of UK inflation. These include VAT rate hikes of $2 \frac{1}{2}$ percentage points each in January 2010 and January 2011. Staff estimates that these hikes have contributed 11/4 percentage points to headline inflation and $1 \frac{1}{2}$ percentage points to core inflation. Excluding these tax effects, core inflation is around 11/4 percent-well below the 2 percent target and similar to rates in other advanced economies. With the last major hike in indirect taxes occurring in April 2011, most tax effects should fall out of headline inflation by the second half of 2012 .
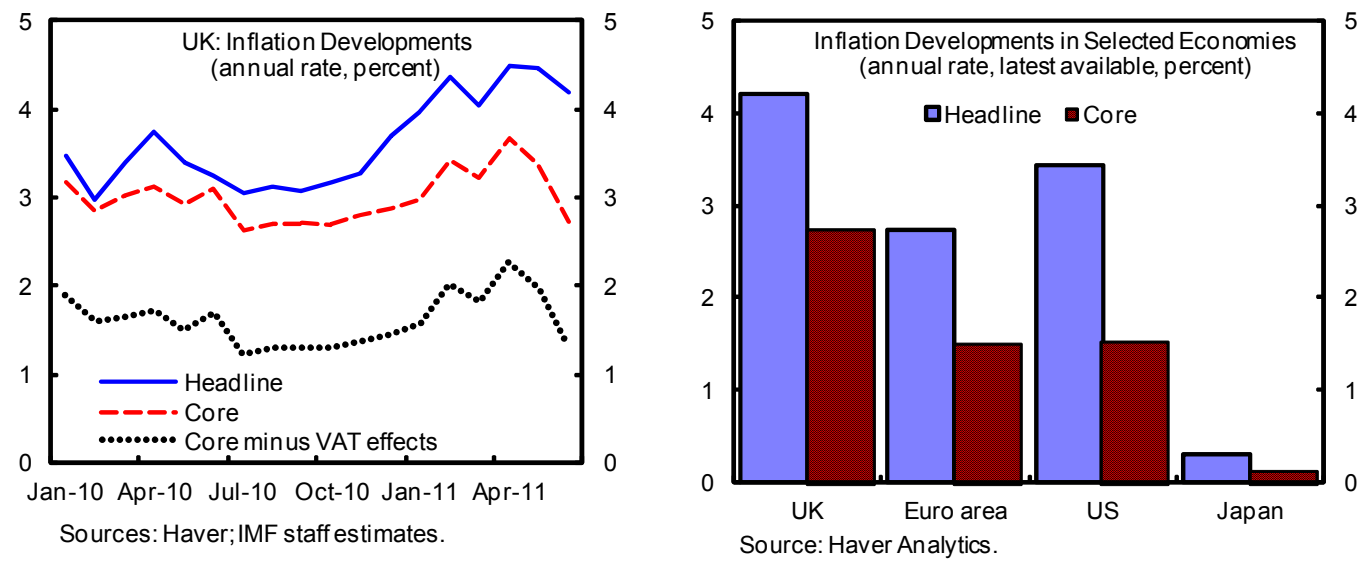

- $\quad$ Part of the inflation overrun in 2010 also reflects low labor productivity growth during the crisis. As the decline in wages was not commensurate with the drop in productivity, unit labor costs increased sharply in 2009 and early 2010, placing pressure on firm profits and limiting price moderation. ${ }^{8}$ Indeed, there is a statistically significant cross-country relationship between changes in unit labor costs over

\footnotetext{
${ }^{7}$ For more detailed analysis of recent inflation dynamics and further explanation of the estimates in this section, see the companion Selected Issues paper.

${ }^{8}$ Throughout this report, "unit labor cost" is used synonymously with "unit wage cost" for expositional ease. In the UK, data are reported for the latter, which excludes nonwage elements of compensation.
} 


\section{Figure 11. Price Developments}
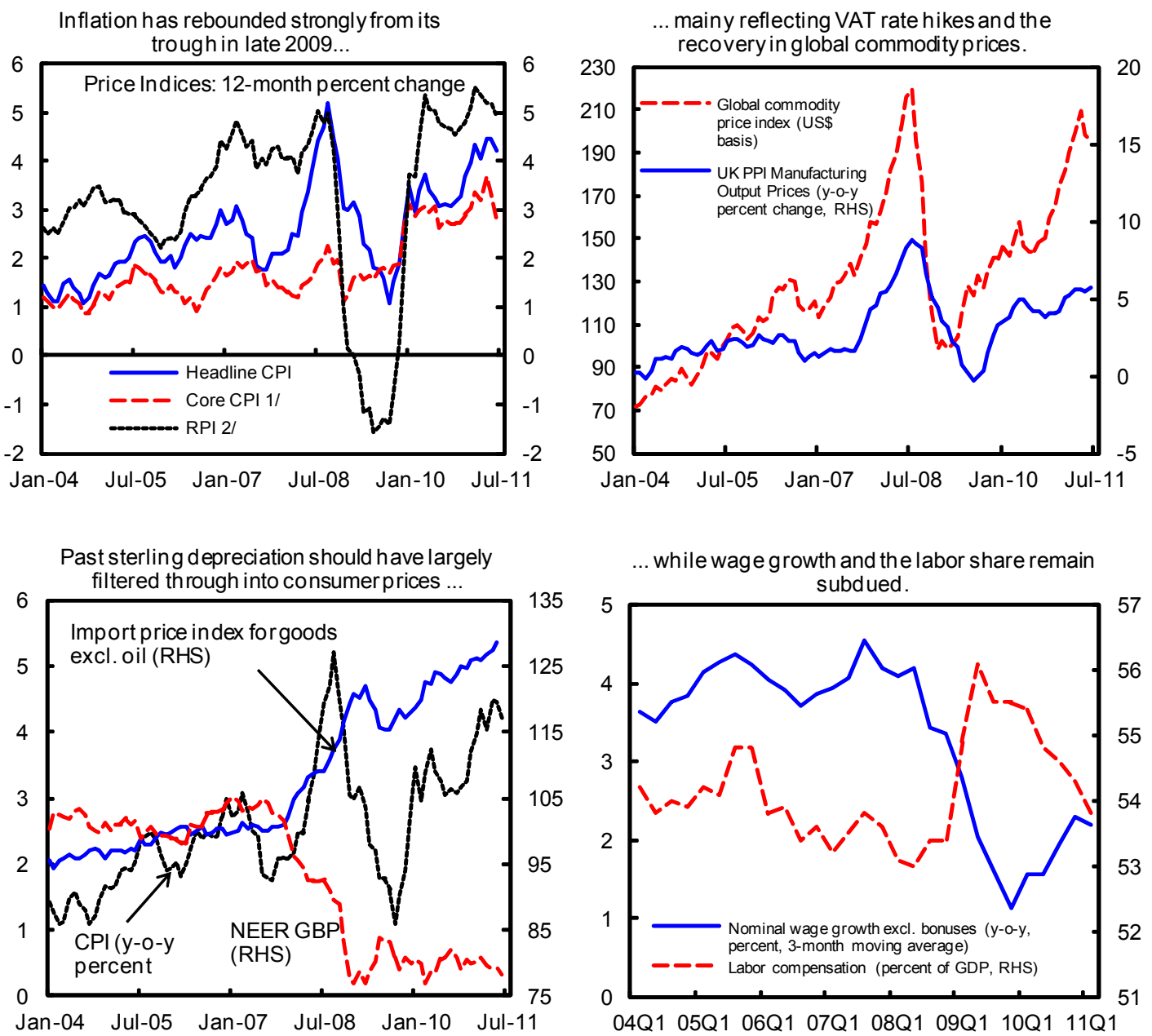

... while wage growth and the labor share remain

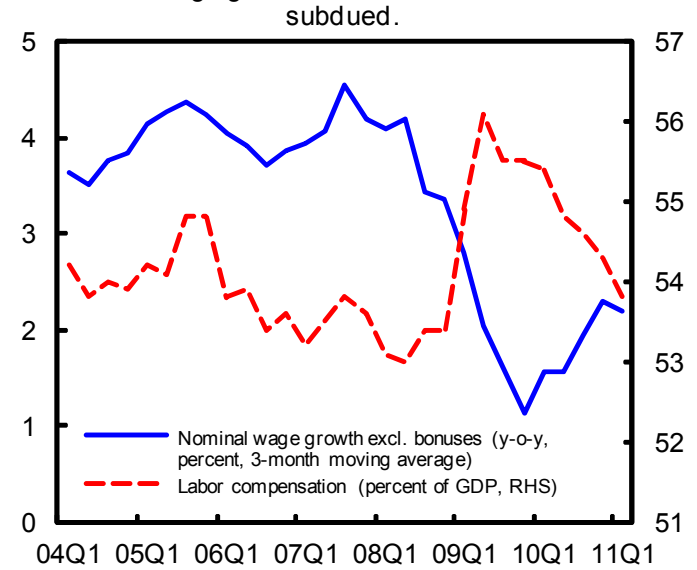

Broad money growth has been stabilizing at a

....and median-term inflation expectations remain anchored at pre-crisis rates, although near-term

low rate...
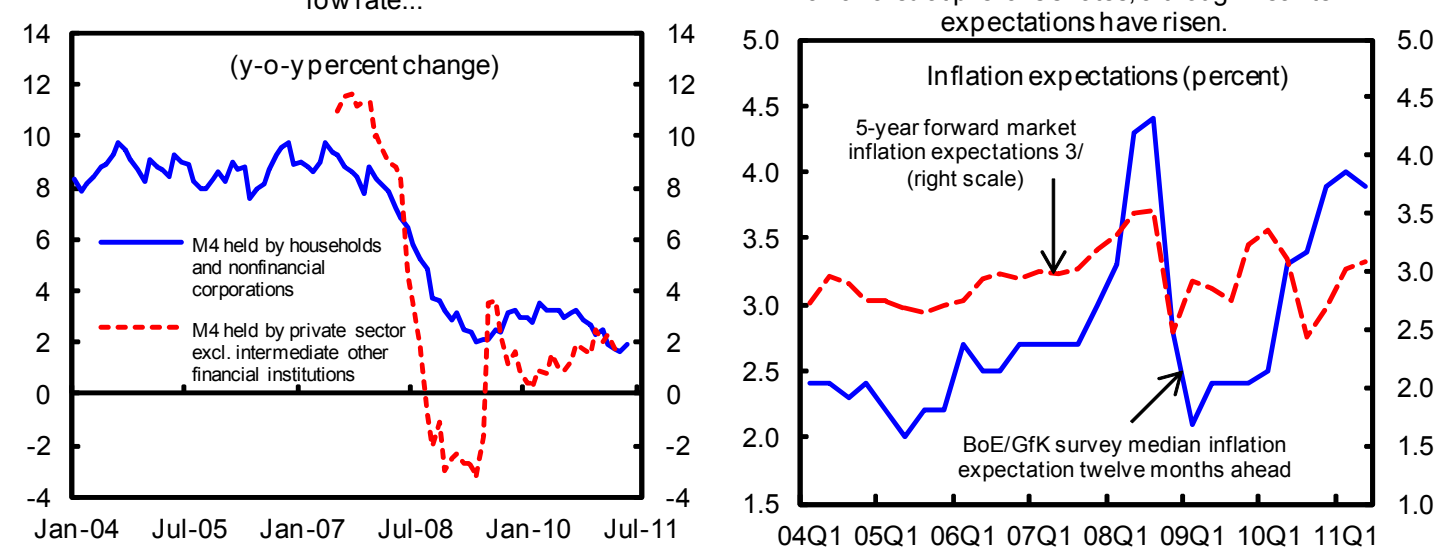

So urces: Bank of England; Office for National Statistics; and IMF staff calculations.

$1 /$ Core CPI excludes energy, food, alcohol, and tobacco.

2/ Retail Price Index; contains cost of housing.

$3 /$ Computed as quarterly average of difference between nominal and real (RPI-linked) forward gilt yields. Estimates likely to be biased upward by the presence of an inflation risk premium, and downward by the liquidity risk premium on real gilts. 
2008-09 and the change in inflation in the subsequent year. Since mid-2010, unit labor cost growth has been subdued as new labor hoarding ceases and productivity growth turns positive. As labor hoarding starts to unwind going forward, this process may accelerate, helping to boost productivity and placing downward pressure on unit labor costs and inflation. However, it is unclear how large such effects will be.
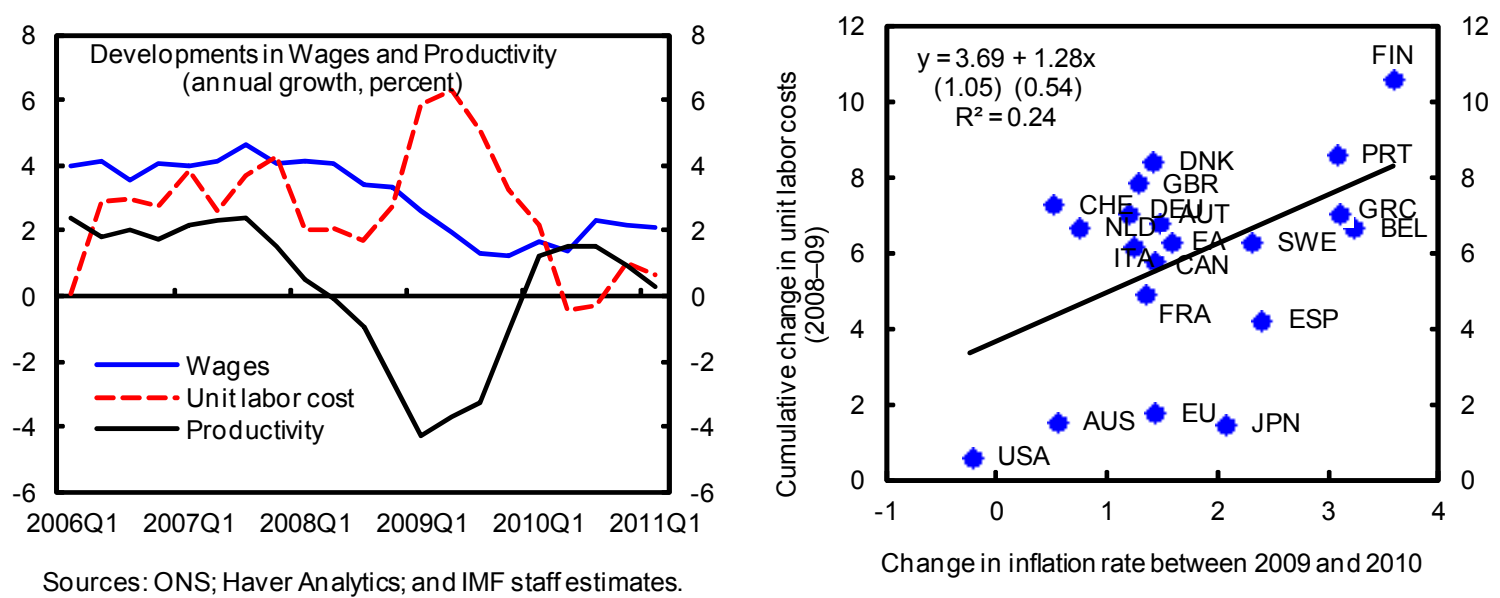

- Another major contributor to inflation during 2009-10 was the delayed pass-through from the large exchange rate depreciation in 2008. However, its contribution is estimated to have tapered off by end- 2010 .

\section{Inflation is likely to approach 5 percent during 2011, but then return near the}

2 percent target around end-2012. Inflation is likely to continue rising in the short run as the impulse from past commodity price increases continues to play out. Disinflation should then occur as the transitory factors noted above dissipate and as significant spare capacity keeps underlying inflation in check. Leading indicators support this outlook:

- $\quad$ growth rates of credit, broad money, and unit labor costs are all low;

- $\quad$ there is little evidence of brewing asset price bubbles (house prices are slightly falling);

- medium-term inflation expectations remain at pre-crisis levels - when the inflation target was consistently met - and thus are consistent with meeting the target ${ }^{9}$ and

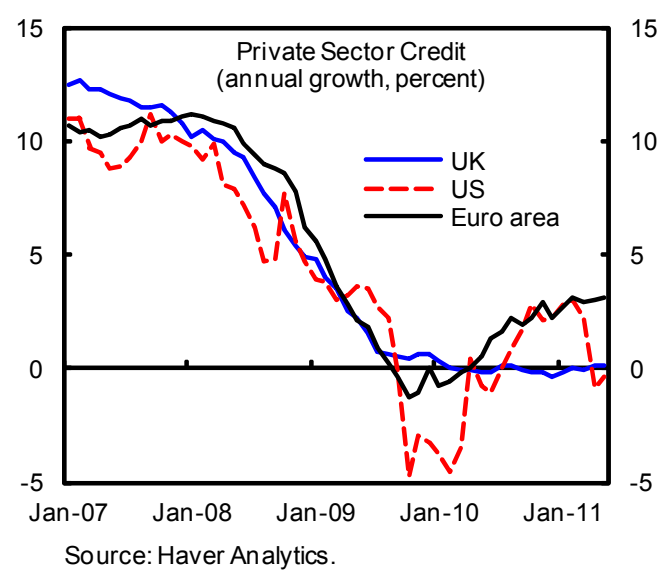

\footnotetext{
${ }^{9}$ For RPI inflation expectations in the chart on the next page, note that RPI inflation typically runs about one percentage point above CPI inflation.
} 

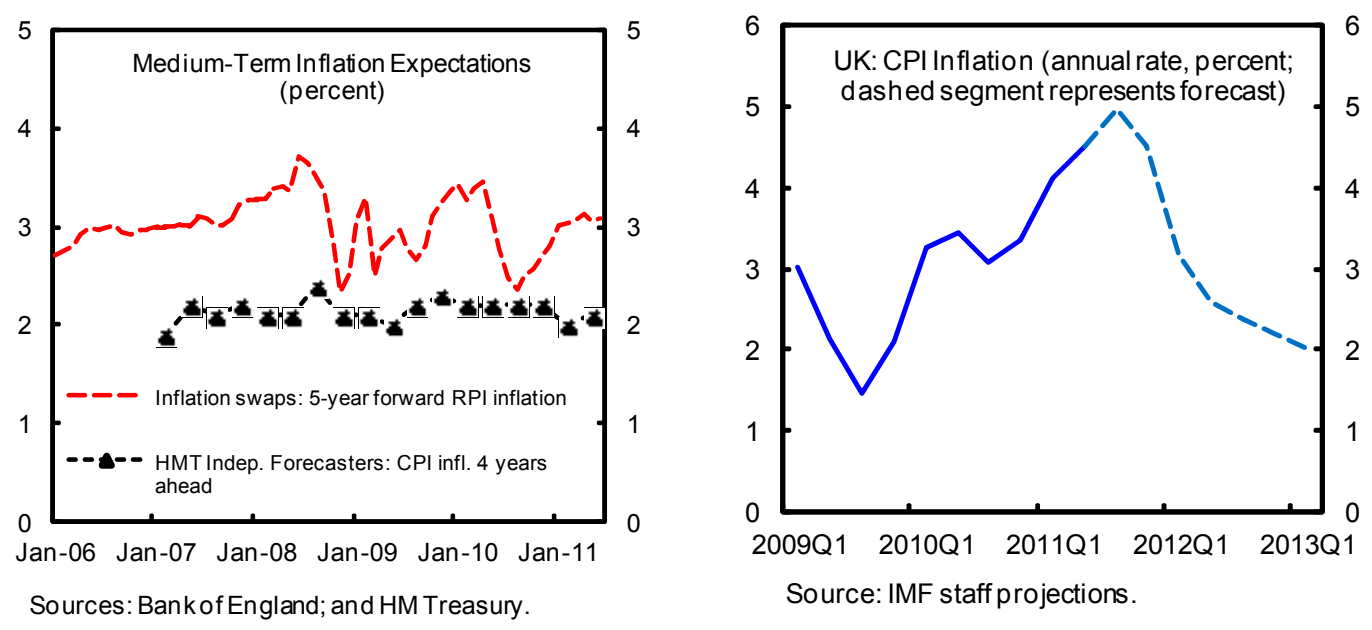

- $\quad$ as detailed in the companion Selected Issues paper, econometric times-series models that have the best out-of-sample predictive power project inflation to return near the target around end-2012.

\section{Risks}

22. Risks around the central scenario are significant. The recent large divergence between GDP growth and other indicators creates substantial uncertainty about the near-term direction of the economy. In addition, there are a number of risks that, if they materialize, could be difficult to offset and thus result in a rapid change in the macroeconomic outlook and policy environment. Key risks include the following:

Euro-area sovereign risks: The UK has notable links to euro-area countries:

- $\quad$ the banking system's exposure to Greece, Ireland, and Portugal is $\$ 178$ billion (25 percent of UK bank capital at end-Q1 2011; Figure 12), with the bulk of this exposure being to Ireland ( $\$ 135$ billion);

- $\quad$ Ireland alone accounts for 7 percent of UK exports; and

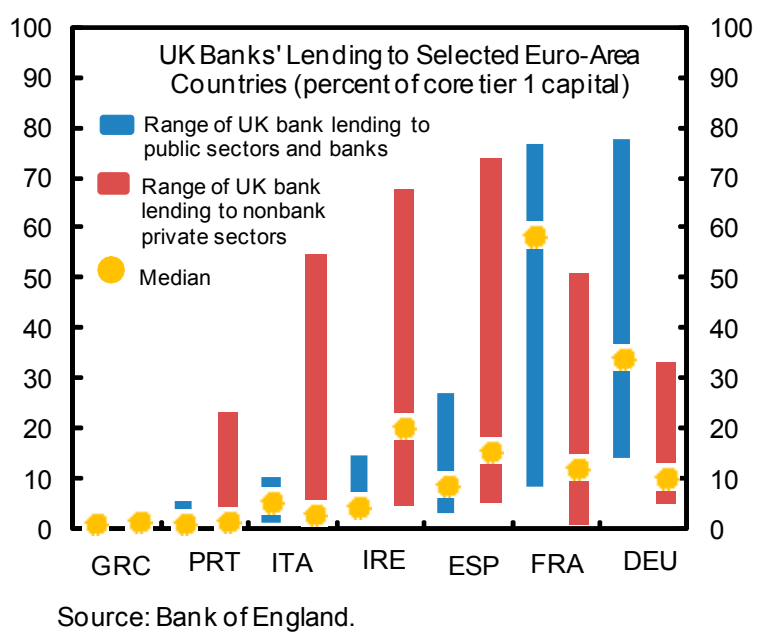

- $\quad$ the UK has further large trade and financial links to countries, such as France and Germany, that could be significantly affected by turmoil in the euro-area periphery.

As noted earlier, UK banks' direct exposures to vulnerable euro-area sovereigns appear manageable in isolation. However, effects on the UK economy would be magnified if heightened turmoil in the euro-area periphery leads to stresses in core European banks or 
Figure 12. External Claims of Consolidated UK-Owned MFIs $1 /$

(Billions of USD, unless indicated otherwise)
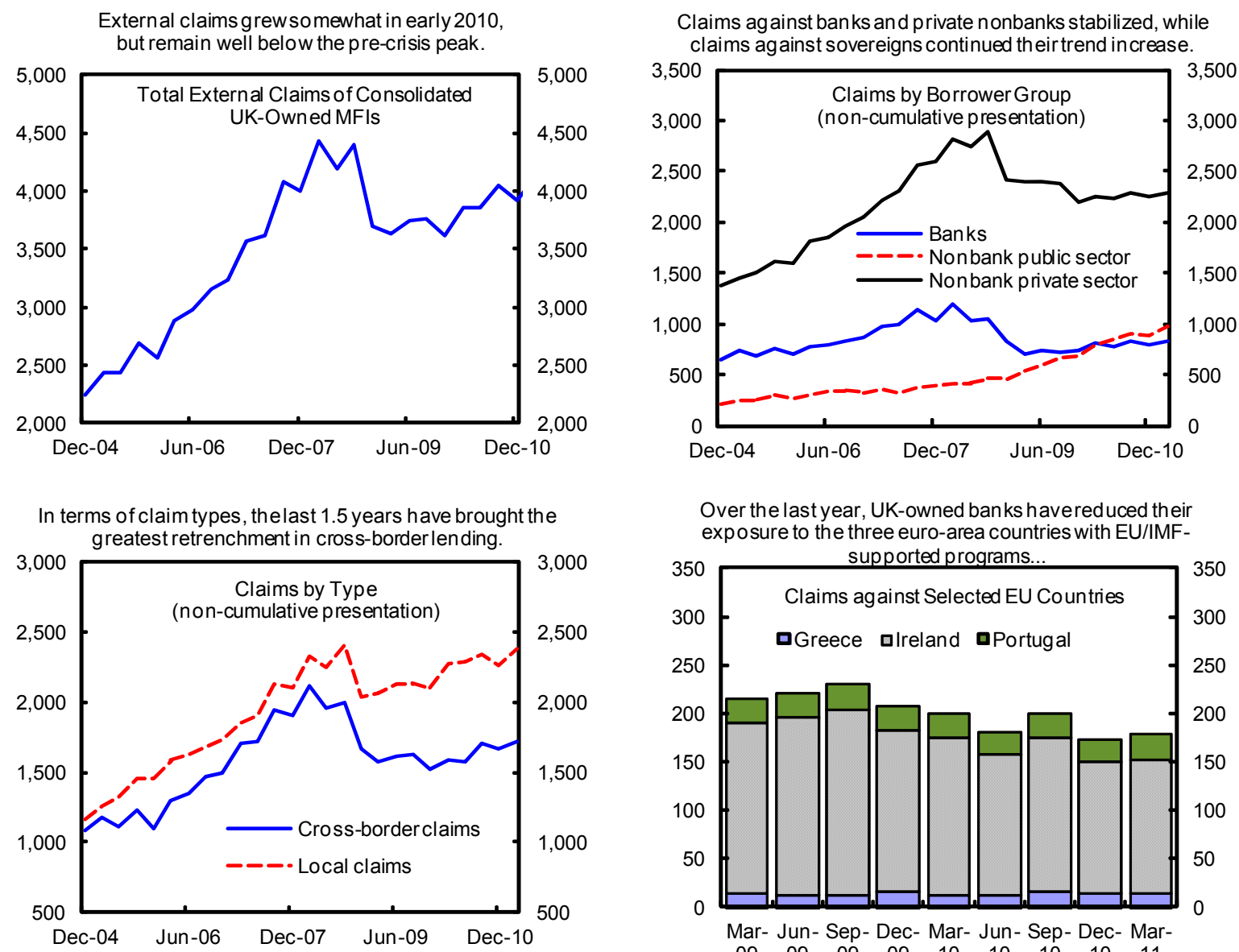

Over the last year, UK-owned banks havereduced their exposure to the three euro-area countries with EU/IMF-

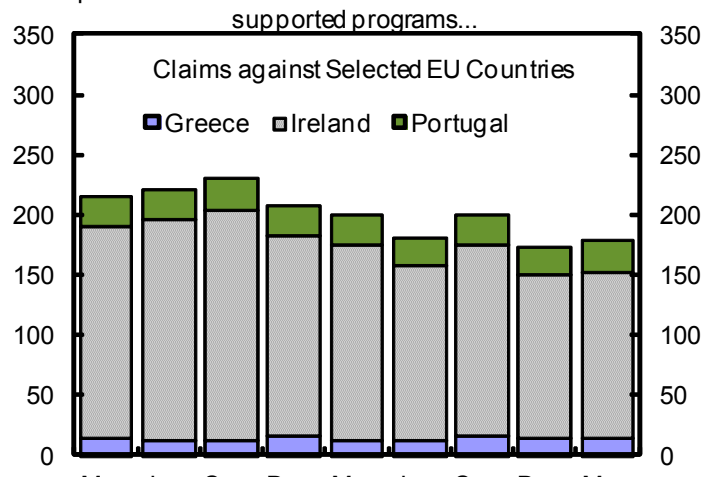

Mar- Jun- Sep- Dec- Mar- Jun- Sep- Dec- Mar$\begin{array}{lllllllll}09 & 09 & 09 & 09 & 10 & 10 & 10 & 10 & 11\end{array}$

...both in absolute amounts and relative to the overall external portfolio.

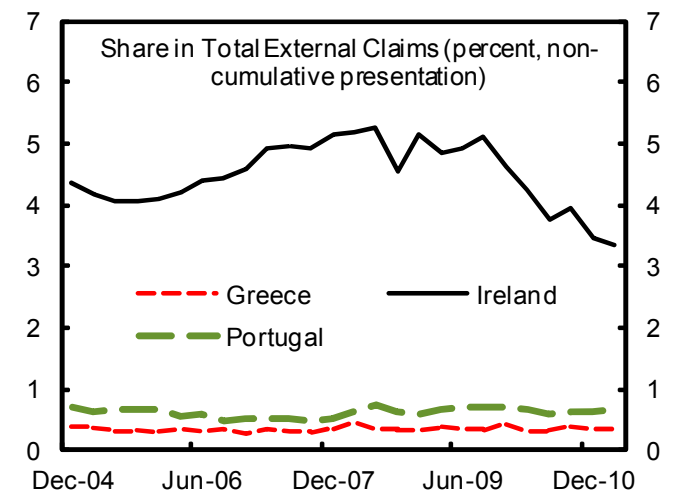

However, the US remains the most important borrower country.

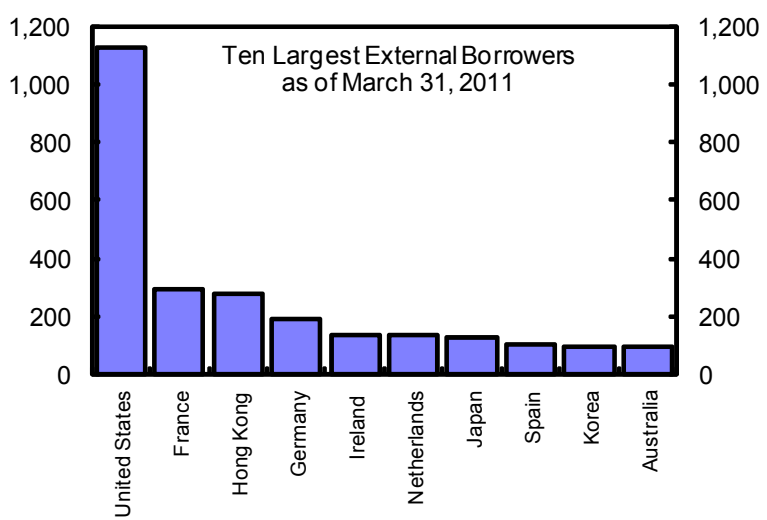

Source: Bank of England.

1/Ultimate risk basis. 
combines with disruptions in wholesale funding markets. Such a combination of forces could set off an adverse and self-reinforcing cycle of higher bank losses and funding costs, tighter credit, lower consumer confidence and exports, and falling real estate prices, resulting in a substantial contractionary shock. However, the UK may also benefit from other effects such as lower commodity prices. On balance, it is unclear how large the net spillover would be. Mitigating policies such as liquidity and capital support facilities may also reduce its impact.

Uncertain fiscal headwinds and commodity prices: Although fiscal consolidation headwinds are estimated using standard multipliers, their magnitude is uncertain. Similarly, volatile commodity import prices pose risks to both growth and inflation. Indeed, unexpected spikes in commodity prices have been a significant factor behind revisions to staff's 2011 inflation and growth forecasts since the 2010 Article IV consultation.

House prices: Another key risk is that house prices may differ from central scenario assumptions, with large effects on residential investment and consumption (via wealth effects). These risks exist in both directions and reflect uncertainty regarding both the path of real interest rates and the degree to which price rises over the last decade reflect structural versus cyclical factors.

Inflation surprises: Continued upside inflation surprises could eventually force rapid monetary tightening to re-anchor inflation expectations, with associated adverse effects on household and corporate balance sheets, consumption, and investment. A key factor behind such inflation risks is the significant uncertainty over the size of the output gap (Box 2). Adverse demand shocks (from risks noted above) could also produce downside inflation surprises, raising short-term real rates and again tightening monetary conditions, unless further asset purchases (quantitative easing) are able to provide an offset.

\section{Authorities' views}

\section{The authorities broadly share the} outlook for the central scenario, though they project slightly higher growth. Both the independent $\mathrm{OBR}$ —on whose forecasts the budget is based - and the Bank of England (BoE) project a pattern of rebalancing away from public and private consumption and toward investment and net exports that is broadly similar to staff's central scenario. However, they

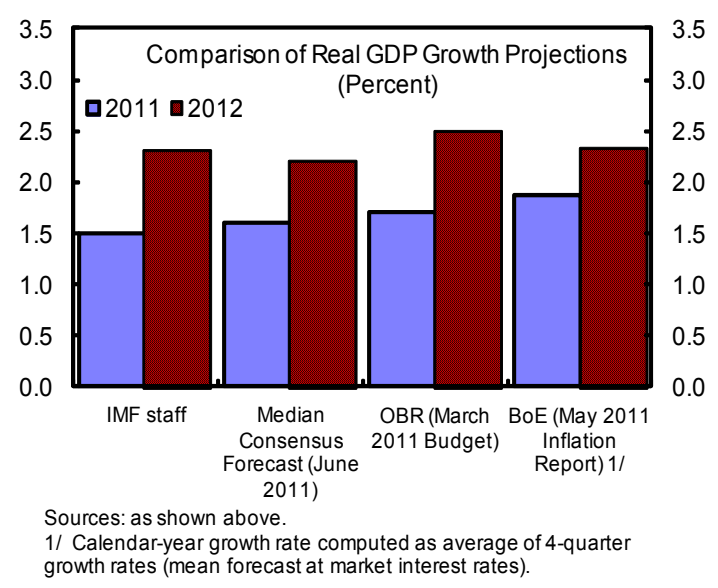
project slightly higher growth rates both in 2011 and 2012, reflecting both a higher estimated output gap now and higher projected potential growth. The BoE's latest inflation projections are broadly similar to those of staff. The authorities see similar risks to the central scenario and put particular emphasis on elevated sovereign and banking risks in parts of the euro area. 


\section{Macroeconomic Policies in the Central Scenario}

\section{A. The Policy Mix}

\section{The multiple challenges of restoring full employment, returning inflation to} target, and repairing public and private balance sheets requires close attention to the policy mix. The overall tightness of macroeconomic policy should be calibrated to balance upside risks to inflation against downside risks to growth. Although both risks are currently substantial, they are broadly offsetting, implying that the overall tightness of policy remains appropriate for now. Within this overall degree of tightness, there is the question of the appropriate mix between monetary and fiscal policy. On this, the case for relatively tight fiscal and relatively loose monetary policy is strong: in addition to restoring fiscal sustainability, such a mix will help keep real interest rates low and sterling competitive. This economic environment will further assist public and private balance sheet repair while promoting expansion of investment and net exports. This is necessary if robust output and employment growth are to be achieved at the same time that private and public consumption are eased to more sustainable levels.

\section{B. The Monetary Policy Decision}

25. The current monetary stance remains appropriate for now. The BoE has maintained a Bank Rate of 0.5 percent and bond purchases of $£ 200$ billion since early 2010 . This highly accommodative stance is appropriate given the central scenario projection that inflation will return to target within a reasonable timeframe, the uncertainty regarding the strength of recovery, and the need to offset significant disinflationary impulses from fiscal policy.

26. If growth resumes as expected in the coming quarters, the case for beginning to withdraw some monetary stimulus will slowly increase. Markets are currently pricing in at least a 50 percent probability of a first rate hike by February 2012 and a second rate hike by August 2012. In the central scenario, the pace at which monetary stimulus is withdrawnwhich could occur through a combination of policy rate hikes and asset sales - should indeed be gradual given the extended period of fiscal contraction and the potentially large effects of higher interest rates on growth, which if too weak could yield persistent inflation undershoots in the medium term. In particular, growth remains vulnerable to a steep drop in house prices (as discussed earlier), which in turn are highly sensitive to short-term interest ratesvariable-rate mortgages account for 70 percent of the market. With household debt levels still elevated by historical standards (see companion Selected Issues paper), rapid interest rate hikes could also cut directly into households' disposable income (and therefore consumption), though this effect would be partially mitigated by households' higher interest income. 


\section{The medium-term "neutral rate" consistent with stable inflation and full} employment may be somewhat lower than before the crisis. Supporting this view are the following factors:

- $\quad$ As described in Section II.A, the central scenario relies on substantial rebalancing toward private and external demand. It is not clear that the required rebalancing will occur in the absence of strong price signals. In particular, an extended period of low real interest rates may be necessary to prompt sufficiently high private consumption, private investment, and net exports.

- $\quad$ Empirically, expected short-term real

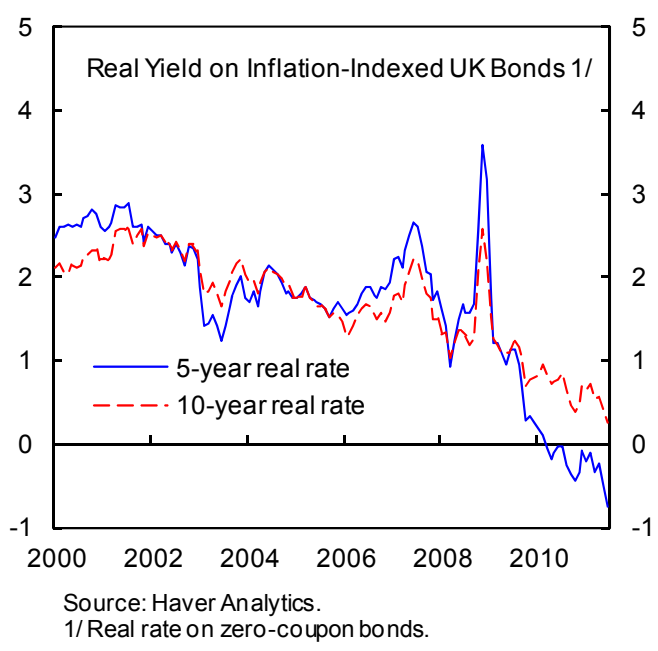
rates - as embedded in medium-term real rates on inflation-indexed bonds - have fallen significantly relative to pre-crisis levels.

- $\quad$ Theoretically, it is likely that the financial crisis has sharply shifted down the demand for investment and consumption at any given interest rate, reducing the equilibrium interest rate consistent with full employment.

This view further supports a gradual tightening, given the more limited amount of total adjustment required by the tightening cycle.

28. Nonetheless, leading indicators should be monitored closely. Monetary tightening will need to accelerate if leading inflation indicators - especially unit labor costs and inflation expectations - turn more worrisome.

\section{Authorities' views}

\section{The authorities broadly agree with staff's assessment regarding the stance of} monetary policy in the central scenario. The Monetary Policy Committee (MPC) has so far judged that monetary policy needs to remain accommodative in order to meet the inflation target in the medium term. But there are differences in view on the Committee on the precise setting necessary to achieve this. The majority of MPC members view the current policy stance as appropriate given the temporary nature of recent inflation outturns, subdued wage growth, and contained inflation expectations. The minority of members favouring a slightly less accommodative policy place more weight on the risks that an extended period of high headline inflation could in future feed into higher inflation expectations and that external price pressures may continue to raise domestic inflation. A third view is that inflation expectations remain well anchored and deflationary pressures will dominate in the medium term, so that further asset purchases are required. 


\section{Fiscal Consolidation Plans}

\section{The March 2011 budget maintains the government's ambitious medium-term}

fiscal consolidation plan (Figure 13). ${ }^{10}$ In June 2010, the new government set itself a "fiscal mandate" to

(i) balance the cyclically adjusted current budget by the end of a rolling five-year forecast period and

(ii) put the public sector net debt-to-GDP ratio on a downward path in FY15/16.

The June 2010 budget aimed to meet these targets one year early through structural adjustment of 8 percent of GDP over 5 years. The March 2011 budget makes only minor adjustments to this consolidation path.

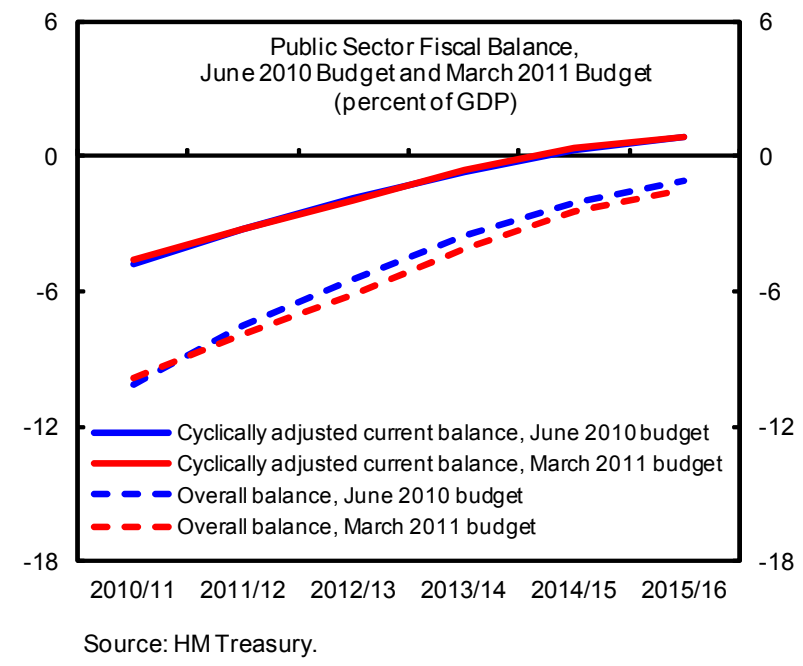

Public Sector Finances (percent of GDP) $1 /$

\begin{tabular}{|c|c|c|c|c|c|c|c|}
\hline & $2009 / 10$ & $2010 / 11$ & $2011 / 12$ & $2012 / 13$ & $2013 / 14$ & $2014 / 15$ & $2015 / 16$ \\
\hline & $\underline{\text { Actual }}$ & Prel. & \multicolumn{5}{|c|}{2011 Budget } \\
\hline Overall balance & -11.1 & -9.7 & -7.9 & -6.2 & -4.1 & -2.5 & -1.5 \\
\hline Cyclically adjusted overall balance & -8.8 & -7.2 & -5.3 & -3.7 & -2.0 & -1.0 & -0.5 \\
\hline Current balance & -7.6 & -7.0 & -5.8 & -4.5 & -2.7 & -1.2 & -0.3 \\
\hline Cyclically adjusted current balance & -5.3 & -4.5 & -3.2 & -2.0 & -0.6 & 0.3 & 0.8 \\
\hline General government gross debt 2/ & 71.5 & 76.8 & 84.1 & 87.0 & 87.2 & 85.7 & 83.5 \\
\hline Public sector net debt & 52.8 & 59.8 & 66.1 & 69.7 & 70.9 & 70.5 & 69.1 \\
\hline Real GDP growth & -3.6 & 1.8 & 1.8 & 2.7 & 2.9 & 2.9 & 2.9 \\
\hline \multirow[t]{2}{*}{ Output gap } & -4.2 & -3.4 & -3.9 & -3.5 & -2.8 & -2.0 & -1.3 \\
\hline & & \multicolumn{6}{|c|}{ Staff projections } \\
\hline Overall balance & -11.1 & -9.7 & -8.0 & -6.4 & -4.3 & -2.9 & -1.8 \\
\hline Cyclically adjusted overall balance & -9.1 & -7.7 & -6.2 & -4.7 & -2.9 & -1.8 & -1.1 \\
\hline Current balance & -7.6 & -7.0 & -6.0 & -4.7 & -2.9 & -1.6 & -0.5 \\
\hline Cyclically adjusted current balance & -5.6 & -5.0 & -4.2 & -3.0 & -1.5 & -0.5 & 0.1 \\
\hline General government gross debt & 71.5 & 76.8 & 81.5 & 84.2 & 84.6 & 83.2 & 80.7 \\
\hline Public sector net debt & 52.8 & 59.8 & 65.7 & 69.3 & 70.2 & 69.7 & 68.0 \\
\hline Real GDP growth & -3.6 & 1.8 & 1.7 & 2.3 & 2.4 & 2.5 & 2.7 \\
\hline Output gap & -3.8 & -2.5 & -2.6 & -2.3 & -1.9 & -1.4 & -0.8 \\
\hline
\end{tabular}

Sources: Office for National Statistics; OBR; and IMF staff estimates.

$1 /$ Fiscal year starts on April 6.

2/ From 2011/12 onwards, budget projections for general government gross debt are on a Maastricht basis.

${ }^{10}$ The fiscal year starts on April 6. 
Figure 13. Fiscal Developments 1/
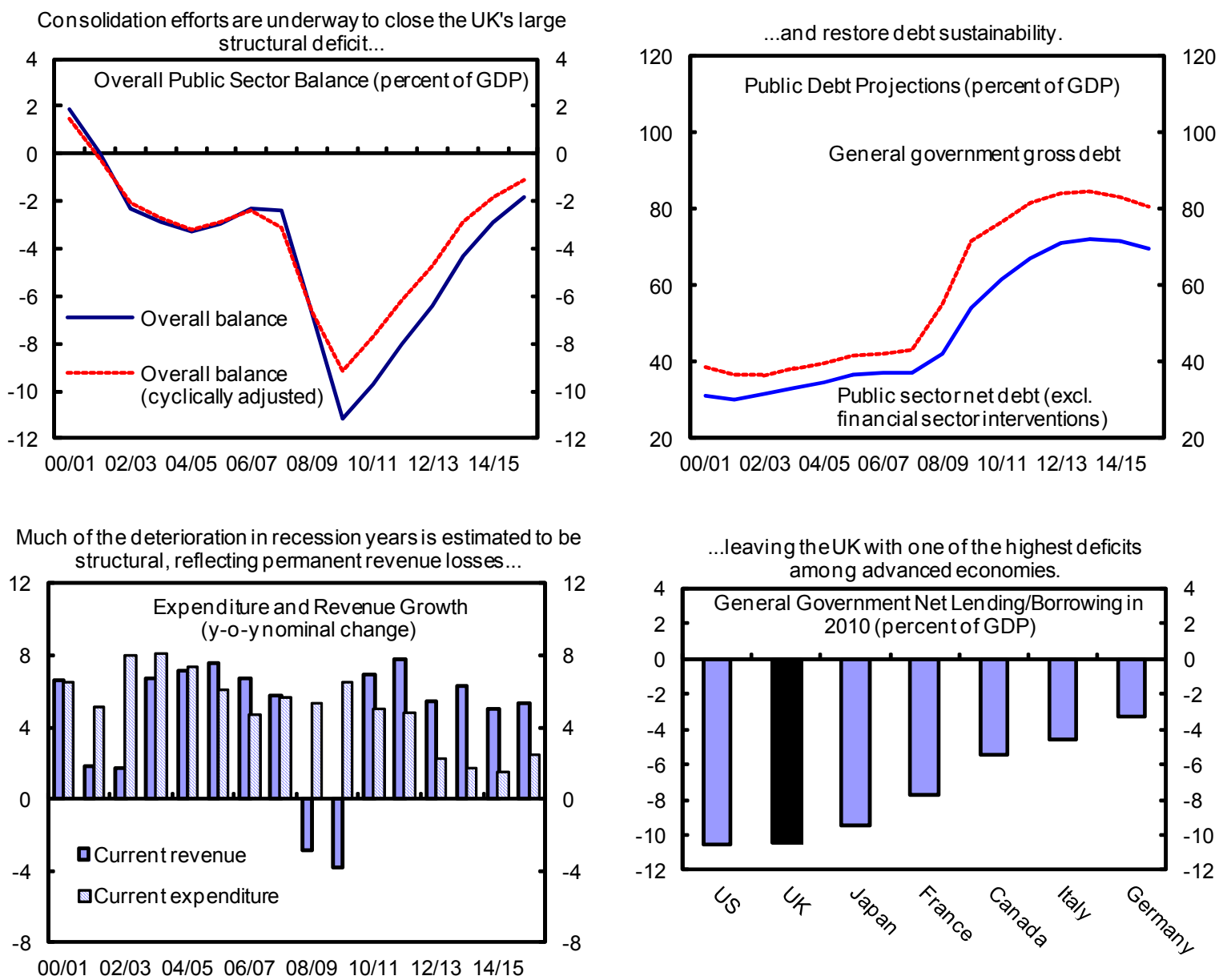

UK sovereign debt has a favorable structure, featuring a longer average maturity than in any comparator

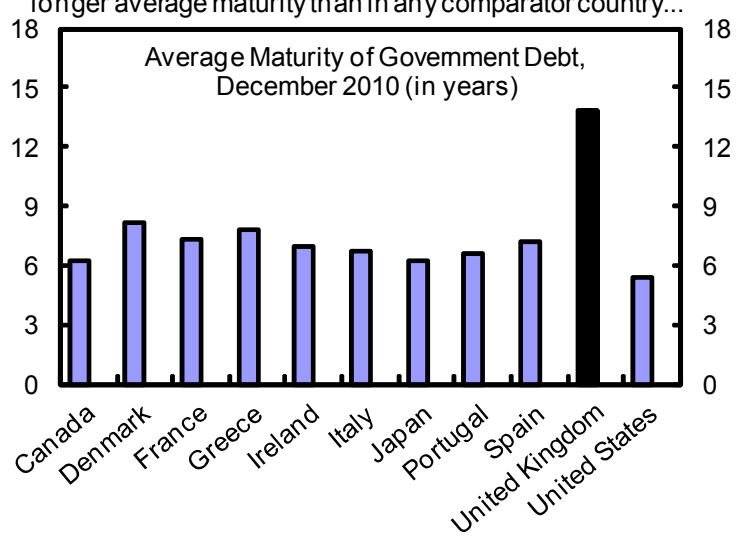

....and the yield on UK sovereign debt remains below that at the onset of of the euro-area sovereign debtcrisis.

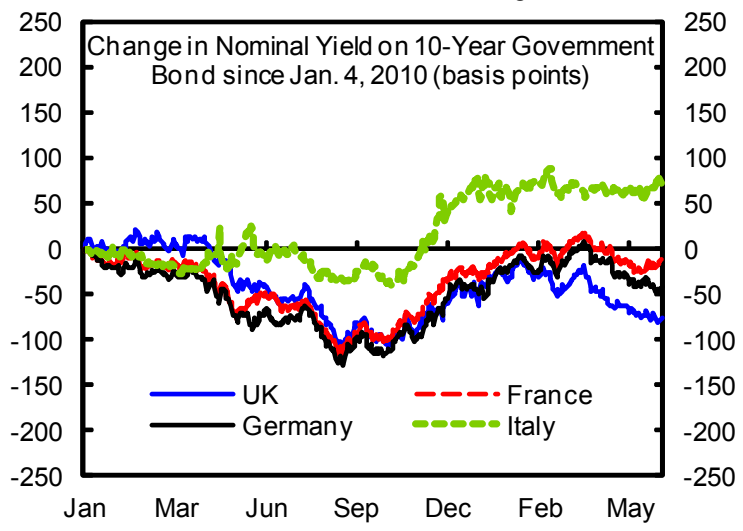

Sources: HMT; DMO; Haver Analytics; WEO; and IMF staff estimates and projections.

$1 /$ The first three charts include IMF staff projections based on IMF staff's central scenario. 


\section{The pace of tightening is expected to ease slightly in FY11/12, but remain}

significant. Preliminary outturns suggest that the fiscal impulse, as measured by the change in the cyclically adjusted primary deficit as a percent of potential GDP, was -2.1 percent in FY10/11. Under the budget's spending plans and staff's macroeconomic forecasts, this fiscal impulse is expected to ease to about -1.8 percent of potential GDP in FY11/12. However, with consolidation just starting in 2010 and with lags in the transmission to economic activity, this implies that fiscal headwinds to growth will remain significant in 2011.

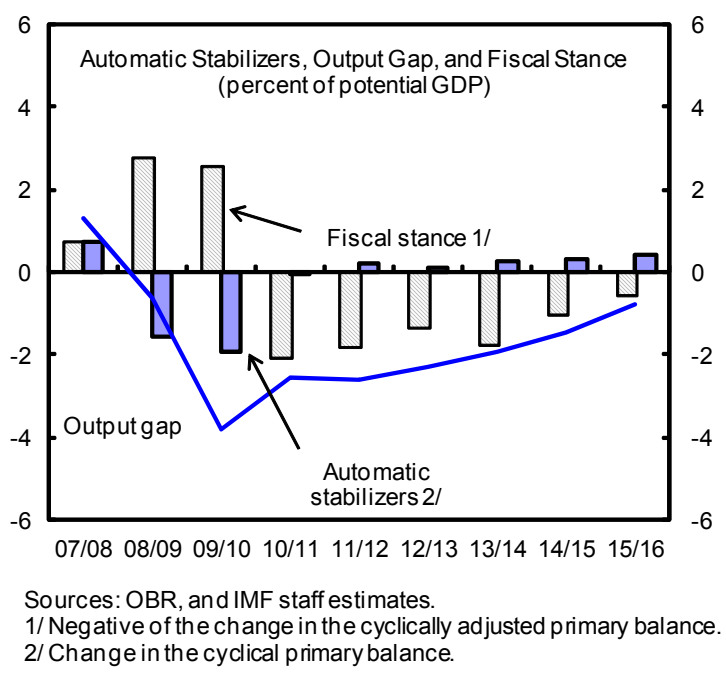

32. The path of fiscal consolidation is appropriate in the central scenario, but is not without risks. Fiscal consolidation is essential to stabilize debt and thereby avoid possible abrupt adjustment later forced by market pressure. As discussed in Section IV.A, fiscal consolidation is also integral to the broader macroeconomic strategy of post-crisis repair. Nonetheless, consolidation plans face the risk that private domestic demand and net exports may not be vibrant enough to pick up the slack from public sector deleveraging. If such risks materialize, macroeconomic policies may need to adjust (Section V).

33. The medium-term consolidation plan is mainly expenditure-based. Spending cuts are spread fairly evenly across the 5-year horizon due to the difficulty of cutting spending quickly. In contrast, the main tax measures - including the January 2011 VAT hike, higher capital gains taxes, and a new bank levy on wholesale liabilities - have already come into force to achieve frontloaded consolidation. The cumulative share of consolidation on the spending side thus rises gradually from 53 percent in FY11/12 to 76 percent by FY15/16. Spending cuts include a 2-year wage freeze, means-testing of many benefits, and a 29 percent real cut in capital spending. Some of the largest spending cuts are in public safety and transfers to local governments. At the other end of the spectrum, healthcare spending is kept broadly constant in real terms, and foreign aid will

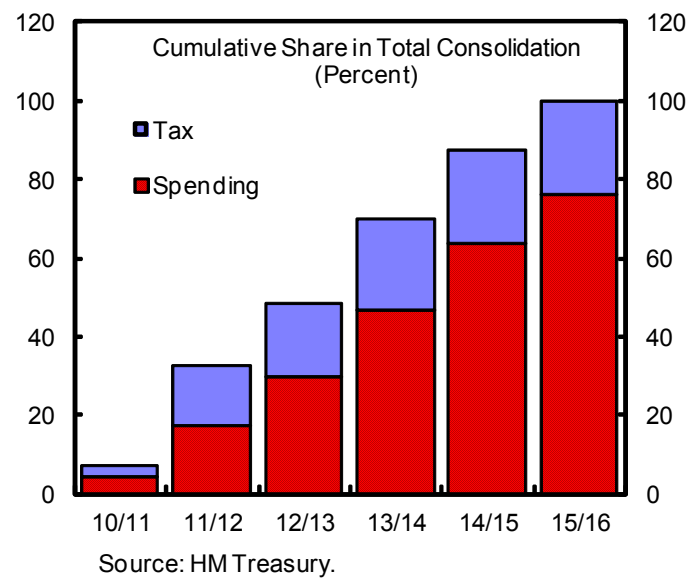
receive a real increase of 30 percent. The overall focus on expenditure reduction appears appropriate, as cyclically adjusted spending rose by 9 percent of GDP over the last decade. 
International evidence also suggests that expenditure-based consolidations are associated with longer-lasting budgetary improvements. ${ }^{11}$

34. Despite flexibility built into the consolidation plans, there are risks to achieving the mandate. The plan to meet the fiscal mandate one year early provides a buffer against implementation risks and forecast errors. The OBR's judgment is that there is a 70 percent probability that the cyclically adjusted current budget will be in balance in five years' time. Nonetheless, risks remain even with this built-in flexibility. One important risk relates to the size of the output gap: the March 2011 budget assumes that the output gap is currently -4 percent and will still be -1.3 percent in FY15/16, helping to bolster the cyclically adjusted balance. In contrast, staff estimates both a lower output gap now (around $-23 / 4$ percent) and a slower potential growth rate such that the output gap nearly closes by FY15/16. In this case, the cyclically adjusted current budget will just reach balance in FY15/16. The consolidation plan thus provides little margin for error under staff's central scenario.

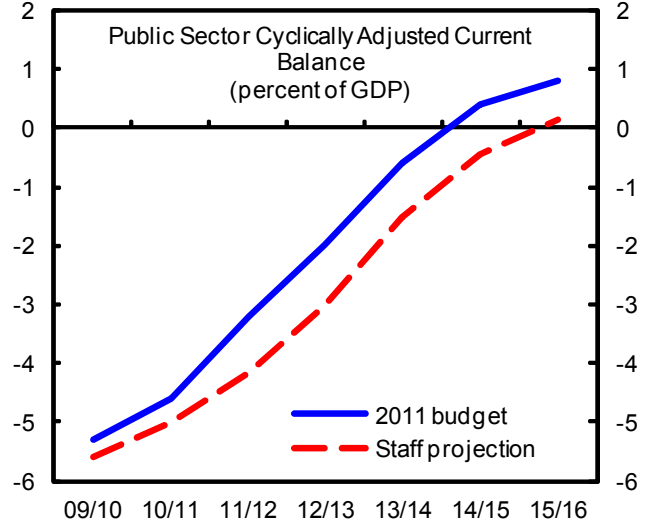

Sources: HM Treasury and IMF staff projections. Furthermore, consolidation has so far relied heavily on tax hikes and the phase-out of stimulus. As consolidation becomes more reliant on structural spending cuts going forward, implementation challenges may rise. Meeting these challenges will require careful management to ensure delivery of the targeted consolidation while shielding the poor. The detailed multi-year spending plans laid out in the October 2010 Spending Review should assist in this regard.

\section{Building on progress already made, further structural reforms could help} address remaining longer-term fiscal imbalances and support medium-term growth. Important planned or potential reforms include the following:

- Accelerating increases in the state pension age and indexing it to longevity. The retirement age for state pensions (the universal scheme for both private and public employees) is now 60 for women and 65 for men. The government has already proposed legislation to equalize the pension age at 65 by 2018 (instead of by 2020 as under current law) and to raise the pension age to 66 by 2020 (instead of 2028 as under current law). However, the currently legislated hikes to age 67 (by 2036) and to age 68 (by 2046) could also be accelerated, with indexation to longevity thereafter. This would reduce longer-term fiscal imbalances due to ageing and could boost medium-to-long-run growth by encouraging longer working lives.

\footnotetext{
${ }^{11}$ See, for example, staff's 2010 Selected Issues paper on the UK.
} 
- $\quad$ Reforming public-service pensions. Studies suggest that the two-year wage freeze will close part of the gap between average public-service wages and private-sector wages for comparable employees. However, public-service pensions remain significantly more generous than those in the private sector. A government-appointed commission (the Independent Public Service Pensions Commission) thus recently recommended a number of reforms to improve the structure of public-service pensions and reduce their cost. Any near-term savings from such reforms (beyond those already budgeted) could fund growth and employment-enhancing measures (e.g., fewer cuts in infrastructure spending), thereby making adjustment more "growth friendly."

- $\quad$ Easing tight planning restrictions. As a supplement to the 2011 budget, the government released The Plan for Growth - a number of measures aimed at boosting potential output. Many of the individual measures are modest in scale, but one area that could have important effects are measures to ease the UK's tight planning restrictions, which hinder new real estate developments. If successful, these measures - which include, for example, a 12-month guarantee for processing planning applications - could provide a fillip to construction and spur productivityenhancing investment. ${ }^{12}$ However, it remains to be seen if the various initiatives will succeed in substantially easing restrictions, which are to a significant degree controlled by local governments.

36. Institutional reforms adopted by the government should assist these objectives. In particular, the government recently passed legislation to put the independent OBR on a permanent footing. This new institution should help strengthen the credibility of fiscal analysis and forecasts, including with the publication of its first fiscal sustainability report (focusing on longer-run fiscal challenges) in July 2011.

\section{Authorities' views}

\section{The authorities stressed that strong fiscal consolidation remains the linchpin of} their economic strategy and were confident about its success. The Government is fully committed to implementing the plans set out in the budget and the spending review. They noted that consolidation plans had provided stimulus by allowing monetary policy to remain loose, by keeping UK sovereign borrowing costs low, and by supporting business confidence. They welcomed staff's support for structural reforms to ease planning restrictions and reform public-service pensions, and they saw merit in making further reforms

\footnotetext{
${ }^{12}$ Note that a boost to real estate supply from looser planning restrictions is likely positive or neutral for shortrun growth, whereas as an adverse shock to real estate demand from higher interest rates is likely negative for growth, even though both shocks may result in lower house prices.
} 
to the state pension age. However, they did not consider it advisable to revisit the composition of expenditure plans, which they believe have allowed key public services and growth-enabling public spending to be protected while increasing fairness and opportunities for social mobility. On fiscal institutions, they viewed the creation of the OBR as a major advance in addressing deficiencies in the previous institutional framework, improving the credibility and independence of economic and fiscal forecasts.

\section{Macroeconomic Policies in Risk Scenarios}

38. Policies will need to react if major risks materialize or appear imminent. On the fiscal side, automatic stabilizers should operate freely, as allowed by the fiscal mandate. Additional policy responses will depend on the nature of the shock. For example:

- If growth and inflationary pressures are stronger than expected, monetary tightening will need to accelerate. Any revenue windfalls should be saved in this case, even if larger than implied by automatic stabilizers.

- If the economy appears likely to experience a prolonged period of weak growth and high unemployment - and if inflationary pressures consequently ease - it will be important to ensure that the slowdown does not become entrenched due to capital scrapping and cyclical unemployment becoming structural. If this appears to be in prospect, then some combination of the following would need to be considered: (i) supplementing the current low monetary policy rate with expanded asset purchases by the BoE and (ii) temporary tax cuts. Tax cuts have the advantage of being faster to implement and more credibly temporary than expenditure shifts. To increase their multipliers, tax cuts should be targeted to low-income households, investment (e.g., temporary investment tax credits, which would also facilitate rebalancing toward investment), or job creation (e.g., temporary cuts in employer payroll taxes to reduce employment costs). Temporary fiscal stimulus should be accompanied by deeper long-run entitlement reform (as discussed in Section IV.C) to safeguard fiscal sustainability and market confidence.

- In the event of both persistent weak growth and high inflation, the appropriate response depends on the source of this condition: if it is due to further commodity price volatility, policies need not respond unless there is clear evidence of secondround effects (e.g., higher import prices feeding into higher wage growth). In the more difficult case in which weak growth and high inflation result from a much narrower-than-estimated output gap (which would be indicated by rapid growth of unit labor costs), policies will have little choice but to tighten to re-anchor inflationary expectations. A narrower output gap would also imply a higher-thancurrently-estimated structural deficit and therefore would require further fiscal tightening over the medium term. 


\section{Authorities' views}

39. The authorities agreed with the relevance of the risk scenarios outlined by staff and are being watchful, though they noted that the economy was still some distance from these scenarios. They stressed that the overriding priority was to successfully implement the fiscal consolidation plans, as ensuring confidence in debt sustainability is a prerequisite for recovery in any scenario. In this regard, any significant adjustments to the expenditure plans would be unhelpful, as they would cast doubt on the credibility of the overall plan. The effectiveness of any spending stimulus would also be hampered by implementation lags. Monetary policy would be the first port of call, as it is better placed to fine-tune macroeconomic conditions. They noted that in some scenarios fiscal stimulus could also be counterproductive to growth if heightened sovereign risk concerns increase the sensitivity of borrowing costs to fiscal deficits. Moreover, the authorities highlighted that their consolidation plans already build in flexibility, including through setting plans to the meet the mandate one year early, with headroom against the mandate in 2015-16, and by specifying the target in cyclically adjusted terms. Consistent with this, they agreed that automatic stabilizers provide an important safeguard against risks.

\section{Financial Sector Policies}

\section{A. Achievements, Challenges, and Spillovers}

\section{The UK financial sector is on the} mend, but strong domestic measures and international coordination are needed to further bolster financial stability. Prospects for orderly rebalancing toward private sectorled growth will depend in part on continued financial sector healing. It is therefore encouraging that banks have strengthened their capital and liquidity positions over the last year. However, the recovery process is not yet complete and vulnerabilities remain in

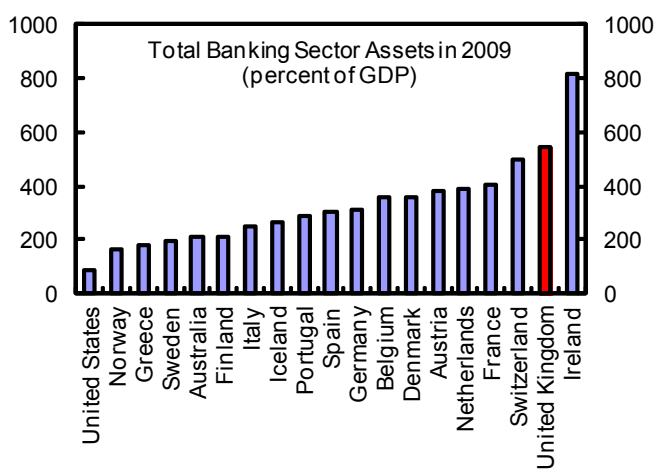

Sources: Central Bank of Iceland; European Banking Federation; Federal Reserve Board; Haver Analytics; and Reserve Bank of Australia. regard to funding and asset quality, as detailed in the accompanying FSSA. The authorities are thus taking wide-ranging reforms to strengthen regulatory and supervisory oversight, including in the context of the international reform agenda under Basel III. Further reforms are needed, as discussed in detail in the FSSA and summarized in Box 3. Indeed, the UK's large financial sector relative to the economy and the resulting fiscal and macro-stability risks put a premium on ambitious financial sector reform. Furthermore, given the size, complexity, and interconnectedness of the UK financial system, shocks have the potential to be widely amplified across the global economy, as seen during the crisis and as highlighted in the accompanying Spillover Report. Ensuring the stability of the UK financial system is therefore critical to promoting global financial stability. 


\section{Box 3. FSSA: Main Recommendations}

This box summarizes the recommendations of the FSSA update. These recommendations aim to enhance the robustness of financial sector oversight. The authorities recognize the importance of these issues and are carefully considering how to take these recommendations forward.

\section{Overall financial sector oversight}

- Revise the legal framework to clarify mandates and include a specific financial stability mandate for the prudential authorities.

- Amend legislation to allow for regulatory power over holding companies of regulated entities.

- Enhance resources for supervision of banks, insurers, and securities firms based on the agreed-upon supervisory operating model and the new macroprudential overlay.

- Establish a forum for ensuring good governance and coordination among organizations in the new regulatory structure.

- Enforce public disclosure by banks, insurers, and securities firms, including prudential returns, as appropriate.

- Amend risk-based assessment methodologies to ensure adequate assessment of anti-money laundering and combating the financing of terrorism risk.

\section{Banking sector oversight}

- Enhance supervision by conducting detailed reviews of credit and market risk assessment by banks, conducting verification and selected model replication reviews on a proactive basis, better integrating specialist work into the supervision programs, and enhancing peer analysis.

- Adopt a proactive intervention framework through triggers for contacts and coordination actions with other authorities and amend legislation as needed.

- Develop a comprehensive plan to enhance prudential reporting and conduct a review to deliver a more systematic approach to data quality.

\section{Insurance sector oversight}

- Extend the new intrusive risk-based approach to supervision to a wider range of insurers.

- Increase the frequency and number of randomly conducted "transaction examinations."

\section{Securities markets oversight}

- Clarify in legislation that the remit of the conduct authority includes market integrity and transparency to ensure adequate emphasis on issues other than consumer protection.

- Increase intensity of supervision with greater use of "bottom-up" analysis of firm operations using on-site examinations to supplement the "top-down" risk analysis.

\section{Payments and securities systems oversight}

- Ensure that sufficient and reliable funding options are in place for central counterparties (CCPs), including committed credit lines subject only to presentment.

- Develop contingency plans to deal with a potential failure of a CCP.

- Offer central bank settlement to CCPs that have been classified as systemic institutions.

- Establish close monitoring of concentration of banks' payments and settlements activities.

- Undertake a unified assessment of the real time gross settlement (RTGS) infrastructure, including an assessment of the finality of transactions.

\section{Crisis management}

- Establish appropriate resolution tools and a framework for potentially systemically important nonbank firms that are not covered by the Special Resolution Regime. 


\section{B. Strengthening Financial System Soundness}

\section{Continued build up of capital and liquidity buffers is essential.}

- $\quad$ Currently, all major banks have core tier 1 ratios over 10 percent and must demonstrate ratios of at least 4 percent under stressed conditions. Given heightened risks, capital buffers should continue to be built up ahead of Basel III requirements, and approval of dividend and variable remuneration should continue to be linked to the outcome of stress tests.

- Similarly, the authorities implemented a new liquidity regime in 2010, ahead of the phase-in schedule agreed internationally. Liquidity requirements - currently more stringent than in other major jurisdictions - are appropriate given the specific vulnerabilities of the UK financial system but, given spillover effects, should be accompanied by home-host coordination to help address cross-border liquidity needs in times of stress.

42. The authorities have strengthened the supervisory framework; plans for further enhancements are welcome and should be a top priority. The crisis revealed serious weaknesses in supervision. Some of these shortcomings have since been addressed by the more proactive and intrusive approach to supervision adopted by the Financial Services Authority (FSA). Plans to further step up supervisory efforts are necessary and welcome, including ongoing work to:

- Strengthen the FSA's assessment of banks' processes, including loan classification, impairment determination, and valuation practices. Achieving this requires (i) more intensive on-site review work involving more specialist expertise and (ii) greater engagement of FSA senior management in the supervision of individual banks.

- Introduce a proactive intervention framework. It is important that framework legislation include explicit support for early intervention by the supervisor in dealing with prudential problems.

- $\quad$ Provide the regulatory authority with oversight powers at the holding company level. This will improve consolidated supervision.

- $\quad$ Enhance data reporting standards. The UK lags behind many other countries in standards for the public disclosure of bank and insurance sector data. Regular and comparable data on an institution basis should be published, including nonconfidential data from prudential returns. 


\section{Strengthening the Domestic Oversight Framework}

43. The transition to the new institutional framework for regulation and supervision needs to be managed carefully to mitigate operational risks. The UK plans to move to a "triple peak" model, with one organization under the BoE responsible for microprudential regulation and supervision - the Prudential Regulatory Authority—and a separate organization responsible for conduct of business and market regulation - the Financial Conduct Authority. The creation of a macroprudential overlay through a Financial Policy Committee (FPC) under the BoE is also in train. Implementing these new arrangements while at the same time stepping up supervision will require careful management. A clear division of responsibilities and close cooperation and information-sharing between all supervisory agencies and the government will be crucial to make the new arrangements work effectively.

44. The establishment of the FPC is an important step in developing mechanisms to mitigate systemic risk. Before the crisis, insufficient attention was given to the analysis and monitoring of system-wide rather than firm-specific risks. The FPC will fill this gap. An interim FPC was created in February 2011 to carry out preparatory work, including analysis of potential macroprudential tools, in advance of the creation of the permanent FPC by end2012. For the FPC to be credible, it will be important to set realistic expectations of what macroprudential regulation can achieve, especially in its early stages of implementation.

\section{The design of an effective macroprudential toolkit and the development of an} operational framework may prove challenging, as no best practices have yet emerged. A range of macroprudential tools should be considered given uncertainties regarding their effects and the nature of future risks. The choice of instruments at the FPC's disposal should be guided by the degree to which they (i) are effective in mitigating the amplitude of economic cycles and creating buffers to be used in periods of stress; (ii) minimize scope for regulatory arbitrage and cross-border spillovers; and (iii) minimize efficiency costs. A partial list of tools that may fit these criteria include countercyclical variation of the following instruments: the countercyclical capital buffer under Basel III, capital risk weights on banks' exposures to specific asset classes, liquidity requirements, limits on loan-to-value and debtto-income ratios, and the bank levy on wholesale funding. Application of jurisdictional reciprocity would make many of these tools more effective by reducing arbitrage possibilities.

\section{Strengthening the Capacity to Deal with Systemically Important Financial Institutions (SIFIs)}

46. Progress has been made in addressing the too-important-to-fail problem, but more needs to be done. The authorities have strengthened regulatory ratios, established more intensive and proactive supervision commensurate with the complexity and risk of each institution, and introduced a bank levy on wholesale funding. To further address the systemic risks posed by SIFIs, policies should aim at reducing the probability of failure (prevention) 
and reducing the impact of failure when they occur (resolution). In regard to the latter, ringfencing of retail operations and establishment of depositor preference, as proposed by the Independent Commission on Banking (ICB), will improve resolvability of the retail entity. However, ring-fencing must be weighed against the costs of such an approach and does not necessarily improve resolvability of the whole entity unless complemented by measures that increase loss absorption capacity and burden-sharing with the private sector (e.g. capital and liquidity surcharges, contingent capital, and debt subject to bail-in), recovery and resolution plans, and cross-border resolution arrangements. International collaboration will be critical for progress in these areas, and the UK authorities should continue exercising leadership on these matters. Ring-fencing should also not create complacency toward risks taken by investment banks or reduce oversight of them, as these activities can also be systemic.

\section{The government could also consider tax measures to mitigate systemic risks}

posed by SIFIs. The corporate tax creates a bias against equity finance and promotes excessive leverage because interest on debt is tax-deductible while equity finance is not. This bias could be reduced by introducing an Allowance for Corporate Equity (ACE) - an explicit deduction for the cost of equity finance, as in Belgium and as proposed by the Mirrlees $\underline{\text { Review }}$ and the IMF Staff Discussion Note Tax Biases to Debt Finance: Assessing the Problem, Finding Solutions. Given the fiscal cost associated with applying an ACE to all corporates, the government could explore the feasibility of applying an ACE initially only to banks - for whom excessive leverage has the highest social costs — with an offsetting hike in the bank levy. This could significantly improve incentives for deleveraging without disadvantaging the UK banking sector on average, as it could be designed to be revenueneutral for the sector as a whole. However, potential intra-group and cross-border taxation issues under such a reform would need to be studied carefully.

\section{Central counterparties (CCPs) should be subject to robust standards to avoid} becoming too-important-to-fail. CCPs enhance transparency and risk management in bilateral clearing, but concentrate counterparty risk. The failure of a major CCP could affect not only the functioning of the domestic financial market, but also have a cross-border dimension due to the global nature of UK financial markets. Therefore, the authorities should ensure:

- $\quad$ robust prudential and risk management standards to protect the integrity of the markets and mitigate adverse spillovers across countries, including ensuring that CCPs have sufficient liquidity; and

- $\quad$ coordinated contingency plans to deal with the failure of a CCP before the crisis occurs.

Such efforts would be bolstered by international coordination of liquidity, capital, risk management, and unwinding regulations for CCPs. 


\section{E. The International Dimension}

49. The stability of the UK financial sector critically depends on a stronger international framework for oversight of cross-border financial institutions. The UK is both home and host to large domestic and international financial institutions. International foreign bank subsidiaries and branches hold half of UK banking assets, but the UK has very limited oversight powers over branches of foreign banks due to European Economic Area passporting rules. Cooperation with international partners - especially European institutions, the US, and Switzerland (the latter two being particularly important in coordinating oversight of investment banks) - and sharing of supervisory information among home and host country authorities is therefore essential. Progress on cross-border resolution will also require international cooperation and high-level political commitment. In the absence of coordination, regulatory arbitrage could undermine the UK's efforts and UK policies could undermine other countries' efforts.

50. The UK authorities should continue to work toward an ambitious international package of regulatory reform and rigorous implementation of this package in the $E U$. Staff strongly support the authorities' efforts to advocate for European legislation under the EU Capital Requirements Directive (CRD4) that enable the establishment of strong standards that (i) exceed Basel III minima, including by setting ambitiously high capital requirements together with significantly topped-up capital demands on SIFIs, and (ii) allow flexibility for national authorities to use a range of macroprudential tools, including adjusting capital and liquidity requirements or varying risk weights, to address emerging financial and systemic risks. Collaboration with other macroprudential bodies will be important to ensure home-host coordination and reciprocity where appropriate.

51. The UK authorities are uniquely placed to contribute to the surveillance of global systemic risks. Given the central role of the UK in the global financial system, the authorities have informational advantages in assessing emerging global risks. Collaboration and information sharing between the FPC and other macroprudential bodies could help mitigate these risks. To this end, the FPC should also consider the outward spillovers of its policy decisions.

\section{Authorities' views}

52. There was broad agreement on the domestic reform agenda. The authorities indicated continued progress on the wide range of initiatives to strengthen the regulatory and supervisory framework and are carefully considering how best to take forward the FSSA recommendations. They concurred with the view that this ambitious reform agenda entails risks and challenges, as the financial sector is still recovering and internationally agreed standards will be implemented simultaneously. They are cognizant of the impact of regulatory uncertainty on the banking system and intend to address this after the final report of the ICB is published in September 2011. 
53. The authorities emphasized the need to achieve an ambitious regulatory framework at the global and EU level. They expressed serious concern about potential proposals in relation to CRD4. In particular, they emphasized the need to fully implement the internationally agreed Basel III framework in detail, as G20 leaders have agreed. They stressed the importance of having national discretion to set higher standards than the minimum levels of Basel III in specific circumstances and to operate countercyclical macroprudential policy in order to protect financial stability. They will continue to work with international partners on outstanding issues, including cross-border resolution, and welcomed the IMF's efforts to strengthen the multilateral dialogue, including through spillover reports.

\section{StAFF APPRAisal}

54. Aided by the implementation of a wide-ranging policy program, the post-crisis repair of the UK economy continues. Over the last year, the government has cut the structural fiscal deficit, banks have bolstered their balance sheets, and businesses have expanded employment. The government has also created new institutions to address weaknesses in the policymaking framework revealed by the crisis. These include a new FPC to oversee macroprudential policy and an independent OBR that should strengthen the credibility of fiscal analysis and forecasts. These developments and reforms move in the right direction, though much remains to be done on the path to recovery.

55. Growth and inflation have been worse-than-expected in recent quarters, but are projected to improve over time. One factor behind recent weak growth is the spike in commodity prices, which dented consumer confidence. Going forward, this drag on growth is expected to lessen and growth is expected to gradually resume, as low interest rates, corporates' strong cash positions, and global growth support expansion led by net exports and investment. However, the pace of recovery will be moderate, as headwinds from fiscal consolidation, a soft housing market, and the ongoing process of household and bank balance sheet repair continue to weigh on growth. Inflation is expected to return near the 2 percent target by end-2012, as transitory factors that have boosted headline inflation dissipate and as significant spare capacity keeps underlying inflation in check.

56. In this central scenario, the current settings of fiscal and monetary policy remain appropriate. The fiscal consolidation plan aims to stabilize government debt within a few years, thereby preserving confidence in debt sustainability. Although consolidation will create headwinds for short-term growth, it will also assist disinflation and can thus be countered by looser monetary policy than otherwise. In this context, the current accommodative monetary stance is appropriate, given the projection that inflation will return to target in a reasonable timeframe and the uncertainty regarding the strength of the recovery.

57. Such a policy mix will support economic rebalancing to a more sustainable equilibrium. Tight fiscal and accommodative monetary policy will help keep real interest rates low and sterling competitive. This economic environment will assist public and private 
balance sheet repair while promoting expansion of investment and net exports. This is necessary if robust output and employment growth are to be achieved at the same time that private and public consumption are eased to more sustainable levels.

58. If growth resumes as expected in the coming quarters, the case for reducing the degree of monetary accommodation will slowly increase. In the central scenario, the pace at which monetary stimulus is withdrawn should be measured, given the extended period of fiscal contraction and the high sensitivity of house prices (and hence consumption and residential investment) to short-term interest rates. Furthermore, the real interest rate consistent with stable inflation and full employment may remain low for some time, as it is likely that the financial crisis has shifted down the demand for investment and consumption at any given interest rate.

59. Fiscal consolidation should be supported by further structural reforms to address longer-term fiscal imbalances and bolster medium-term growth. Further accelerating increases in the state pension age and indexing it to longevity would reduce longer-term fiscal imbalances and could raise labor supply by encouraging longer working lives. Reform of public-service pensions, along the lines recommended by the Independent Public Service Pensions Commission, would help improve their structure and better align average public-service compensation with private-sector equivalents. Efforts to ease tight planning restrictions are also welcome, as they could spur construction and productivityenhancing development.

\section{The central scenario is nonetheless subject to large risks and policy flexibility}

will be essential to respond to shocks. Key risks arise from uncertainties surrounding commodity prices, euro-area sovereign turmoil, the housing market, and the size of the output gap and fiscal multipliers. On the upside, if growth and inflationary pressures are stronger than expected, monetary tightening should accelerate and all fiscal windfalls should be saved. Conversely, if the economy appears likely to experience prolonged weak growth and lower inflation, fiscal automatic stabilizers should operate freely and monetary policy should be kept loose for an extended period. To prevent a downturn from becoming entrenched, additional stimulus may be required from $\mathrm{BoE}$ asset purchases and temporary targeted tax cuts, combined with deeper long-run entitlement reform to safeguard fiscal sustainability and market confidence. In the event further commodity price volatility temporarily extends the period of weak growth and high inflation, policies need not respond. However, if weak growth and high inflation reflect a much narrower-than-estimated output gap (as indicated by rapid growth of unit labor costs), policies will have to tighten to reanchor inflationary expectations.

61. UK financial sector stability is a global public good, requiring the highest quality regulation and supervision. The UK's stringent capital and liquidity regulations - including the pressure from supervisors to use strong earnings to build up capital ahead of official requirements and linking the approval of dividends and variable remuneration to the outcome 
of FSA stress tests - are thus proper and necessary. To be effective, regulatory requirements should be accompanied by more intrusive supervision, and FSA plans to make improvements in this regard are welcome. To support this work, forthcoming framework legislation should also provide (i) explicit support for early intervention by the supervisor in dealing with prudential problems and (ii) regulatory enforcement powers at the holding company level to enhance consolidated supervision.

62. The active use of macroprudential tools, under the purview of the FPC, should help reduce systemic risk going forward. The FPC should focus on tools that are most effective against the cycle and minimize efficiency costs and scope for regulatory arbitrage. For the FPC to be credible, it will be important to set realistic expectations of what macroprudential regulation can achieve, especially in its early stages of implementation.

63. Progress has been made in addressing the too-important-to-fail problem, but more needs to be done. Further tax reforms, such as a revenue-neutral allowance for corporate equity, could be considered to help reduce incentives for excessive leverage. Given the systemic importance of CCPs, the authorities should subject them to robust risk management standards and establish contingency plans to deal with possible failures. Ringfencing of retail operations and establishment of depositor preference, as proposed by the ICB, will improve resolvability of the retail entity. However, ring-fencing must be weighed against the costs of such an approach and does not necessarily improve resolvability of the whole entity unless complemented by comprehensive measures - including improved loss absorption capacity, recovery and resolution plans, and cross-border resolution arrangements - on which international coordination is critical.

64. Indeed, strong cooperation with and from international partners is essential to securing financial stability. It will be important that European legislation under CRD4 enables the establishment of strong standards that exceed Basel III minima and allows broad flexibility for national authorities to introduce countercyclical macroprudential tools. Collaboration between the FPC and other macroprudential bodies will be important to ensure home-host coordination (including to address cross-border liquidity needs in times of stress), reciprocity where appropriate, and information sharing. Given the UK's global importance, the FPC should also consider the outward spillovers of its policy decisions.

65. The UK lags behind many other countries in standards for the public disclosure of bank and insurance sector data. Work underway to allow publication of regular and comparable data on an institution basis is therefore welcome.

66. It is recommended that the next Article IV consultation with the United Kingdom be held on the standard 12-month cycle. 
Table 1. United Kingdom: Selected Economic and Social Indicators, 2007-12

\begin{tabular}{|c|c|c|c|c|c|c|}
\hline & 2007 & 2008 & 2009 & 2010 & $\begin{array}{c}2011 \\
\text { Proj. }\end{array}$ & $\begin{array}{r}2012 \\
\text { Proj. } \\
\end{array}$ \\
\hline \multicolumn{7}{|l|}{ Real Economy (change in percent) } \\
\hline Real GDP & 2.7 & -0.1 & -4.9 & 1.4 & 1.5 & 2.3 \\
\hline Domestic demand & 3.1 & -0.7 & -5.5 & 2.7 & -0.1 & 1.4 \\
\hline Private final domestic demand & 3.3 & -1.4 & -6.5 & 1.3 & 0.0 & 2.5 \\
\hline $\mathrm{CPI}$, end period & 2.1 & 3.1 & 2.9 & 3.7 & 4.5 & 2.2 \\
\hline Unemployment rate (in percent) $1 /$ & 5.4 & 5.6 & 7.5 & 7.9 & 7.7 & 7.6 \\
\hline Gross national saving (percent of GDP) & 15.6 & 15.0 & 11.8 & 11.8 & 11.5 & 12.5 \\
\hline Gross domestic investment (percent of GDP) & 18.2 & 16.6 & 13.5 & 15.0 & 14.0 & 14.5 \\
\hline \multicolumn{7}{|l|}{ Public Finance (fiscal year, percent of GDP) 2/ } \\
\hline General government overall balance & -2.7 & -6.7 & -11.3 & -9.8 & -7.9 & -6.3 \\
\hline Public sector overall balance & -2.4 & -6.7 & -11.1 & -9.7 & -8.0 & -6.4 \\
\hline Cyclically adjusted overall balance (staff estimates) & -3.1 & -6.7 & -9.1 & -7.7 & -6.2 & -4.7 \\
\hline General government gross debt & 43.1 & 55.4 & 71.5 & 76.8 & 81.5 & 84.2 \\
\hline Public sector net debt & 36.6 & 43.3 & 52.8 & 59.8 & 65.7 & 69.3 \\
\hline \multicolumn{7}{|l|}{ Money and Credit (end-period, 12-month percent change) 3/ } \\
\hline M4 & 12.8 & 15.5 & 6.7 & -1.4 & -0.2 & $\ldots$ \\
\hline Net lending to private sector & 10.8 & 4.9 & 0.6 & -0.4 & 0.1 & $\ldots$ \\
\hline \multicolumn{7}{|l|}{ Interest rates (percent; year average) 4/ } \\
\hline Three-month interbank rate & 6.0 & 5.8 & 1.2 & 0.7 & 0.8 & $\ldots$ \\
\hline Ten-year government bond yield & 5.0 & 4.7 & 3.6 & 3.6 & 3.7 & $\ldots$ \\
\hline \multicolumn{7}{|l|}{ Balance of Payments (percent of GDP) } \\
\hline Current account balance & -2.6 & -1.6 & -1.7 & -3.2 & -2.6 & -1.9 \\
\hline Trade balance & -3.1 & -2.6 & -2.1 & -3.4 & -2.0 & -1.3 \\
\hline Net exports of oil & -0.3 & -0.4 & -0.2 & -0.3 & -0.4 & -0.4 \\
\hline Exports of goods and services (volume change in percent) & -2.6 & 1.0 & -10.1 & 5.2 & 7.5 & 5.5 \\
\hline Imports of goods and services (volume change in percent) & -0.8 & -1.2 & -11.9 & 8.8 & 1.6 & 2.4 \\
\hline Terms of trade (percent change) & 1.4 & 0.0 & -0.9 & -0.2 & -1.1 & -0.6 \\
\hline FDI net & -4.4 & -2.6 & 1.2 & -0.7 & $\ldots$ & $\ldots$ \\
\hline Reserves (end of period, billions of US dollars) 4/ & 57.9 & 53.9 & 66.4 & 78.8 & 91.2 & $\ldots$ \\
\hline \multicolumn{7}{|l|}{ Fund Position (as of June 30, 2011) } \\
\hline Holdings of currency (in percent of quota) & & & & & & 69.2 \\
\hline Holdings of SDRs (in percent of allocation) & & & & & & 92.1 \\
\hline Quota (in millions of SDRs) & & & & & & $10,738.5$ \\
\hline \multicolumn{7}{|l|}{ Exchange Rates } \\
\hline Exchange rate regime & & & & & & Floating \\
\hline Bilateral rate (June 30,2011$)$ & & & & & US\$1 & $=£ 0.6228$ \\
\hline Nominal effective rate $(2005=100) 3 / 5 /$ & 102.3 & 89.3 & 78.8 & 79.3 & 79.1 & $\ldots$ \\
\hline Real effective rate $(2005=100) 3 / 5 / 6 /$ & 102.3 & 89.3 & 80.4 & 82.2 & 83.0 & $\ldots$ \\
\hline
\end{tabular}

Sources: Office for National Statistics; HM Treasury; Bank of England; IFS; INS; and IMF staff estimates and projections.

1/ ILO unemployment; based on Labor Force Survey data.

2/ The fiscal year begins in April. Data exclude the temporary effects of financial sector interventions. Debt stock data refers to the end of the fiscal year using centered-GDP as a denominator.

3/ 2011: actual data through May.

4/ 2011: actual data through June.

5/ Average. An increase denotes an appreciation.

$6 /$ Based on relative consumer prices. 
Table 2. United Kingdom: Statement of Public Sector Operations, 2009/10-15/16 1/ (Percent of GDP)

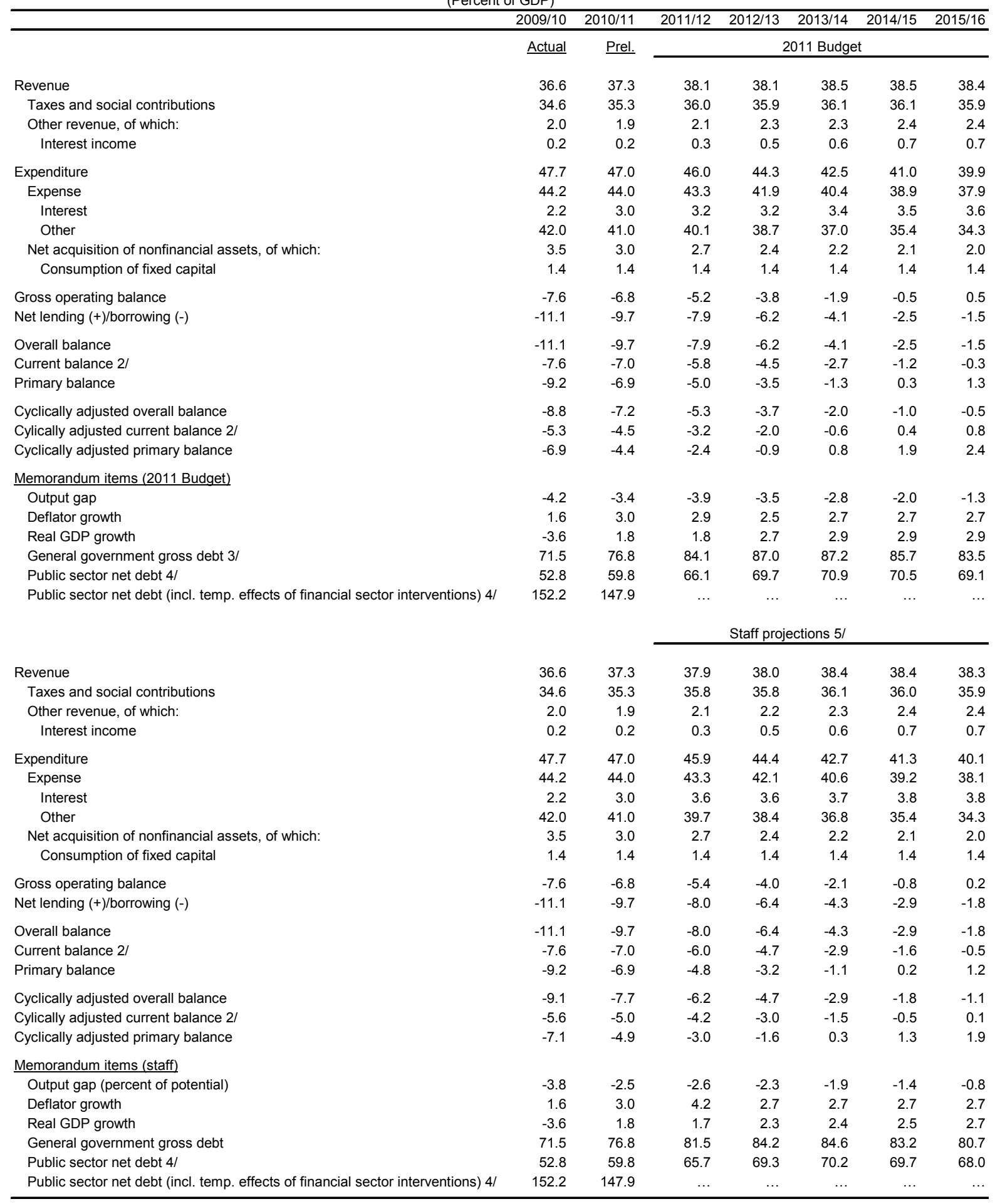

Sources: Office for National Statistics (ONS), HM Treasury, and IMF staff estimates.

$1 /$ Excludes the temporary effects of financial sector interventions unless otherwise noted.

2/ Includes depreciation.

3/ From 2011/12 onwards, budget projections for general government gross debt are on a Maastricht basis.

$4 /$ End of fiscal year using centered-GDP as the denominator.

5/ IMF staff projections based on Budget 2011 expenditure plans and staff's macroeconomic assumptions. 
Table 3. Statement of General Government Operations, 2004-2010

\begin{tabular}{|c|c|c|c|c|c|c|c|}
\hline & 2004 & 2005 & 2006 & 2007 & 2008 & 2009 & 2010 \\
\hline & \multicolumn{7}{|c|}{ (Percent of GDP) } \\
\hline Revenue & 39.6 & 40.8 & 41.5 & 41.3 & 42.5 & 40.3 & 40.6 \\
\hline Taxes & 28.2 & 28.9 & 29.7 & 29.3 & 30.3 & 27.8 & 28.6 \\
\hline Social contributions & 8.1 & 8.4 & 8.3 & 8.2 & 8.4 & 8.5 & 8.5 \\
\hline Other & 3.2 & 3.5 & 3.6 & 3.7 & 3.8 & 3.9 & 3.6 \\
\hline Expense & 42.9 & 44.1 & 44.2 & 44.0 & 47.4 & 51.4 & 50.8 \\
\hline Expense & 42.1 & 44.4 & 43.4 & 43.2 & 46.1 & 49.8 & 49.4 \\
\hline Compensation of employees & 11.0 & 11.3 & 11.2 & 10.9 & 11.1 & 11.8 & 11.7 \\
\hline Use of goods and services & 11.1 & 11.4 & 11.8 & 11.7 & 12.3 & 13.5 & 13.0 \\
\hline Consumption of fixed capital & 0.9 & 0.9 & 0.9 & 0.9 & 0.9 & 1.0 & 1.0 \\
\hline Interest & 2.0 & 2.1 & 2.1 & 2.2 & 2.3 & 1.9 & 2.9 \\
\hline Subsidies & 0.5 & 0.6 & 0.7 & 0.7 & 0.6 & 0.7 & 0.6 \\
\hline Grants & 0.3 & 0.3 & 0.3 & 0.3 & 0.0 & 0.0 & 0.0 \\
\hline Social benefits & 12.8 & 12.9 & 12.6 & 12.7 & 13.1 & 15.1 & 15.2 \\
\hline Other & 3.8 & 5.2 & 4.1 & 4.1 & 5.8 & 5.9 & 4.8 \\
\hline Net acquisition of nonfinancial assets & 0.8 & -0.3 & 0.8 & 0.8 & 1.3 & 1.6 & 1.5 \\
\hline Consumption of fixed capital & 0.9 & 0.9 & 0.9 & 0.9 & 0.9 & 1.0 & 1.0 \\
\hline Gross operating balance & -1.7 & -2.7 & -0.9 & -1.0 & -2.7 & -8.6 & -7.7 \\
\hline Net operating balance & -2.6 & -3.6 & -1.8 & -1.9 & -3.6 & -9.6 & -8.8 \\
\hline Net lending/borrowing & -3.4 & -3.3 & -2.6 & -2.7 & -4.9 & -11.2 & -10.2 \\
\hline Net Acquisition of Financial assets & 0.3 & 0.6 & 0.9 & 0.4 & 4.5 & 3.2 & 0.5 \\
\hline Currency and deposits & 0.1 & -0.1 & 0.6 & 0.7 & 2.1 & 0.5 & -1.0 \\
\hline Securities other than shares & 0.2 & 0.3 & 0.2 & 0.1 & 0.2 & -0.6 & 0.6 \\
\hline Loans & 0.1 & 0.2 & 0.2 & 0.3 & 0.3 & 0.4 & 0.5 \\
\hline Shares and other equity & -0.3 & -0.3 & -0.2 & -0.6 & 0.7 & 2.7 & 0.0 \\
\hline Insurance technical reserves & 0.0 & 0.0 & 0.0 & 0.0 & 0.0 & 0.0 & 0.0 \\
\hline Financial derivatives & 0.0 & 0.0 & 0.0 & 0.0 & 0.0 & 0.1 & 0.0 \\
\hline Other accounts receivable & 0.2 & 0.5 & 0.2 & -0.1 & 1.1 & 0.1 & 0.4 \\
\hline Monetary gold and SDRs & 0.0 & 0.0 & 0.0 & 0.0 & 0.0 & 0.0 & 0.0 \\
\hline Net Incurrence of Liabilities & 3.7 & 3.8 & 3.6 & 3.2 & 9.4 & 15.4 & 10.5 \\
\hline Currency and deposits & 0.2 & 0.5 & 0.4 & 0.6 & 1.3 & 0.6 & -0.4 \\
\hline Securities other than shares & 2.9 & 2.9 & 3.0 & 2.7 & 7.5 & 15.9 & 11.5 \\
\hline Loans & 0.7 & 0.3 & -0.1 & 0.0 & 1.0 & -1.4 & -0.4 \\
\hline Shares and other equity & 0.0 & 0.0 & 0.0 & 0.0 & 0.0 & 0.0 & 0.0 \\
\hline Insurance technical reserves & 0.0 & 0.0 & 0.0 & 0.0 & 0.0 & 0.0 & 0.0 \\
\hline Financial derivatives & 0.0 & 0.0 & 0.0 & 0.0 & 0.0 & 0.0 & 0.0 \\
\hline Other accounts receivable & -0.2 & 0.2 & 0.3 & -0.1 & -0.5 & 0.3 & -0.2 \\
\hline
\end{tabular}

Source: IMF Government Fiscal Statistics. 
Table 4. General Government Stock Positions, 2004-2010

\begin{tabular}{|c|c|c|c|c|c|c|c|}
\hline & 2004 & 2005 & 2006 & 2007 & 2008 & 2009 & 2010 \\
\hline & \multicolumn{7}{|c|}{ (Percent of GDP) } \\
\hline Net worth & $\ldots$ & $\ldots$ & $\ldots$ & $\ldots$ & $\ldots$ & $\ldots$ & $\ldots$ \\
\hline Nonfinancial assets & $\ldots$ & & $\ldots$ & $\ldots$ & $\ldots$ & $\ldots$ & $\ldots$ \\
\hline Net financial worth & -26.0 & -27.2 & -27.9 & -28.6 & -33.5 & -45.0 & -56.4 \\
\hline Financial assets & 20.2 & 21.6 & 20.9 & 21.0 & 26.2 & 30.3 & 28.6 \\
\hline Currency and deposits & 2.4 & 2.2 & 2.5 & 3.2 & 5.1 & 5.3 & 3.3 \\
\hline Securities other than shares & 1.8 & 2.0 & 1.9 & 1.9 & 2.7 & 2.1 & 2.5 \\
\hline Loans & 2.3 & 2.4 & 2.4 & 2.6 & 2.8 & 3.4 & 3.6 \\
\hline Shares and other equity & 10.1 & 11.0 & 10.1 & 9.6 & 10.9 & 13.6 & 13.2 \\
\hline Insurance technical reserves & 0.1 & 0.1 & 0.1 & 0.1 & 0.1 & 0.1 & 0.1 \\
\hline Financial derivatives & 0.0 & 0.0 & 0.1 & 0.0 & -0.2 & -0.1 & 0.0 \\
\hline Other accounts receivable & 3.4 & 3.6 & 3.6 & 3.3 & 4.4 & 4.8 & 4.7 \\
\hline Monetary gold and SDRs & 0.2 & 0.3 & 0.3 & 0.3 & 0.4 & 1.1 & 1.2 \\
\hline Liabilities & 46.2 & 48.9 & 48.7 & 49.5 & 59.6 & 75.2 & 85.0 \\
\hline Currency and deposits & 6.9 & 7.0 & 7.1 & 7.2 & 8.4 & 9.2 & 8.4 \\
\hline Securities other than shares & 33.2 & 35.6 & 35.5 & 36.4 & 45.0 & 61.4 & 72.2 \\
\hline Loans & 3.7 & 3.8 & 3.5 & 3.5 & 3.6 & 1.9 & 1.7 \\
\hline Shares and other equity & 0.0 & 0.0 & 0.0 & 0.0 & 0.0 & 0.0 & 0.0 \\
\hline Insurance technical reserves & 0.0 & 0.0 & 0.0 & 0.0 & 0.0 & 0.0 & 0.0 \\
\hline Financial derivatives & 0.0 & 0.0 & 0.0 & 0.0 & 0.0 & 0.0 & 0.0 \\
\hline Other accounts receivable & 2.4 & 2.5 & 2.7 & 2.3 & 2.7 & 2.8 & 2.7 \\
\hline
\end{tabular}

Source: IMF Government Fiscal Statistics. 
Table 5. United Kingdom: Balance of Payments, 2004-16

\begin{tabular}{|c|c|c|c|c|c|c|c|c|c|c|c|c|c|}
\hline & 2004 & 2005 & 2006 & 2007 & 2008 & 2009 & 2010 & $\begin{array}{l}2011 \\
\text { Proj. }\end{array}$ & $\begin{array}{l}2012 \\
\text { Proj. }\end{array}$ & $\begin{array}{l}2013 \\
\text { Proj. }\end{array}$ & $\begin{array}{l}2014 \\
\text { Proj. }\end{array}$ & $\begin{array}{l}2015 \\
\text { Proj. }\end{array}$ & $\begin{array}{l}2016 \\
\text { Proj. }\end{array}$ \\
\hline & \multicolumn{13}{|c|}{ (Percent of GDP) } \\
\hline Current account & -2.1 & -2.6 & -3.4 & -2.6 & -1.6 & -1.7 & -3.2 & -2.6 & -1.9 & -1.3 & -0.9 & -0.6 & -0.3 \\
\hline Trade balance & -2.7 & -3.4 & -3.1 & -3.1 & -2.6 & -2.1 & -3.4 & -2.0 & -1.3 & -0.6 & -0.2 & 0.1 & 0.3 \\
\hline Trade in goods & -5.1 & -5.5 & -5.7 & -6.4 & -6.4 & -5.9 & -6.8 & -5.5 & -4.7 & -4.1 & -3.8 & -3.5 & -3.3 \\
\hline Exports & 15.9 & 16.9 & 18.3 & 15.7 & 17.4 & 16.3 & 18.2 & 19.9 & 20.0 & 20.0 & 20.1 & 20.3 & 20.4 \\
\hline Imports & 20.9 & 22.3 & 24.1 & 22.1 & 23.9 & 22.2 & 25.0 & 25.4 & 24.6 & 24.2 & 23.9 & 23.8 & 23.7 \\
\hline Trade in services & 2.4 & 2.1 & 2.6 & 3.3 & 3.8 & 3.8 & 3.4 & 3.5 & 3.4 & 3.5 & 3.6 & 3.6 & 3.6 \\
\hline Exports & 9.4 & 9.5 & 10.1 & 10.9 & 11.8 & 11.7 & 11.2 & 10.8 & 10.5 & 10.4 & 10.4 & 10.4 & 10.4 \\
\hline Imports & 7.0 & 7.5 & 7.5 & 7.6 & 8.0 & 7.9 & 7.8 & 7.2 & 7.1 & 6.9 & 6.9 & 6.8 & 6.7 \\
\hline Income balance & 1.5 & 1.7 & 0.6 & 1.4 & 1.9 & 1.5 & 1.6 & 0.6 & 0.4 & 0.4 & 0.4 & 0.4 & 0.4 \\
\hline Current transfers & -0.9 & -0.9 & -0.9 & -1.0 & -1.0 & -1.1 & -1.4 & -1.2 & -1.1 & -1.1 & -1.1 & -1.1 & -1.1 \\
\hline $\begin{array}{l}\text { Capital and financial account } \\
\text { Of which: }\end{array}$ & 2.6 & 2.4 & 3.2 & 1.9 & 2.0 & 2.4 & 3.2 & $\cdots$ & $\ldots$ & $\ldots$ & $\cdots$ & $\cdots$ & $\ldots$ \\
\hline Direct investment & -1.7 & 4.3 & 3.0 & -4.4 & -2.6 & 1.2 & -0.7 & $\ldots$ & $\ldots$ & $\ldots$ & $\ldots$ & $\ldots$ & $\ldots$ \\
\hline Portfolio investment & -3.6 & -1.7 & 1.0 & 9.0 & 22.4 & 2.3 & 3.6 & $\ldots$ & $\ldots$ & $\ldots$ & $\ldots$ & $\ldots$ & $\ldots$ \\
\hline Other investment & 7.8 & -0.2 & -0.9 & -2.7 & -18.1 & -0.9 & 0.2 & $\ldots$ & $\ldots$ & $\ldots$ & $\ldots$ & $\ldots$ & $\ldots$ \\
\hline
\end{tabular}

Sources: Office for National Statistics (ONS) and IMF staff projections. 
Table 6. United Kingdom: Net Investment Position, 2004-2010 1/

(Percent of GDP)

\begin{tabular}{|c|c|c|c|c|c|c|c|}
\hline & 2004 & 2005 & 2006 & 2007 & 2008 & 2009 & 2010 \\
\hline Assets & 325 & 383 & 456 & 551 & 760 & 624 & $\ldots$ \\
\hline Direct investment abroad & 56 & 56 & 55 & 64 & 72 & 73 & $\ldots$ \\
\hline Portfolio investment abroad & 91 & 109 & 115 & 121 & 115 & 135 & $\ldots$ \\
\hline Other investment abroad & 176 & 216 & 220 & 267 & 290 & 254 & $\ldots$ \\
\hline Reserve assets & 2 & 2 & 2 & 2 & 3 & 3 & 3 \\
\hline Liabilities & 343 & 403 & 485 & 574 & 767 & 643 & $\cdots$ \\
\hline Direct investment in the UK & 32 & 39 & 43 & 44 & 46 & 48 & $\ldots$ \\
\hline Portfolio investment in the UK & 102 & 117 & 128 & 139 & 137 & 170 & $\ldots$ \\
\hline Other investment in the UK & 210 & 247 & 246 & 293 & 313 & 273 & $\ldots$ \\
\hline Net investment position & -18 & -20 & -29 & -23 & -7 & -21 & -13 \\
\hline Direct investment & 25 & 17 & 12 & 20 & 26 & 27 & 26 \\
\hline Portfolio investment & -11 & -8 & -13 & -18 & -22 & -38 & -31 \\
\hline Other investment & -33 & -31 & -27 & -27 & -23 & -19 & -16 \\
\hline Reserve assets & 2 & 2 & 2 & 2 & 3 & 3 & 3 \\
\hline Monetary financial institutions & -16 & -12 & -13 & -17 & -10 & -18 & -10 \\
\hline Other sectors & 2 & -2 & -8 & 4 & 15 & 10 & 15 \\
\hline Public sectors & -4 & -6 & -8 & -9 & -12 & -13 & -18 \\
\hline \multicolumn{8}{|l|}{ Memorandum items: } \\
\hline Change in the net investment position & -8.6 & -2.5 & -10.0 & 4.5 & 15.3 & -13.8 & 7.0 \\
\hline Current account balance & -2.1 & -2.6 & -3.4 & -2.6 & -1.6 & -1.7 & -2.5 \\
\hline
\end{tabular}

Source: ONS.

1/ Data corresponds to the end of the indicated period, expressed as a percent of the cumulated GDP of the four preceding quarters. 
Table 7. United Kingdom: Medium-Term Scenario, 2006-16

(Percentage change, unless otherwise indicated)

\begin{tabular}{|c|c|c|c|c|c|c|c|c|c|c|c|}
\hline & 2006 & 2007 & 2008 & 2009 & 2010 & $\begin{array}{c}2011 \\
\text { Proj. }\end{array}$ & $\begin{array}{r}2012 \\
\text { Proj. }\end{array}$ & $\begin{array}{l}2013 \\
\text { Proj. }\end{array}$ & $\begin{array}{c}2014 \\
\text { Proj. }\end{array}$ & $\begin{array}{c}2015 \\
\text { Proj. }\end{array}$ & $\begin{array}{l}2016 \\
\text { Proj. }\end{array}$ \\
\hline Real GDP & 2.8 & 2.7 & -0.1 & -4.9 & 1.4 & 1.5 & 2.3 & 2.4 & 2.5 & 2.7 & 2.7 \\
\hline Q4/Q4 1/ & 2.7 & 2.4 & -2.7 & -2.8 & 1.5 & 2.1 & 2.5 & 2.4 & 2.5 & 2.8 & 2.6 \\
\hline Real domestic demand & 2.5 & 3.1 & -0.7 & -5.5 & 2.7 & -0.1 & 1.4 & 1.7 & 2.0 & 2.3 & 2.4 \\
\hline Private consumption & 1.8 & 2.2 & 0.4 & -3.2 & 0.7 & 0.0 & 1.7 & 1.9 & 2.2 & 2.2 & 2.2 \\
\hline Government consumption & 1.4 & 1.3 & 1.6 & 1.0 & 1.0 & 0.7 & -1.2 & -1.8 & -2.4 & -1.9 & -0.4 \\
\hline Fixed investment & 6.4 & 7.8 & -5.0 & -15.4 & 3.7 & -1.6 & 3.6 & 6.3 & 7.1 & 7.4 & 6.2 \\
\hline Public 2/ & 4.4 & 6.4 & 24.5 & 18.9 & 1.4 & -9.7 & -9.7 & -5.4 & -1.8 & 2.9 & 0.7 \\
\hline Residential & 8.4 & 2.8 & -11.8 & -25.5 & 6.9 & -0.5 & 6.1 & 6.9 & 6.6 & 6.0 & 5.8 \\
\hline Business 2/ & 4.8 & 12.5 & -1.1 & -18.9 & 3.5 & 1.9 & 6.7 & 9.0 & 9.1 & 8.7 & 7.3 \\
\hline Stocks $3 /$ & 0.0 & 0.1 & -0.5 & -1.2 & 1.5 & 0.1 & 1.8 & 0.0 & 0.0 & 0.0 & 0.0 \\
\hline External balance $3 /$ & 0.2 & -0.5 & 0.7 & 0.9 & -1.1 & 1.5 & 0.8 & 0.7 & 0.5 & 0.5 & 0.4 \\
\hline Exports of Goods and Services & 11.1 & -2.6 & 1.0 & -10.1 & 5.2 & 7.5 & 5.5 & 5.8 & 6.0 & 6.0 & 5.9 \\
\hline Imports of Goods and Services & 9.1 & -0.8 & -1.2 & -11.9 & 8.8 & 1.6 & 2.4 & 3.3 & 4.2 & 4.5 & 4.7 \\
\hline Exports of Goods and Services (ex. fraud) 4/ & 8.1 & 3.0 & 1.0 & -10.1 & 5.1 & 8.1 & 5.5 & 5.8 & 6.0 & 6.0 & 5.9 \\
\hline Imports of Goods and Services (ex. fraud) 4/ & 6.4 & 4.3 & -1.2 & -11.9 & 8.7 & 2.2 & 2.4 & 3.3 & 4.2 & 4.5 & 4.7 \\
\hline Current account 5/ & -3.4 & -2.6 & -1.6 & -1.7 & -3.2 & -2.6 & -1.9 & -1.3 & -0.9 & -0.6 & -0.3 \\
\hline CPI Inflation, end period & 3.0 & 2.1 & 3.1 & 2.9 & 3.7 & 4.5 & 2.2 & 2.0 & 2.0 & 2.0 & 2.0 \\
\hline Output gap 6/ & 0.3 & 1.0 & 0.7 & -3.8 & -2.7 & -2.7 & -2.4 & -2.0 & -1.6 & -0.9 & -0.2 \\
\hline \multicolumn{12}{|l|}{ Employment and productivity } \\
\hline Employment & 0.9 & 0.7 & 0.7 & -1.6 & 0.3 & 0.9 & 0.7 & 0.8 & 0.8 & 0.8 & 0.8 \\
\hline Unemployment rate $7 /$ & 5.4 & 5.4 & 5.6 & 7.5 & 7.9 & 7.7 & 7.6 & 7.3 & 7.0 & 6.5 & 6.1 \\
\hline Productivity $8 /$ & 2.0 & 2.0 & -0.8 & -3.2 & 1.4 & 0.6 & 1.6 & 1.6 & 1.6 & 1.8 & 1.9 \\
\hline \multicolumn{12}{|l|}{ Memorandum } \\
\hline Private final domestic demand & 2.7 & 3.3 & -1.4 & -6.5 & 1.3 & 0.0 & 2.5 & 3.0 & 3.3 & 3.3 & 3.1 \\
\hline Household saving rate $9 /$ & 3.5 & 2.7 & 2.0 & 6.0 & 5.3 & 5.3 & 5.2 & 4.9 & 4.8 & 4.6 & 4.5 \\
\hline Private saving rate & 14.3 & 16.0 & 16.3 & 18.1 & 18.4 & 16.8 & 16.6 & 16.2 & 16.1 & 16.2 & 16.1 \\
\hline
\end{tabular}

Sources: Office for National Statistics; and IMF staff projections.

1/ Percentage change in quarterly real GDP in the fourth quarter on four quarters earlier.

2/ Public investment and business investment in 2006 excludes the transfer of nuclear reactors.

3/ Contribution to the growth of GDP.

4/ These numbers exclude VAT-related fraudulent activity.

$5 /$ In percent of GDP.

6/ In percent of potential GDP.

7/ In percent of labor force, period average; based on the Labor Force Survey.

8/ Whole economy, per worker.

9/ Percent of total household available resources. 


\section{Annex: Public Sector Debt Sustainability}

General government gross debt is projected to increase from a trough of 42 percent of GDP in FY06/07 to a peak of about 85 percent of GDP in FY13/14 under the government's planned consolidation (Table A1). The debt ratio would come down to about 78 percent of GDP by FY16/17. The baseline scenario for this debt sustainability analysis builds on staff's central scenario and hence takes into account announced policies. The general government primary deficit is expected to have peaked in FY09/10 at 91/4 percent of GDP and reach a surplus of 2 percent of GDP by FY16/17. As a result, the debt ratio would be on a downward path from FY14/15. Gross financing needs in the near term are high, but are expected to ease slightly to about 15 percent of GDP in FY11/12 after peaking at $163 / 4$ percent of GDP in FY10/11.

Alternative scenarios and bound tests highlight the uncertainties surrounding the projected debt path (Figure A1). Different policy paths or growth scenarios would significantly affect debt outcomes:

- Debt would increase rapidly in the absence of fiscal consolidation. In a scenario with a constant primary balance (in percent of GDP) over FY11/12-16/17, debt would increase to 101 percent of GDP by FY16/17 and be on a firm upward path. The impact of unchanged policies would be even higher than this estimate if concerns about sovereign debt dynamics lead to higher interest rates.

- If medium-term growth rates are persistently lower than anticipated, stabilizing the debt ratio would require further adjustment. Assuming expenditure plans remain unchanged, the debt-to-GDP ratio could reach 89 percent of GDP by FY16/17 should growth be 1.1 percentage points ( $1 / 2$ a standard deviation) lower each year than in the central scenario. 
Table A1. United Kingdom: Public Sector Debt Sustainability Framework, 2006-2016

(Fiscal year basis; percent of GDP, unless otherwise indicated) 1/

\begin{tabular}{|c|c|c|c|c|c|c|c|c|c|c|c|c|}
\hline & \multicolumn{5}{|c|}{ Actual } & \multicolumn{6}{|c|}{ Projections } & \multirow{3}{*}{$\begin{array}{c}\text { Debt-stabilizing } \\
\text { primary } \\
\text { balance } 9 /\end{array}$} \\
\hline & 2006 & 2007 & 2008 & 2009 & 2010 & 2011 & 2012 & 2013 & 2014 & 2015 & 2016 & \\
\hline & & & & & & & & & & & & \\
\hline Baseline: General government consolidated gross debt & 42.4 & 43.1 & 55.4 & 71.5 & 76.8 & 81.5 & 84.2 & 84.6 & 83.2 & 80.7 & 78.0 & -0.5 \\
\hline $\mathrm{o} / \mathrm{w}$ foreign-currency denominated & 0.1 & 0.1 & 0.0 & 0.0 & 0.0 & 0.0 & 0.0 & 0.0 & 0.0 & 0.0 & 0.0 & \\
\hline Change in public sector debt & 0.7 & 0.7 & 12.3 & 16.1 & 5.3 & 4.7 & 2.7 & 0.3 & -1.4 & -2.5 & -2.6 & \\
\hline Identified debt-creating flows $(4+7+12)$ & 0.2 & 0.5 & 7.1 & 13.1 & 6.5 & 3.6 & 2.4 & 0.0 & -1.4 & -2.5 & -2.6 & \\
\hline Primary deficit & 0.5 & 0.5 & 4.6 & 9.2 & 6.9 & 4.5 & 2.8 & 0.7 & -0.8 & -1.8 & -2.1 & \\
\hline Revenue and grants & 38.0 & 38.1 & 37.2 & 36.1 & 36.8 & 37.4 & 37.5 & 37.9 & 37.8 & 37.8 & 37.2 & \\
\hline Primary (noninterest) expenditure & 38.5 & 38.6 & 41.8 & 45.3 & 43.7 & 41.9 & 40.3 & 38.6 & 37.0 & 35.9 & 35.1 & \\
\hline Automatic debt dynamics $2 /$ & -0.3 & 0.0 & 1.9 & 3.4 & -0.3 & -0.9 & -0.5 & -0.6 & -0.6 & -0.7 & -0.5 & \\
\hline Contribution from interest rate/growth differential $3 /$ & -0.3 & 0.0 & 1.8 & 3.4 & -0.3 & -0.9 & -0.5 & -0.6 & -0.6 & -0.7 & -0.5 & \\
\hline Of which contribution from real interest rate & 0.7 & 1.0 & 1.0 & 1.3 & 0.9 & 0.3 & 1.3 & 1.3 & 1.4 & 1.4 & 1.5 & \\
\hline Of which contribution from real GDP growth & -1.0 & -1.0 & 0.8 & 2.1 & -1.3 & -1.2 & -1.8 & -1.9 & -2.0 & -2.1 & -2.0 & \\
\hline Contribution from exchange rate depreciation $4 /$ & 0.0 & 0.0 & 0.0 & 0.0 & 0.0 & & & & & & & \\
\hline Other identified debt-creating flows & 0.0 & 0.0 & 0.7 & 0.5 & 0.0 & 0.0 & 0.0 & 0.0 & 0.0 & 0.0 & 0.0 & \\
\hline Privatization receipts (negative) & 0.0 & 0.0 & 0.0 & 0.0 & 0.0 & 0.0 & 0.0 & 0.0 & 0.0 & 0.0 & 0.0 & \\
\hline Recognition of implicit or contingent liabilities & 0.0 & 0.0 & 0.0 & 0.0 & 0.0 & 0.0 & 0.0 & 0.0 & 0.0 & 0.0 & 0.0 & \\
\hline Other (specify, e.g. bank recapitalization) & 0.0 & 0.0 & 0.7 & 0.5 & 0.0 & 0.0 & 0.0 & 0.0 & 0.0 & 0.0 & 0.0 & \\
\hline Residual, including asset changes (2-3) $5 /$ & 0.5 & 0.2 & 5.2 & 3.1 & -1.3 & 1.1 & 0.3 & 0.3 & 0.0 & 0.0 & 0.0 & \\
\hline General government debt-to-revenue ratio & 111.7 & 113.2 & 148.9 & 198.0 & 208.8 & 218.1 & 224.6 & 223.2 & 219.9 & 213.6 & 209.4 & \\
\hline Gross financing need $6 /$ & 6.2 & 5.9 & 9.2 & 15.6 & 16.7 & 14.9 & 13.4 & 11.4 & 10.6 & 8.8 & 8.2 & \\
\hline in billions of U.S. dollars & 155.1 & 166.6 & 245.4 & 343.7 & 381.0 & 375.6 & 355.7 & 318.0 & 311.8 & 273.3 & 270.4 & \\
\hline Scenario with key variables at their historical averages 71 & & & & & & 81.5 & 85.1 & 88.7 & 92.1 & 95.5 & 98.9 & 1.1 \\
\hline Scenario with no policy change (constant primary balance) in 2011-2016 & & & & & & 81.5 & 85.9 & 90.0 & 93.9 & 97.6 & 101.4 & -0.7 \\
\hline \multicolumn{13}{|l|}{ Key Macroeconomic and Fiscal Assumptions Underlying Baseline } \\
\hline Real GDP growth (in percent) & 2.6 & 2.5 & -1.9 & -3.6 & 1.8 & 1.7 & 2.3 & 2.4 & 2.5 & 2.7 & 2.7 & \\
\hline Average nominal interest rate on public debt (in percent) $8 /$ & 5.3 & 5.4 & 5.1 & 3.9 & 4.4 & 4.7 & 4.5 & 4.5 & 4.5 & 4.6 & 4.7 & \\
\hline Average real interest rate (nominal rate minus change in GDP deflator, in percent) & 1.9 & 2.5 & 2.3 & 2.3 & 1.4 & 0.5 & 1.8 & 1.7 & 1.8 & 1.9 & 2.0 & \\
\hline Nominal appreciation (increase in US dollar value of local currency, in percent) & 14.0 & 2.1 & -27.2 & 11.1 & -3.3 & & & & & & & \\
\hline Inflation rate (GDP deflator, in percent) & 3.4 & 2.9 & 2.8 & 1.6 & 3.0 & 4.2 & 2.7 & 2.7 & 2.7 & 2.7 & 2.7 & \\
\hline Growth of real primary spending (deflated by GDP deflator, in percent) & 2.2 & 2.8 & 6.2 & 4.5 & -1.8 & -2.4 & -1.5 & -2.1 & -1.6 & -0.3 & 0.3 & \\
\hline Primary deficit & 0.5 & 0.5 & 4.6 & 9.2 & 6.9 & 4.5 & 2.8 & 0.7 & -0.8 & -1.8 & -2.1 & \\
\hline
\end{tabular}

$1 /$ Data are for general government and on a fiscal year basis (which starts in April).

$2 /$ Derived as $[(r-\pi(1+g)-g+\alpha \varepsilon(1+r)] /(1+g+\pi+g \pi))$ times previous period debt ratio, with $r=$ interest rate; $\pi=$ growth rate of GDP deflator; $g=$ real GDP growth rate; $\alpha=$ share of foreign-currency

denominated debt; and $\varepsilon=$ nominal exchange rate depreciation (measured by increase in local currency value of U.S. dollar).

$3 /$ The real interest rate contribution is derived from the denominator in footnote $2 /$ as $r-\pi(1+g)$ and the real growth contribution as $-g$

$4 /$ The exchange rate contribution is derived from the numerator in footnote $2 /$ as $\alpha \varepsilon(1+r)$.

5/ For projections, this line includes exchange rate changes.

6/ Defined as public sector deficit, plus amortization of medium and long-term public sector debt plus short-term debt at end of previous period.

$7 /$ The key variables include real GDP growth; real interest rate; and primary balance in percent of GDP.

.

9/ Assumes that key variables (real GDP growth, real interest rate, and other identified debt-creating flows) remain at the level of the last projection year. 
Figure A1. United Kingdom: Public Debt Sustainability: Bound Tests 1/2/ (General government gross debt in percent of GDP)
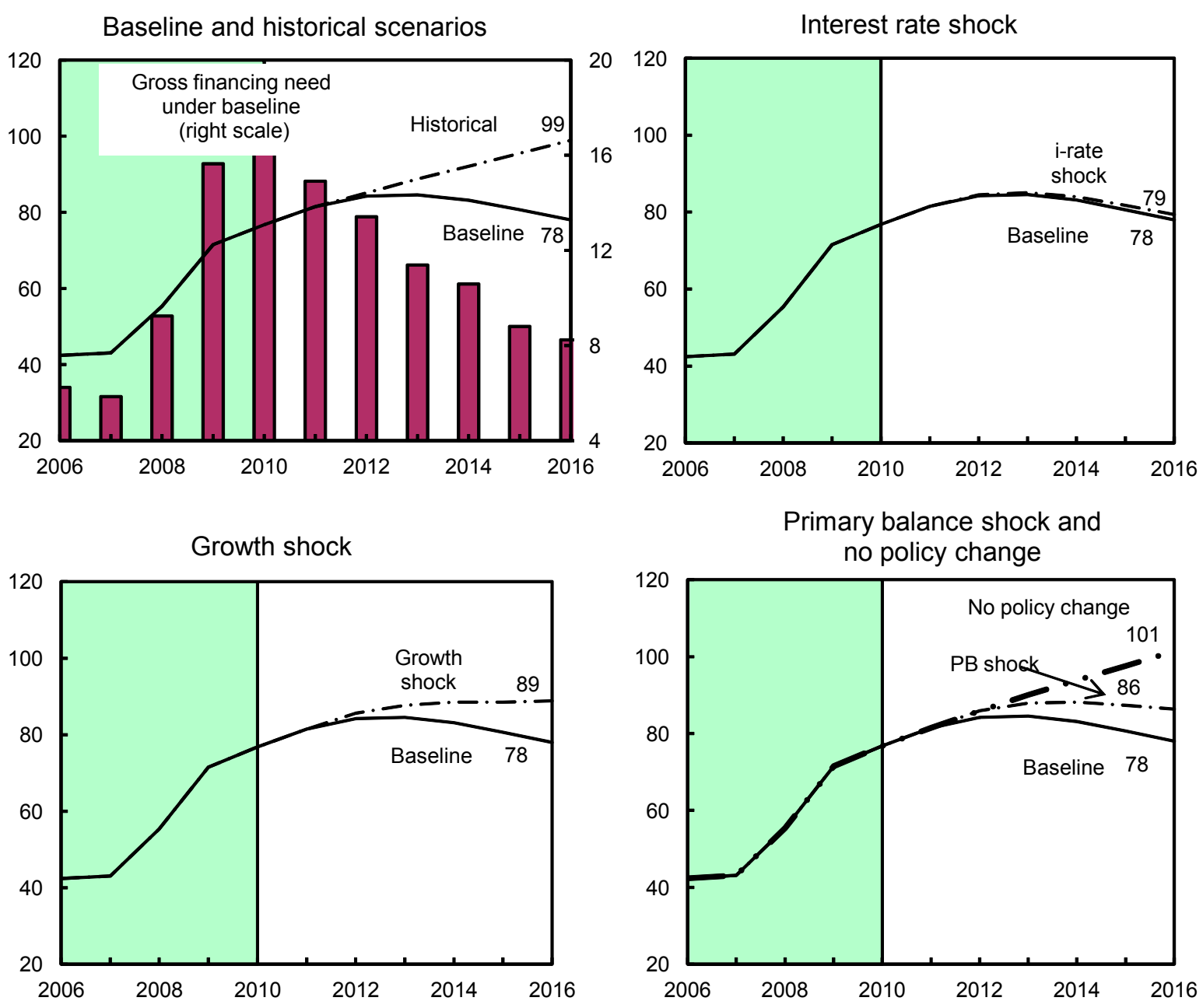

Combined shock $3 /$

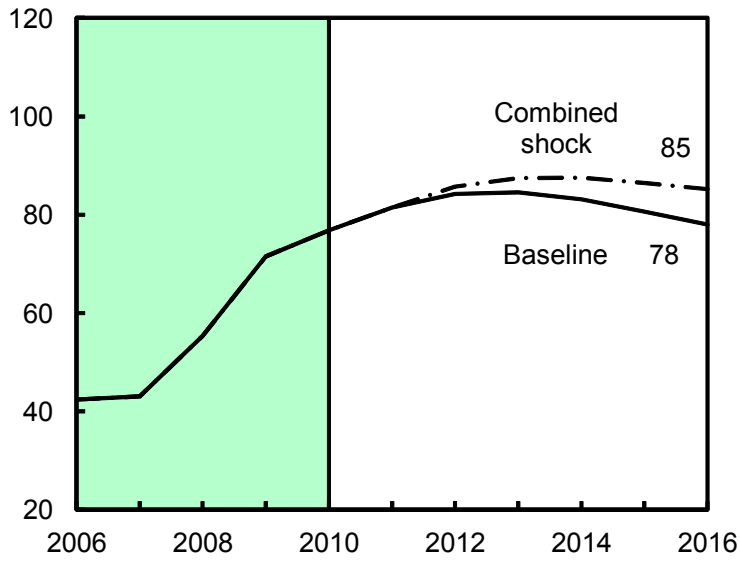

Contingent liabilities shocks 4/

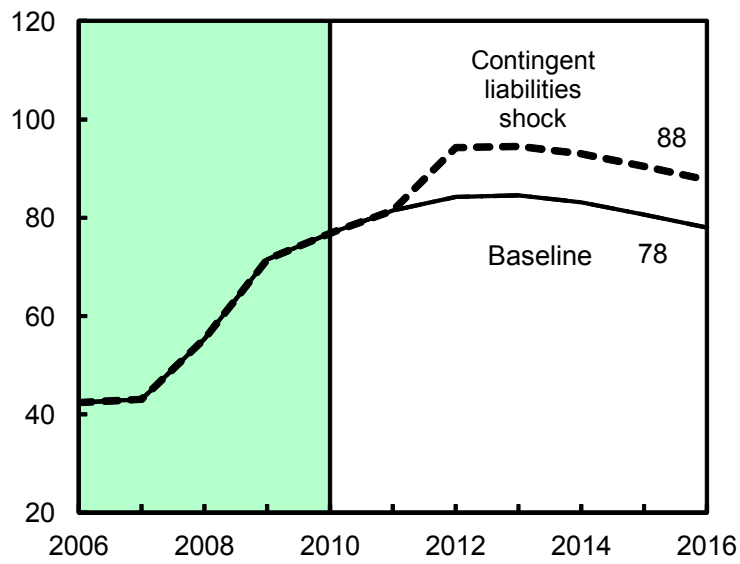

Sources: IMF, country desk data, and staff estimates. Data for fiscal years.

$1 /$ Shaded areas represent actual data. Individual shocks are permanent one-half standard deviation shocks. Figures in the boxes represent average projections for the respective variables in the baseline and scenario being presented.

2/ For historical scenarios, the historical averages are calculated over the last ten years, and the information is used to projec debt dynamics five years ahead.

3/ Permanent $1 / 4$ standard deviation shocks applied to real interest rate, growth rate, and primary balance.

4/ A 10 percent of GDP shock to contingent liabilities occurs in 2011. 


\section{INTERNATIONAL MONETARY FUND \\ UNITED KINGDOM}

\section{Staff Report for the 2011 Article IV Consultation-Informational Annex}

Prepared by Staff Representatives for the 2011 Consultation with the United Kingdom

(In consultation with other departments)

July 12, 2011

Contents

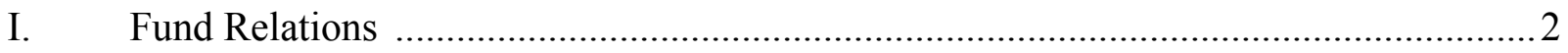

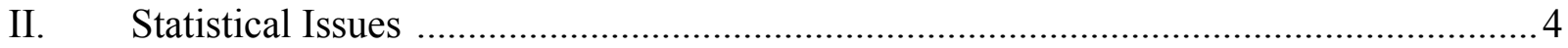




\section{ANNEX I. Fund RELATIONS}

(Data as of June 30, 2011)

I. Membership Status: Joined December 27, 1945; accepted Article VIII.

II. General Resources Account:

Quota

Fund holdings of currency

Reserve Tranche Position

Lending to the Fund
SDR Million

$10,738.50$

$7,427.25$

$3,311.37$

$1,126.00$
Percent Quota

100.00

69.16

30.84
III. SDR Department:

Net cumulative allocation

Holdings

Designation Plan
SDR Million

$10,134.20$

$9,334.54$

0.00
Percent Allocation

100.00

92.11

IV. Outstanding Purchases and Loans: None

V. Financial Arrangements: None

VI. Projected Payments to Fund: ${ }^{1 /}$ (SDR million; based on present holdings of SDRs):

Forthcoming

Principal

$\begin{array}{llllll}\text { Charges/Interest } & 2.21 & 4.54 & 4.53 & 4.53 & 4.53\end{array}$

$\begin{array}{llllll}\text { Total } & 2.21 & 4.54 & 4.53 & 4.53 & 4.53\end{array}$

\footnotetext{
"When a member has overdue financial obligations outstanding for more than three months, the amount of such arrears will be shown in this section
}

\section{Exchange Rate Arrangement:}

The UK authorities maintain a free floating regime. As of June 20, 2011 the exchange rate for sterling was \$1.62. In accordance with UN resolutions and EU restrictive measures, the United Kingdom applies targeted financial sanctions under legislation relating to Al-Qaeda and Taliban, and individuals, groups, and organizations associated with terrorism; and certain persons associated with: the former Government of Iraq, the former Government of Liberia, the current Government of Burma (aka Myanmar), the former Government of the Republic of Yugoslavia and International Criminal Tribunal Indictees, the current Government of Zimbabwe, the current government of Belarus, the current government of North Korea; the current government of Iran and persons considered to be a threat to peace and reconciliation in Sudan, Cote d'Ivoire, and Democratic Republic of Congo; and persons considered by the UN to have been involved in the assassination of former Lebanese Prime Minister Rafik Hariri. These restrictions have been notified to the Fund under Decision 144-(52/51). 


\section{Article IV Consultation:}

Discussions for the 2011 Article IV consultation were conducted in London during May 24-June 6, 2011. The Staff Report (IMF Country Report) was considered by the Executive Board on July 27, 2011.

IX. FSAP

The FSAP update was completed at the time of the 2011 Article IV Consultation.

X. Technical Assistance: None

XI. Resident Representative: None 


\section{ANNEX II. STATISTICAL ISSUES-UNITED KINGDOM}

Economic and financial data provided to the Fund are considered adequate for surveillance purposes. The United Kingdom subscribes to the Special Data Dissemination Standard (SDDS) and meets the SDDS specifications for the coverage, periodicity, and timeliness of data. SDDS metadata are posted on the Dissemination Standard Bulletin Board (DSBB).

\section{TABLE OF COMMON INDICATORS REQUIRED FOR SURVEILLANCE}

(As of June 20, 2011)

\begin{tabular}{|l|c|c|c|c|c|}
\hline & $\begin{array}{c}\text { Date of latest } \\
\text { observation }\end{array}$ & $\begin{array}{c}\text { Date } \\
\text { received }\end{array}$ & $\begin{array}{c}\text { Frequency } \\
\text { of } \\
\text { Data }^{7}\end{array}$ & $\begin{array}{c}\text { Frequency } \\
\text { of } \\
\text { Reporting }\end{array}$ & $\begin{array}{c}\text { Frequency } \\
\text { of }^{7}\end{array}$ \\
\hline Publication
\end{tabular}

\footnotetext{
${ }^{1}$ Includes reserve assets pledged or otherwise encumbered as well as net derivative positions.

${ }^{2}$ Both market-based and officially-determined, including discount rates, money market rates, rates on treasury bills, notes and bonds.

${ }^{3}$ Foreign, domestic bank, and domestic nonbank financing.

${ }^{4}$ The general government consists of the central government (budgetary funds, extra budgetary funds, and social security funds) and state and local governments.

${ }_{6}^{5}$ Including currency and maturity composition.

${ }^{6}$ Includes external gross financial asset and liability positions vis-à-vis nonresidents.

${ }^{7}$ Daily (D); weekly (W); monthly (M); quarterly (Q); annually (A); irregular (I); and not available (NA).
} 
INTERNATIONAL MONETARY FUND

UNITED KINGDOM

Staff Report for the 2011 Article IV Consultation-Supplementary Information

Prepared by the European Department

(In consultation with other departments)

Approved by Ajai Chopra and Tamim Bayoumi

July 25, 2011

This supplement provides an update on key developments that occurred after the staff report was finalized. These developments do not affect the thrust of the staff appraisal.

\section{The Office for Budget Responsibility (OBR) published its first Fiscal}

Sustainability Report (FSR) on July 13. The report makes long-term fiscal projections assuming implementation of the government's consolidation plan through FY15/16 and unchanged policies thereafter.

- In this central scenario, the OBR projects that population aging and associated increases in pension and healthcare spending will slowly reduce the primary balance and increase public sector net debt to 107 percent of GDP by FY60/61.

- $\quad$ However, the central scenario assumes that healthcare spending per elderly individual grows with per capita GDP. If

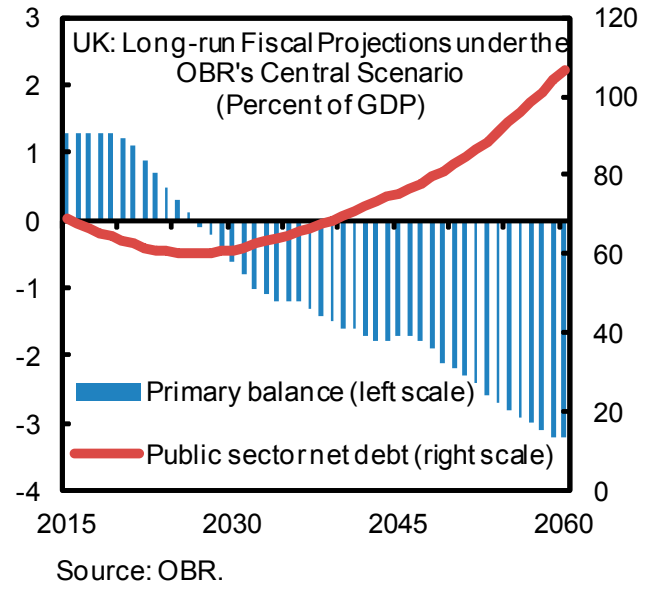
instead annual healthcare spending growth is 1 percentage point faster (historically, healthcare spending per elderly has been 1-2 percentage points faster than per capita GDP growth), the FSR projects that the primary deficit would be more than 5 percent of GDP higher than in the central scenario by FY60/61.

- These projections highlight that substantial fiscal consolidation after FY15/16 will be necessary to ensure fiscal sustainability over the long run. However, the UK is not unique in this regard - its long-run fiscal challenge from population aging is similar to that of many European economies. ${ }^{1}$ The large planned fiscal consolidation over the

\footnotetext{
${ }^{1}$ See Sustainability Report 2009 (European Commission, 2009).
} 
next 5 years also greatly reduces the total amount of consolidation required in the long run.

At the same time as the FSR, the Treasury released Whole of Government Accounts for FY09/10, which for the first time presented the public-sector financial position on the basis of commercial accounting standards, including future liabilities arising from public-service pensions. This release does not fundamentally affect IMF staff's view of the fiscal situation, but it is a step forward for fiscal transparency.

\section{All four UK banks included in the European Banking Authority (EBA) stress}

tests passed. The stress test results show that each of the four banks-Lloyds Banking Group (LBG), Barclays, Royal Bank of Scotland (RBS), and HSBC - would maintain core tier 1 ratios of at least 5 percent (the minimum level set by the EBA) under a stressed scenario of low GDP growth over two years, falling property prices, rising unemployment, and moderate haircuts on trading book holdings of peripheral European sovereign bonds. ${ }^{2}$ The results are broadly in line with those of the FSAP stress tests for these banks. ${ }^{3}$
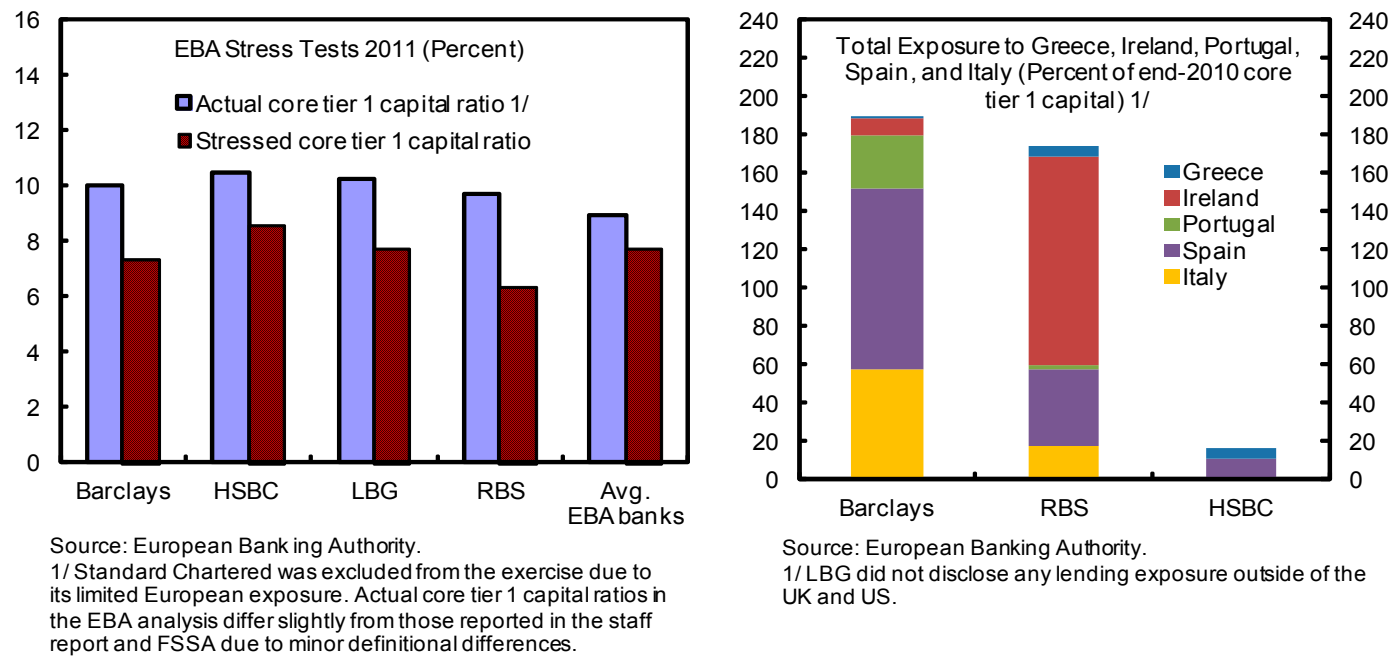

\footnotetext{
${ }^{2}$ The EBA adverse scenario of a slight contraction in the first year and small positive growth in the second is roughly equivalent to the mild adverse scenario in the FSAP stress test, which entails approximately a one standard deviation shock to real GDP growth over the first two years of a five-year stress horizon. The FSAP also conducted stress tests under two additional adverse scenarios (a two standard deviation shock to real GDP growth and prolonged slow growth).

${ }^{3}$ In addition to the EBA four, the other major UK banks in the FSAP solvency stress test sample include Standard Chartered, Santander UK, and Nationwide. All major UK banks exceeded the Basel III and Financial Service Authority hurdle rates in these scenarios. FSAP assumptions include haircuts to bank debt and sovereign debt holdings in both the banking and trading books. The FSAP also includes liquidity stress tests of the major UK banks, building societies, and foreign investment banks.
} 
3. On July 20, the EU Commission adopted a proposal to implement the Basel III agreements through new EU-wide legislation. The package includes regulation and a directive ("CRD4"), both of which are subject to approval through the EU Council and Parliament - a process that will likely take at least six months. The proposal falls short of IMF staff recommendations (see paragraph 50 of the staff report) and hence is a disappointment. Specifically:

- $\quad$ The common standards are too weak. The Commission suggests a common standard (maximum harmonization) set at the level of Basel III minimum requirements.

Moreover, the Commission has softened the definition of core tier 1 capital relative to the Basel III recommendations in some areas. In contrast, staff has called for common standards that exceed the Basel III minima, given prevailing balance sheet uncertainties and the lack of EU-wide resolution arrangements and a fully unified fiscal backstop.

- $\quad$ More flexibility is needed for macroprudential policies. National authorities can only set system-wide higher capital requirements on loans secured by real estate or using the Basel III countercyclical capital buffer, although they have more freedom with regard to individual banks. National authorities are likely to need more flexibility to use a range of macroprudential tools, given the uncertainty surrounding the tools required for effective macroprudential policy and future macroprudential risks.

- $\quad$ Furthermore, the Commission proposal lacks a firm commitment to implement the leverage ratio or net stable funding ratio in 2018, as was agreed under Basel III.

It will be important to strengthen the legislation as it is finalized, including by creating stronger common standards and ensuring sufficient flexibility for macroprudential policies. 


\section{Statement by the IMF Staff Representative on the United Kingdom}

July 26, 2011

This note reports on information that has become available since the staff report (SM/11/181) and staff supplement were issued and does not alter the thrust of the staff appraisal.

1. UK GDP grew at 0.2 percent (quarter-on-quarter, seasonally adjusted) in Q2 according to preliminary estimates released today. Several one-off factors, such as the additional bank holiday associated with the royal wedding and the impact of supply-chain disruptions in the wake of the Japanese earthquake and tsunami, affected growth during Q2. The Office for National Statistics notes that it is not possible to be precise about the impact of such special effects, but their broad-brush analysis indicates that these factors may have had a net downward effect on Q2 GDP of 0.4 percent in the services sector and 0.1 percent in the production sector. The GDP outturn is slightly lower than what staff had projected and will be incorporated into the next update of staff's projections for the September 2011 World Economic Outlook. However, the outturn does not materially alter the central scenario of continued recovery at a moderate pace. 
Public Information Notice (PIN) No. 11/103 FOR IMMEDIATE RELEASE

August 1, 2011
International Monetary Fund

$70019^{\text {th }}$ Street, NW

Washington, D. C. 20431 USA

\section{IMF Executive Board Concludes 2011 Article IV Consultation with the United Kingdom}

On July 27, 2011 the Executive Board of the International Monetary Fund (IMF) concluded the Article IV consultation with the United Kingdom. ${ }^{1}$ This consultation included a Financial System Stability Assessment (FSSA) under the IMF's Financial Sector Assessment Program, which analyzes financial sector health and associated policies. It also included discussion of the first UK Spillover Report, which analyzes spillovers emanating from UK policies to the rest of the world and is being conducted this year for five systemic economies.

\section{Background}

Economic growth has recently been sluggish and inflation has been high in the UK, though both indicators are projected to improve gradually over time. Recent increases in indirect taxes and commodity prices will keep headline inflation well above 4 percent during 2011. However, it should return near the 2 percent target by end-2012 as these transitory factors dissipate and as significant spare capacity keeps underlying inflation in check. Growth, which has also been adversely affected by spiking commodity prices, is expected to gradually accelerate from around $1 \frac{1}{2}$ percent in 2011 to $2 \frac{1}{2}$ percent in the medium term, as low interest rates and global growth support expansion led by net exports and investment. Nonetheless, there are large risks around this central scenario,

\footnotetext{
${ }^{1}$ Under Article IV of the IMF's Articles of Agreement, the IMF holds bilateral discussions with members, usually every year. A staff team visits the country, collects economic and financial information, and discusses with officials the country's economic developments and policies. On return to headquarters, the staff prepares a report, which forms the basis for discussion by the Executive Board. At the conclusion of the discussion, the Managing Director, as Chairman of the Board, summarizes the views of Executive Directors, and this summary is transmitted to the country's authorities. An explanation of any qualifiers used in summings up can be found here: http://www.imf.org/external/np/sec/misc/qualifiers.htm.
} 
including from uncertainties surrounding turmoil in parts of the euro area, headwinds from fiscal consolidation, volatile commodity prices, and the housing market.

A wide-ranging policy program has been put in place to aid the post-crisis repair of the UK economy. The agenda includes restoring confidence in public finances, moving to a safer financial sector, and rebalancing the economy away from public and private consumption and toward more sustainable sources of growth (net exports and investment). As part of this program, the government has undertaken institutional reform to address weaknesses in the policymaking framework. These reforms include moving the microprudential regulator under the Bank of England (BoE), establishing a Financial Policy Committee (FPC) to oversee macroprudential policy, and creating an independent Office for Budget Responsibility (OBR) aimed at strengthening the credibility of fiscal analysis and forecasts.

The government has made progress on its medium-term fiscal consolidation plan, which is a central component of its overall macroeconomic strategy. The cyclically adjusted primary balance (as a percent of potential GDP) is estimated to have improved by about 2 percentage points in FY10/11. Going forward, the pace of adjustment is projected to ease slightly and become increasingly reliant on spending restraint.

The BoE has maintained an accommodative monetary policy stance, with the Bank Rate at 0.5 percent and the stock of outstanding asset purchases at $£ 200$ billion. This stance reflects the BoE's forecast that inflation will return to target over the forecast horizon, taking into account disinflationary forces from fiscal consolidation.

Meanwhile, banks have strengthened their balance sheets and reduced funding vulnerabilities over the last year, with all major banks ahead of schedule in their transition to Basel III rules. Nonetheless, the recovery process is not yet complete. Despite recent progress, funding risks remain a key vulnerability, as highlighted by the FSSA.

\section{Executive Board Assessment}

Executive Directors welcomed progress made in repairing the UK economy, including a lower fiscal deficit, higher bank capital, and expanded employment. Nonetheless, they noted that the combination of low growth and above-target headline inflation poses policy challenges.

Directors considered the current mix of accommodative monetary and tight fiscal policy to be appropriate. They noted that such a mix will help keep real interest rates low and sterling competitive, thereby assisting public and private balance sheet repair while rebalancing growth toward investment and net exports. This rebalancing is necessary if robust growth is to be achieved at the same time that private and public consumption are eased to more sustainable levels. 
Directors noted that the growth outlook is subject to considerable uncertainties. They agreed that policies may need to adjust in the event of a change in macroeconomic conditions. In particular, if growth and inflation surprise on the upside, monetary tightening would need to accelerate. Conversely, mounting evidence that weak demand is likely to cause the economy to stall and enter a period of prolonged low growth would call for looser macroeconomic policies.

Directors stressed the importance of accelerating structural reforms to promote long-term fiscal sustainability and bolster the growth potential, along the lines outlined in the authorities' Growth Review. In this regard, they welcomed the creation of a permanent Office for Budget Responsibility and supported the reform of the pension system.

Directors noted that efforts to strengthen the resilience of the financial sector have yielded improvements as bank capital levels have improved significantly and all major banks passed the recent EU stress-tests. They considered, however, that the sector remains vulnerable to risks relating to their funding model and their asset quality.

Directors concurred with the findings of the FSSA and called for implementing its recommendations, including improving the standards for the public disclosure of financial data. In this context, they welcomed the establishment of the FPC, whose explicit mandate for macroprudential oversight should help reduce systemic risk.

Directors agreed with the conclusions of the spillover report that the UK's potential for spillovers is concentrated in the financial sector. They stressed that, given its central position, the stability and efficiency of the UK financial sector is a global public good, requiring that financial supervision and regulation be strengthened and held to the highest standards. International cooperation between regulatory agencies in ensuring effective cross-border resolution arrangements, group-wide liquidity management, information sharing, and jurisdictional reciprocity will be essential for the UK to fulfill its potential to support global financial stability.

Public Information Notices (PINs) form part of the IMF's efforts to promote transparency of the IMF's views and analysis of economic developments and policies. With the consent of the country (or countries) concerned, PINs are issued after Executive Board discussions of Article IV consultations with member countries, of its surveillance of developments at the regional level, of post-program monitoring, and of ex post assessments of member countries with longer-term program engagements. PINs are also issued after Executive Board discussions of general policy matters, unless otherwise decided by the Executive Board in a particular case. The staff report (use the free Adobe Acrobat Reader to view this pdf file) for the 2011 Article IV Consultation with the United Kingdom is also available. 
United Kingdom: Selected Economic and Social Indicators, 2007-12

\begin{tabular}{|c|c|c|c|c|c|c|}
\hline & 2007 & 2008 & 2009 & 2010 & $\begin{array}{l}2011 \\
\text { Proj. }\end{array}$ & $\begin{array}{l}2012 \\
\text { Proj. }\end{array}$ \\
\hline \multicolumn{7}{|l|}{ Real Economy } \\
\hline Real GDP (change in percent) & 2.7 & -0.1 & -4.9 & 1.4 & 1.5 & 2.3 \\
\hline Domestic demand (change in percent) & 3.1 & -0.7 & -5.5 & 2.7 & -0.1 & 1.4 \\
\hline $\mathrm{CPI}$ (change in percent, period average) & 2.3 & 3.6 & 2.1 & 3.3 & 4.5 & 2.6 \\
\hline Unemployment rate (in percent) $1 /$ & 5.4 & 5.6 & 7.5 & 7.9 & 7.7 & 7.6 \\
\hline Gross national saving (percent of GDP) & 15.6 & 15.0 & 11.8 & 11.8 & 11.5 & 12.5 \\
\hline Gross domestic investment (percent of GDP) & 18.2 & 16.6 & 13.5 & 15.0 & 14.0 & 14.5 \\
\hline \multicolumn{7}{|l|}{ Public Finance 2/ } \\
\hline General government balance & -2.7 & -6.7 & -11.3 & -9.8 & -7.9 & -6.3 \\
\hline Public sector balance & -2.4 & -6.7 & -11.1 & -9.7 & -8.0 & -6.4 \\
\hline Cyclically adjusted balance (staff estimates) & -3.1 & -6.7 & -9.1 & -7.7 & -6.2 & -4.7 \\
\hline Public sector net debt & 36.6 & 43.3 & 52.8 & 59.8 & 65.7 & 69.3 \\
\hline \multicolumn{7}{|c|}{ Money and Credit (end-period, 12-month percent change) 3/ } \\
\hline M4 & 12.8 & 15.5 & 6.7 & -1.4 & -0.2 & $\ldots$ \\
\hline Net lending to the private sector & 10.8 & 4.9 & 0.6 & -0.4 & 0.1 & $\ldots$ \\
\hline \multicolumn{7}{|l|}{ Interest rates (year average) $4 /$} \\
\hline Three-month interbank rate & 6.0 & 5.8 & 1.2 & 0.7 & 0.8 & $\ldots$ \\
\hline Ten-year government bond yield & 5.0 & 4.7 & 3.6 & 3.6 & 3.7 & $\ldots$ \\
\hline \multicolumn{7}{|l|}{ Balance of Payments } \\
\hline Trade balance (percent of GDP) & -3.1 & -2.6 & -2.1 & -3.4 & -2.0 & -1.3 \\
\hline Current account balance (percent of GDP) & -2.6 & -1.6 & -1.7 & -3.2 & -2.6 & -1.9 \\
\hline Exports (percent of GDP) & 26.6 & 29.3 & 28.0 & 29.4 & 30.6 & 30.4 \\
\hline Export volume (change in percent) & -2.6 & 1.0 & -10.1 & 5.2 & 7.5 & 5.5 \\
\hline Imports (percent of GDP) & 29.7 & 31.9 & 30.1 & 32.8 & 32.6 & 31.7 \\
\hline Import volume (change in percent) & -0.8 & -1.2 & -11.9 & 8.8 & 1.6 & 2.4 \\
\hline Reserves (end of period, billions of US dollars) & 57.9 & 53.9 & 66.4 & 78.8 & 91.2 & $\ldots$ \\
\hline \multicolumn{7}{|l|}{ Fund Position (as of June 30,2011 ) } \\
\hline Holdings of currency (percent of quota) & & & & & & 69.2 \\
\hline Holdings of SDRs (percent of allocation) & & & & & & 92.1 \\
\hline Quota (millions of SDRs) & & & & & & $10,738.5$ \\
\hline \multicolumn{7}{|l|}{ Exchange Rates } \\
\hline Exchange rate regime & & & & & & Floating \\
\hline Bilateral rate (June 30,2011$)$ & & & & & US\$1 = & $£ 0.6228$ \\
\hline Nominal effective rate $(2005=100) 3 / 5 /$ & 102.3 & 89.3 & 78.8 & 79.3 & 79.1 & $\ldots$ \\
\hline Real effective rate $(2005=100) 3 / 5 / 6 /$ & 102.3 & 89.3 & 80.4 & 82.2 & 83.0 & $\ldots$ \\
\hline \multicolumn{7}{|c|}{ Social Indicators (reference year): } \\
\hline \multicolumn{7}{|c|}{$\begin{array}{l}\text { Income per capita (in US dollars, 2009) : 35,165; Income distribution (ratio of income received by top and bottom quintiles, } 2009 \text { ): } 5.2 \\
\text { Life expectancy at birth (2009): } 78.1 \text { (male) and } 82.1 \text { (female); Automobile ownership (2009): } 459 \text { per thousand; }\end{array}$} \\
\hline
\end{tabular}

Sources: Office for National Statistics; HM Treasury; Bank of England; International Financial Statistics; INS; World Development Indicators; Eurostat; and IMF staff estimates.

1/ ILO unemployment; based on Labor Force Survey data.

2/ Fiscal data refer to the fiscal year, which begins in April. For example, fiscal balance data for 2005 refers to FY2005/06. Debt stock data refer to the end of the fiscal year using centered-GDP as a denominator. Data exclude the temporary effects of financial sector interventions.

3/ 2011: actual data through May.

4/ 2011: actual data through June.

5/ Average. An increase denotes an appreciation.

6/ Based on relative consumer prices. 


\section{Statement by Alex Gibbs, Executive Director for the United Kingdom July 27, 2011}

We thank staff for a very good and comprehensive set of documents based on a number of productive staff missions in the first half of 2011. The reports appropriately capture the views of my authorities and reflect the fact that, for the most part, they agreed with the staff analysis and recommendations.

\section{$\underline{\text { Outlook and recent economic developments }}$}

The 2011 Article IV mission took place just over six months after the 2010 Board discussion. Since then, temporary factors have clouded assessment of the state of the UK economy. The growth numbers have been choppy, with a contraction of 0.5 percent in 2010Q4 reversed by growth of 0.5 percent in 2011Q1. However, as the staff report notes, other economic indicators - including employment data, growth in tax revenues and manufacturing performance - have been suggestive of a stronger recovery.

The weakness in the growth figures relative to forecast largely reflects the impact of transitory factors, including rising energy prices, supply chain disruptions and weather related shocks. The latest forecast from the Office for Budget Responsibility (OBR) projects a sustained recovery, with 1.7 percent growth in 2011 continuing to strengthen before peaking at 2.9 percent in 2013 . This is consistent with rebalancing from private consumption and government spending to net trade and investment. The latest survey data indicates that corporate investment intentions remain strong.

On the inflation outlook, while headline inflation is currently at around $4 \frac{1}{4}$ percent, reflecting the increase in VAT, higher energy and import prices, and some rebuilding of companies' margins, core inflation excluding indirect tax rises is just over 1 percent. Inflation is likely to fall back through 2012 and into 2013 as the temporary impact of those factors wanes and some downward pressure from spare capacity persists. Medium-term inflation expectations remain contained and continue to be consistent with meeting the inflation target.

\section{$\underline{\text { Fiscal Policy }}$}

In their last Article IV report, staff supported the UK Government's commitment to fiscal consolidation and its ambitious medium-term targets for adjustment, which themselves were consistent with staff advice in previous Article IV consultations.

The 2011 Article IV report highlights that fiscal consolidation is still essential to reduce fiscal risks and achieve a more sustainable budgetary position. My authorities welcome the staff conclusion that the current path of fiscal consolidation remains appropriate in their central case. Since the consolidation path was announced, yields on UK sovereign debt have fallen significantly and remain below the levels at the onset of the euro-area sovereign debt 
crisis. Retaining fiscal credibility is essential to maintain this improvement in market confidence.

As staff's very thorough analysis shows, risks still remain, both to the upside and the downside. The economy is still some distance from the risk scenarios set out in the report but the UK authorities are continuing to monitor developments closely. If risks do materialize, the policy response will need to be calibrated to the nature and cause of the particular shock. However, the successful implementation of the Government's fiscal consolidation plan is the key to maintaining confidence in debt sustainability and will continue to be a prerequisite in any scenario.

Implementation is now fully underway. Consistent with previous staff advice, the plan is tilted clearly to expenditure-based measures: of a total consolidation of $£ 126$ billion a year by $2015-16, £ 95$ billion comes through spending cuts and $£ 30$ billion through taxation. The Government has delivered the $£ 6.2$ billion of savings announced in May 2010 and has implemented departmental budgets and the reforms to welfare and public service pensions that were outlined in the October 2010 Spending Review. Where necessary, legislation has now been introduced to Parliament. Mindful of the need to sustain commitment to implementing spending measures over a period of years, my authorities have established a Public Expenditure Cabinet Committee to oversee departments' performance. On the revenue side, the Government has put in place the planned 2011-12 tax reforms, including the increase in the standard rate of VAT to 20 percent.

Nevertheless, my authorities remain committed to protecting Overseas Development Assistance from the expenditure cuts, and their spending plans provide for achieving the ODA target of 0.7 percent of GDP.

My authorities welcome the staff advice on further structural reforms that could help address longer-term fiscal pressures and support medium-term growth. Measures have already been taken. For example, the rise in the State Pension Age (SPA) from 65 to 66 has already been brought forward to 2020 from 2026. My authorities have committed to bring forward proposals to manage future increases in the SPA more automatically, as staff propose. Since the Article IV mission, the OBR has published its first Fiscal Sustainability Report, which looks at these issues in detail.

A key focus of the structural reform effort is to ensure sustainable growth, and to that end a Growth Review, launched in November 2010, has identified a programme of structural reforms to boost competitiveness and improve the business environment. The focus is on reforms to the tax system, measures to encourage investment and rebalancing towards exports and action to improve education and skills. Implementation is underway, with 16 of 182 proposed measures already implemented and major milestones passed in 92 others. The second phase of the Growth Review was launched in June and will report in the autumn. 


\section{Fiscal Framework}

The independent Office for Budget Responsibility (OBR) was established in May 2010 to strengthen the fiscal framework and provide greater transparency and credibility to the official economic and fiscal forecasts - in line with recommendations that the IMF had been making to the UK authorities for a number of years. The OBR has now been placed on a permanent, statutory footing and has produced all the official forecasts of the economy and public finances since the General Election, independently of Ministers.

To promote transparent fiscal policy-making and strengthen the new fiscal framework, my authorities have legislated a new requirement for each Government to set out its fiscal policy objectives and fiscal mandate before Parliament in the Charter for Budget Responsibility. The Government published the Charter on 4 April 2011.

\section{Monetary Policy}

The central view of the Monetary Policy Committee (MPC) continues to be that a margin of spare capacity in the economy is likely to push down inflation and bring it back towards the 2 percent target in the medium term, as the impact of factors temporarily boosting inflation subside. However material risks exist in both directions.

At its last meeting earlier this month, the Committee maintained its highly accommodative monetary policy stance, with Bank Rate set at 0.5 percent and asset purchases of $£ 200$ billion. A minority of members voted for less accommodative policy - preferring higher Bank Rate - and a smaller minority for an extension of asset purchases.

The MPC will continue to set policy to balance risks around the 2 percent inflation target. If it becomes clear that one of those risks has crystallised - and the medium-term outlook for inflation has deviated materially from the target - the Committee will change its monetary policy stance accordingly. The MPC's next decision will be on 4 August.

\section{$\underline{\text { Financial Sector }}$}

This year's FSAP update comes at a critical time when reforms are being pursued in parallel at the domestic, regional and global levels. Collaboration with the FSAP team was excellent and my authorities have found the exercise extremely valuable for policy development. The team has produced a detailed and comprehensive set of reports, including robust analysis and a wide-ranging set of recommendations, which we intend to publish in full. My authorities are now carefully considering how best to take these recommendations forward. 
As staff note, the UK financial sector is on the mend. Conditions have continued to improve with UK banks taking major steps to repair their balance sheets. Core tier 1 capital ratios are now above 10 percent for all the major UK banks, the funding gap has continued to decline and the dependence on wholesale funding has been significantly reduced. The in-depth FSAP stress tests, which include haircuts to sovereign and bank debt, demonstrate that the resilience of the sector has increased. Results show that banks have solid capital buffers and are resilient against severe stresses - only an extreme "tail of the tail" risk, with multiple severe shocks would pose a challenge to the banking system. Similarly, even under the Fund's new and most severe 30-day liquidity stress test scenario - which in effect tests institutions to the point of failure - staff note that liquidity shortfalls remain largely contained.

Having said that, my authorities remain mindful that challenges remain, particularly given the ongoing uncertainties over the global economic outlook. For that reason, the UK is continuing to strengthen its regulatory and supervisory frameworks. In particular, the FSA is continuing to adopt a more proactive and intrusive supervisory approach, including for example, the introduction of a proactive intervention framework to ensure that prudential problems are tackled at an early stage. A new strengthened liquidity regime has also been implemented that imposes stringent resilience requirements under stress conditions and determines the approval of dividends and remuneration policy.

Many of the FSAP recommendations are already being taken forward through the overhaul of the current system of financial regulation and supervision. Much progress has been made since last September to lay the foundations for the move to the 'triple peak' model. An interim version of the Financial Policy Committee (FPC) has been up and running since June 2011 - this will have a clear macroprudential remit to identify and address systemic risks. Significant steps have also been taken to clarify the mandates for the new Prudential Regulation Authority (PRA) and the Financial Conduct Authority, which will have responsibility for microprudential regulation and supervision, and conduct of business and market regulation, respectively. The Government published a White Paper and draft Bill in June, which will act as a blueprint for the reforms, and primary legislation is expected to be introduced later this year.

The Government is particularly focused on tackling the risks posed by systemically important financial institutions (SIFIs). The Independent Commission on Banking (ICB) has delivered its interim report and is considering options on bail-in and the ring-fencing of retail banking activities. The Government has endorsed these proposals and will take action to address these issues once the ICB has delivered its final report in September, recognising the impact of ongoing regulatory uncertainty.

As staff stress, a strong international response is vital. Stability in the UK financial sector critically depends on a stronger international framework of oversight for cross-border SIFIs. 
Given the risks of global regulatory arbitrage and the constraints on oversight of institutions hosted in the UK, domestic reform alone will not ensure stability. The UK is therefore fully committed to the development and implementation of an ambitious international regulatory reform. We will continue to work closely with our European partners and our global partners to ensure full implementation of the Basel III standards around the world. Like staff, we believe national regulators do need discretion to go beyond those standards when national circumstances require to safeguard financial stability. The UK has shown leadership on these matters in international fora, and will continue to do so.

Finally, the Article IV staff report notes that the UK still needs to improve its disclosure of financial sector data. My authorities fully agree and work is underway to deliver this. As part of its commitment to encourage more market discipline, the PRA will seek to publish some regulatory returns and the interim-FPC has requested the FSA to take action to make enhanced disclosure of sovereign and banking sector exposures a permanent part of major banks' reporting framework. In addition, we have consented to publish all the UK FSAP standard assessment reports and technical notes, including on stress testing, where the IMF has pioneered extremely demanding liquidity tests. Together with the establishment of the OBR, as an independent forecaster, and the publication of the whole of government accounts, these measures represent a significant increase in the transparency of government.

\section{$\underline{\text { Spillovers }}$}

The UK strongly supports the drive to improve the Fund's analysis of spillovers, particularly its understanding of financial interlinkages. As with the other "S5" spillover reports, the report on the UK is a good first step towards bridging the gap between the Fund's standard bilateral and multilateral surveillance products.

The UK report focuses almost entirely on financial spillovers. We welcome the staff's effort to develop better understanding of some financial linkages that are not well captured - if at all - in traditional models. Nevertheless we also recognise that, as with other work in this field, gaps in the data and the lack of an established economists' financial spillover toolkit increased the difficulty of the task. This is an area of Fund surveillance that merits significant further attention, alongside better modeling of real economy linkages, which the spillover reports overall have tended to downplay.

We agree with the high-level conclusions of the report. The size and interconnectedness of the UK financial sector make it a powerful originator, transmitter and potential dampener of global shocks - more must now be done to understand the complexities of transmission mechanisms and identify more clearly how and when the UK could potentially have these different impacts. The report appropriately stresses the international dimension, as shocks affecting the UK or transmitted through institutions based in the UK, frequently arise elsewhere. Action taken domestically to strengthen capital and liquidity buffers may have an 
impact on global asset and liability management, but the benefits for global financial stability must surely exceed any potential efficiency costs. In general, we believe the objectives of national and global financial stability are well aligned.

My authorities are strongly committed to continuing to engage in, and exercise leadership on, the global financial repair and reform agenda. Effective global surveillance and regulation will require sustained cooperation with European and global partners, particularly other financial centres, through ongoing work at the IMF, FSB and ESRB. 